\title{
Study of the Acoustic Effects of Hydrokinetic Tidal Turbines in Admiralty Inlet, Puget Sound
}

Final Report

DOE Award: DE-EE0002654

Public Utility District No. 1 of Snohomish County

Craig Collar, Project Director

Jessica Spahr, Project Manager

University of Washington, Northwest National Marine Renewable Energy Center

Brian Polagye, Principal Investigator

Jim Thomson, co-Principal Investigator

Chris Bassett

Joe Graber

Robert Cavagnaro

Joe Talbert

Alex deKlerk

Capt. Andy Reay-Ellers

Sea Mammal Research Unit, Ltd.

Dom Tollit, co-Principal Investigator

Jason Wood

Pacific Northwest National Laboratory

Andrea Copping, co-Principal Investigator

Tom Carlson, co-Principal Investigator

Michele Halvorsen, co-Principal Investigator
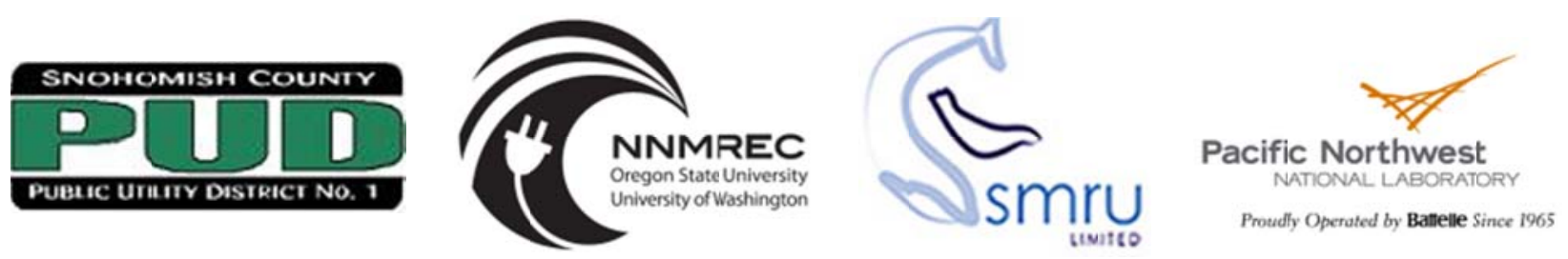

March 30, 2012 


\section{Executive Summary}

Hydrokinetic turbines will be a source of noise in the marine environment - both during operation and during installation/removal. High intensity sound can cause injury or behavioral changes in marine mammals and may also affect fish and invertebrates. These noise effects are, however, highly dependent on the individual marine animals; the intensity, frequency, and duration of the sound; and context in which the sound is received. In other words, production of sound is a necessary, but not sufficient, condition for an environmental impact. At a workshop on the environmental effects of tidal energy development, experts identified sound produced by turbines as an area of potentially significant impact, but also high uncertainty.

The overall objectives of this project are to improve our understanding of the potential acoustic effects of tidal turbines by:

- Characterizing sources of existing underwater noise;

- Assessing the effectiveness of monitoring technologies to characterize underwater noise and marine mammal responsiveness to noise;

- Evaluating the sound profile of an operating tidal turbine; and

- Studying the effect of turbine sound on surrogate species in a laboratory environment.

This study focuses on a specific case study for tidal energy development in Admiralty Inlet, Puget Sound, Washington (USA), but the methodologies and results are applicable to other turbine technologies and geographic locations. The project succeeded in achieving the above objectives and, in doing so, substantially contributed to the body of knowledge around the acoustic effects of tidal energy development in several ways:

- Through collection of data from Admiralty Inlet, established the sources of sound generated by strong currents (mobilizations of sediment and gravel) and determined that low-frequency sound recorded during periods of strong currents is non-propagating pseudo-sound. This helped to advance the debate within the marine and hydrokinetics acoustic community as to whether strong currents produce propagating sound.

- Analyzed data collected from a tidal turbine operating at the European Marine Energy Center to develop a profile of turbine sound and developed a framework to evaluate the acoustic effects of deploying similar devices in other locations. This framework has been applied to Public Utility District No. 1 of Snohomish Country's demonstration project in Admiralty Inlet to inform postinstallation acoustic and marine mammal monitoring plans.

- Demonstrated passive acoustic techniques to characterize the ambient noise environment at tidal energy sites (fixed, long-term observations recommended) and characterize the sound from anthropogenic sources (drifting, short-term observations recommended).

- Demonstrated the utility and limitations of instrumentation, including bottom mounted instrumentation packages, infrared cameras, and vessel monitoring systems. In doing so, also demonstrated how this type of comprehensive information is needed to interpret observations from each instrument (e.g., hydrophone data can be combined with vessel tracking data to evaluate the contribution of vessel sound to ambient noise).

- Conducted a study that suggests harbor porpoise in Admiralty Inlet may be habituated to high levels of ambient noise due to omnipresent vessel traffic. The inability to detect behavioral 
changes associated with a high intensity source of opportunity (passenger ferry) has informed the approach for post-installation marine mammal monitoring.

- Conducted laboratory exposure experiments of juvenile Chinook salmon and showed that exposure to a worse than worst case acoustic dose of turbine sound does not result in changes to hearing thresholds or biologically significant tissue damage. Collectively, this means that Chinook salmon may be at a relatively low risk of injury from sound produced by tidal turbines located in or near their migration path.

In achieving these accomplishments, the project has significantly advanced the District's goals of developing a demonstration-scale tidal energy project in Admiralty Inlet. Pilot demonstrations of this type are an essential step in the development of commercial-scale tidal energy in the United States. This is a renewable resource capable of producing electricity in a highly predictable manner. 


\section{Table of Contents}

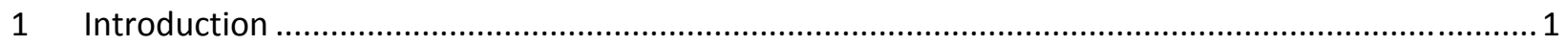

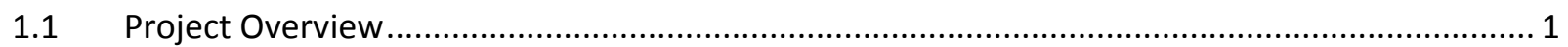

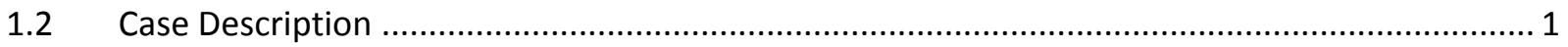

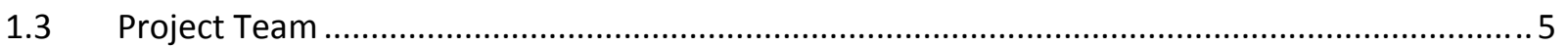

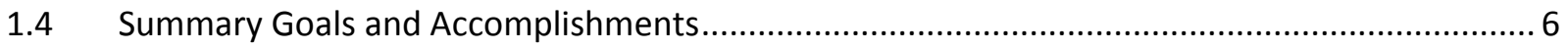

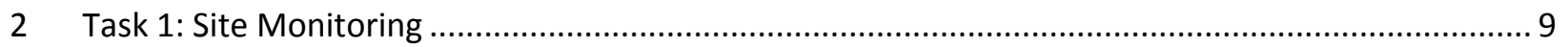

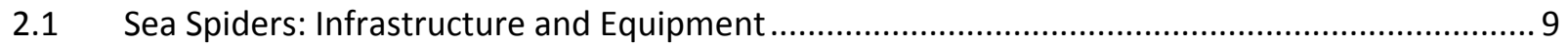

2.2 Bottom-Mounted Instrumentation: Ambient Noise............................................................... 20

2.3 Bottom-Mounted Instrumentation: Marine Mammal Echolocation ..........................................24

2.4 Shore-based Infrared Monitoring of Marine Mammals ......................................................... 31

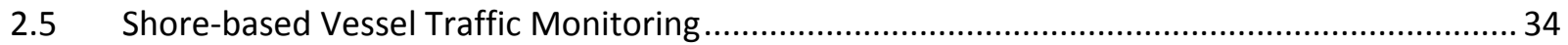

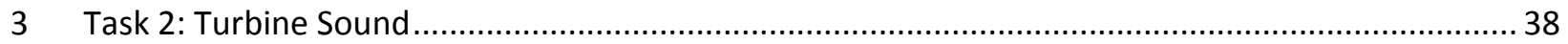

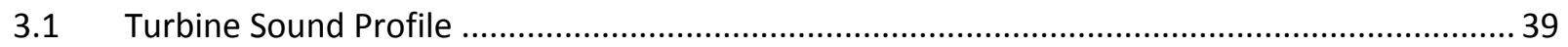

3.2 Estimating Effect of Turbine Noise for the Admiralty Inlet Demonstration Project...................41

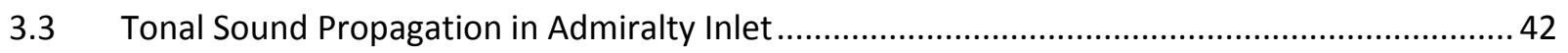

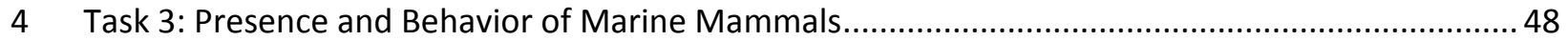

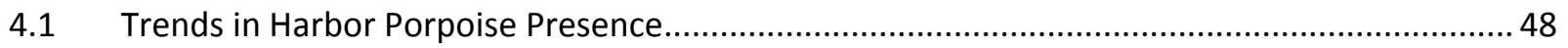

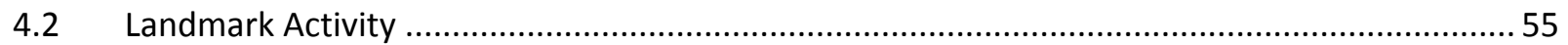

4.3 Effects of Existing Anthropogenic Noise on Harbor Porpoise ...................................................56

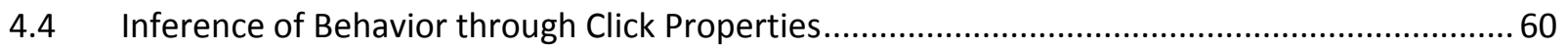

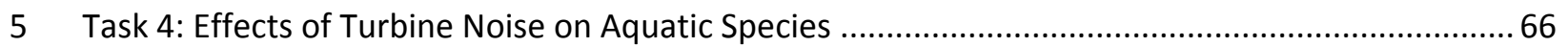

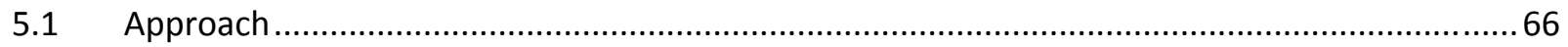

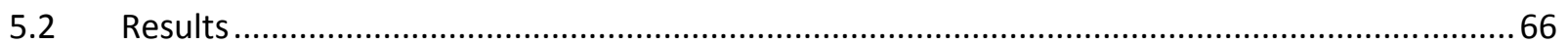

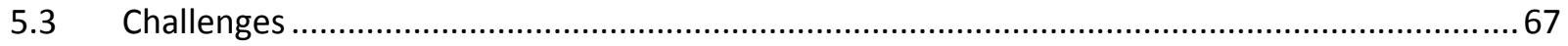

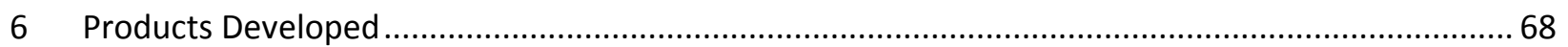

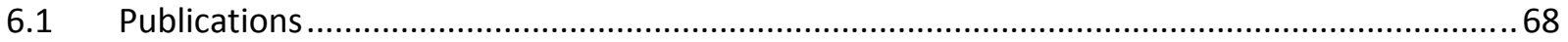

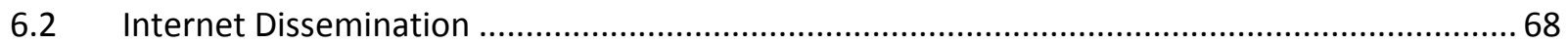

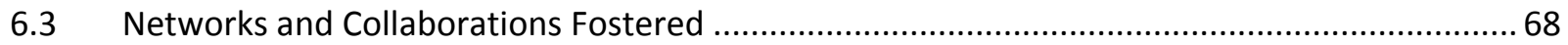

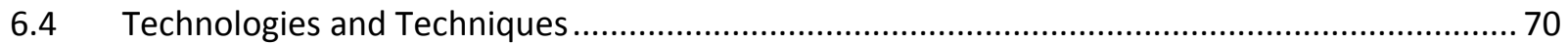

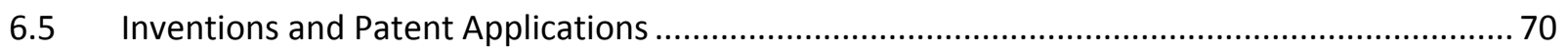

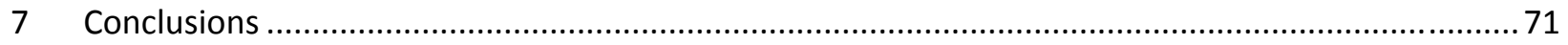

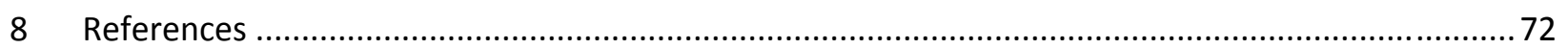




\section{List of Figures}

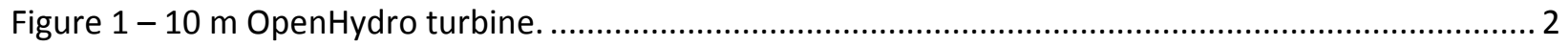

Figure 2 - Puget Sound, Washington (USA) and detail of turbine deployment site. ................................ 3

Figure 3 - Turbine deployment location in northern Admiralty Inlet. ..................................................... 4

Figure 4 - Sea Spider instrumentation packages deployed over the course of this project ......................11

Figure 5 - Sea Spider (SS\#02 Mark II) after recovery with instrumentation and infrastructure as

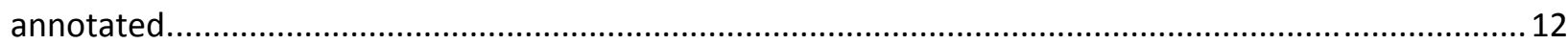

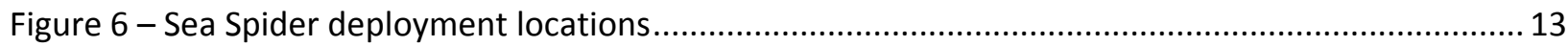

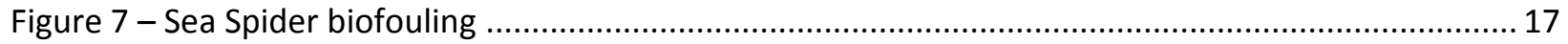

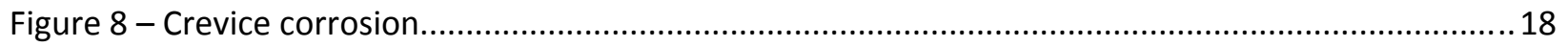

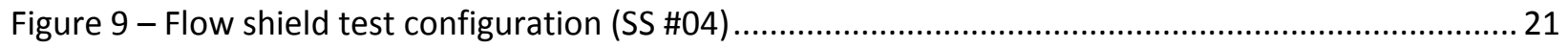

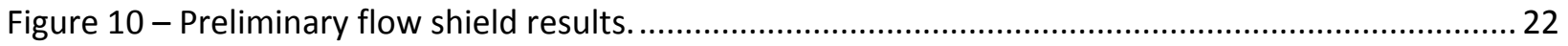

Figure 11 - Cumulative probability distribution function of unweighted broadband SPLs $(0.02$..............23

Figure 12 - Hourly (a), daily (b) and monthly (c) average broadband (0.02 - $30 \mathrm{kHz}$ ) and M-................ 24

Figure 13 - Porpoise detection positive minutes per day, as classified by different instrument/software

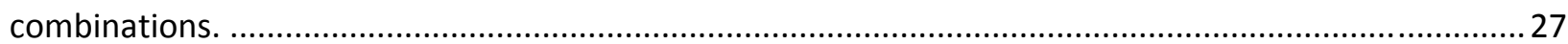

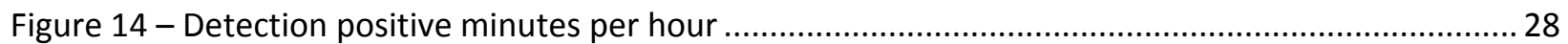

Figure 15 - C-POD/Doppler profiler interference test configuration ...................................................29

Figure 16 - Infrared imagery of Southern Resident killer whales recorded from Lime Kiln State Park on San Juan Island including the output of the automated detection algorithm......................................... 32

Figure 17 - Infrared image of potential targets for cetacean detection ...............................................32

Figure 18 - Southern Resident killer whale detections over a three day observation at Lime Kiln State

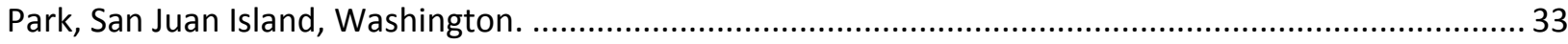

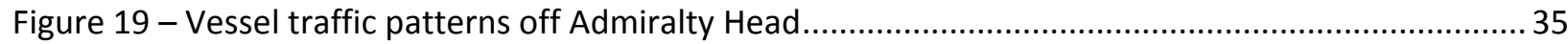

Figure 20 - Ship traffic density map plotted on a $100 \mathrm{~m}$ x $100 \mathrm{~m}$ horizontal grid ...................................36

Figure 21 - Cumulative probability distributions of underwater ambient noise in study area for measurements (all ambient noise sources) and the model for vessel noise............................................37

Figure 22 - One-third octave source levels from measurements of an OpenHydro turbine at EMEC ...... 40

Figure 23 - Probability distribution of turbine source levels................................................................. 40

Figure 24 - Broadband $(25-25000 \mathrm{~Hz}$ ) received levels at four inflow velocities.................................. 41

Figure 25 - Probability of mid-frequency cetacean (killer whale) detecting turbine noise (30 m depth

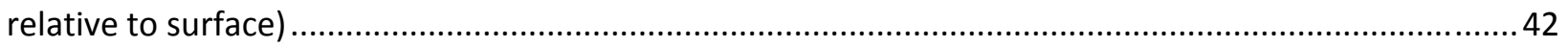

Figure 26 - Transmission loss coefficients for cabled and free-drifting hydropohones........................... 45

Figure 27 - Transmission losses between source and receiver versus the distance from the source........ 46

Figure 28 - DPM per day. Gaps in data represent C-POD retrieval and deployment periods ...................50

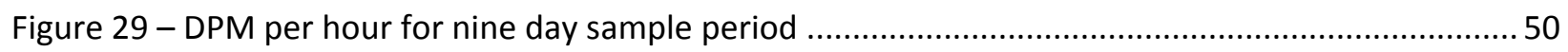


Figure 30 - Periodogram of DPM per hour with 95\% confidence interval (grey line).

Figure 31 - Boxplots of grouped DPM/hour. Dots above bars represent outliers..................................5 52

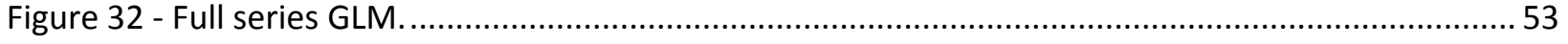

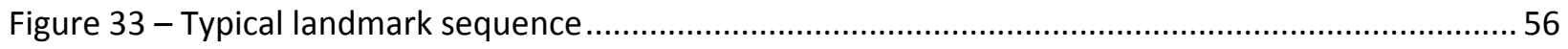

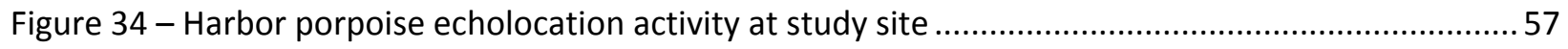

Figure 35 - Received levels associated with shipping and $6 \mathrm{~m}$ OpenHydro turbine at equivalent distances 58

Figure 36 - Latency (in minutes) from time of ferry closest point of approach to first recorded porpoise

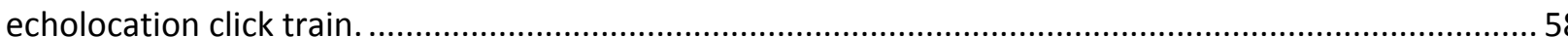

Figure 37 - Proportion of cases with detection positive minutes as a function of time before and after ferry closest point of approach on first inbound run of the day.

Figure 38 - Mean Inter Click Interval (ms) of the max and min ICl in each click train across day and season

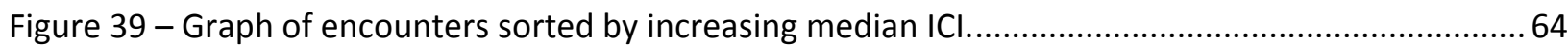

Figure 40 - Bar plot of the number of encounters by month with low, mid or hi ICl. .65 


\section{List of Tables}

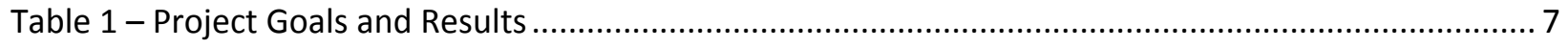

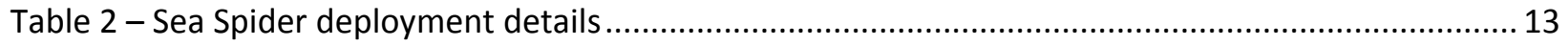

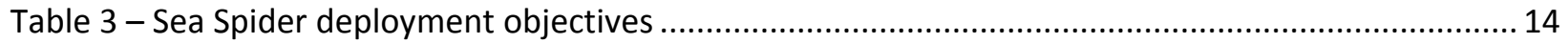

Table 4 - Temporal-spatial variability in porpoise detection positive minutes per day. ..........................28

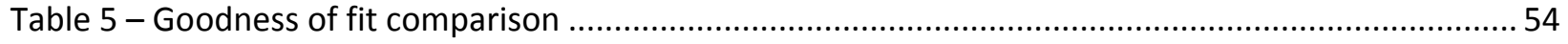

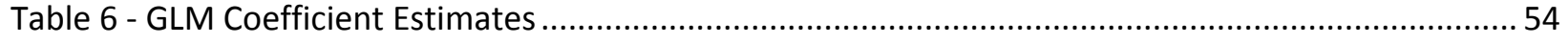

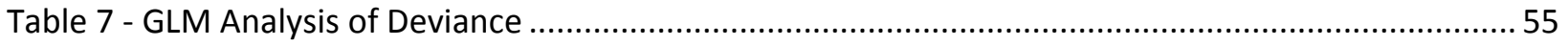

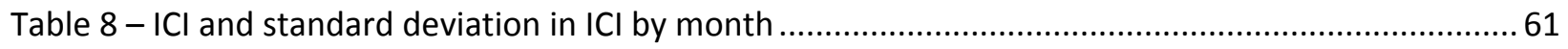

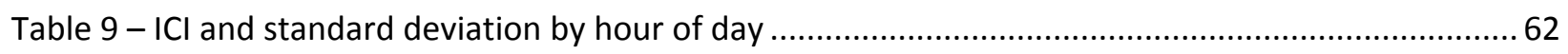

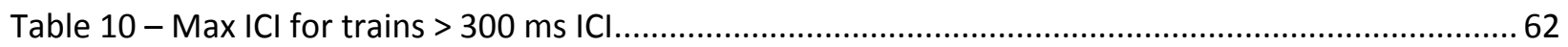

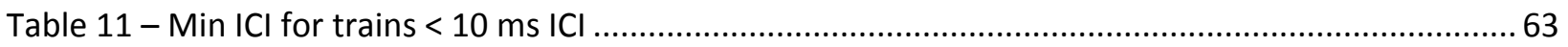




\section{Introduction}

\subsection{Project Overview}

Hydrokinetic turbines will be a source of noise in the marine environment - both during operation and during installation/removal. High intensity sound can cause injury or behavioral changes in marine mammals (Southall et al., 2007) and may also affect fish and invertebrates (Hawkins and Popper, 2012). These noise effects are, however, highly dependent on the individual marine animals; the intensity, frequency, and duration of the sound; and context in which the sound is received. In other words, production of sound is a necessary, but not sufficient, condition for an environmental impact. At a workshop on the environmental effects of tidal energy development, experts identified sound produced by turbines as an area of potentially significant impact, but also high uncertainty (Polagye et al., 2011). The overall objectives of this project are to improve our understanding of the potential acoustic effects of tidal turbines by:

- Characterizing sources of existing underwater noise;

- Assessing the effectiveness of monitoring technologies to characterize underwater noise and marine mammal responsiveness to noise;

- Evaluating the sound profile of an operating tidal turbine; and

- Studying the effect of turbine sound on surrogate species in a laboratory environment.

This study focuses on a specific case study for tidal energy development in Admiralty Inlet, Puget Sound, Washington (USA), but the methodologies and results are applicable to other turbine technologies and geographic locations.

\subsection{Case Description}

Public Utility District No. 1 of Snohomish County has proposed to deploy two OpenCentre turbines as a tidal energy demonstration project. The turbines are manufactured by OpenHydro, Ltd., an Irish turbine developer and consist of a $6 \mathrm{~m}$ diameter shrouded rotor mounted to a gravity tri-frame with tubular cans contacting the seabed at the vertices. The OpenHydro turbines are fixed-pitch, high-solidity rotors with an open center. The rotor cassette is the single moving part and is supported by water-lubricated bearings. A permanent magnet generator is contained in the shroud surrounding the blades. Anti-fouling coatings are applied to the interior surface of the shroud, hub, and rotor blades, but the gravity frame (steel, ballasted by concrete and aggregate) is left bare. The turbine shown in Figure 1 represents the 10 $\mathrm{m}$ version of $6^{\text {th }}$ Generation technology. The turbines deployed in Puget Sound will be $6 \mathrm{~m}$ variants of this generation technology. 


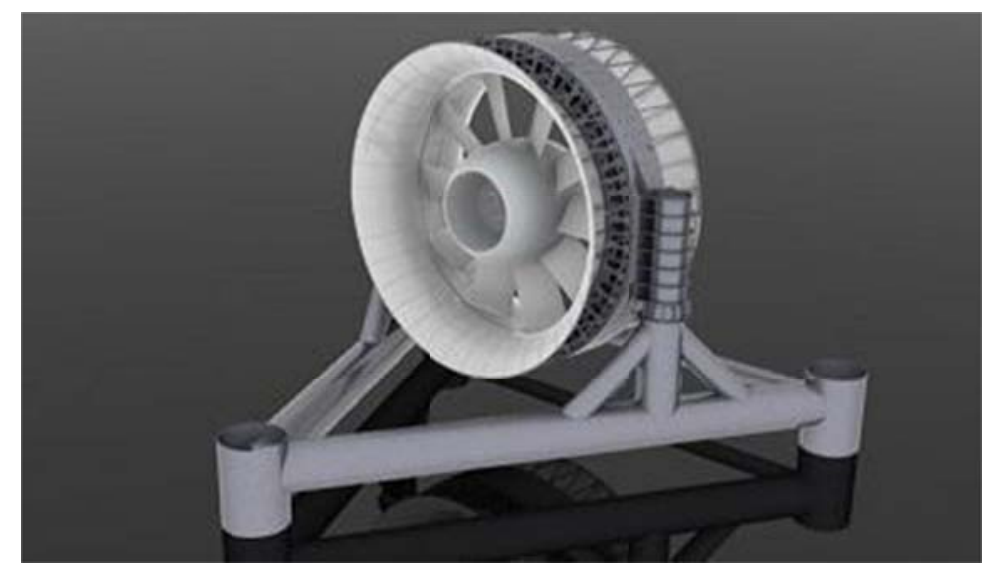

Figure 1-10 m OpenHydro turbine. Blade geometry, shroud geometry, and tri-frame design reflect $6^{\text {th }}$ Generation technology.

The deployment site is in northern Admiralty Inlet, Puget Sound, Washington. Admiralty Inlet is a constricted sill separating the deep Main Basin of Puget Sound from the Straits of Juan de Fuca and Straits of Georgia (Figure 2). At the narrowest point, between Admiralty Head and Point Wilson, the channel is approximately $5 \mathrm{~km}$ wide and $70 \mathrm{~m}$ deep. Excepting a small exchange through Deception Pass, the entire tidal prism of Puget Sound passes through this constriction, giving rise to tidal currents that routinely exceed $3 \mathrm{~m} / \mathrm{s}$ (6 knots) at mid-water. The project site is approximately $1 \mathrm{~km}$ SE of Admiralty Head in 55 m of water (Figure 3). The project location was chosen on the basis of strong tidal currents (intensified by the proximity to the headland), negligible seabed slope (necessary to deploy the gravity foundation), separation from high vessel traffic areas (federal navigation lanes, ferry route), and ease of cable routing back to shore.

During deployment, the turbines will be lowered to the seabed by the three points on the triangular base shown in Figure 1. Hydraulic jacks are used to connect to the frame and are detached and recovered once the turbine is in position on the seabed. During recovery, a frame is positioned over the subsea base. The forward face of the shroud (facing the apex of the triangular base) is used to align the recovery frame. Hydraulics on the frame then engage with the subsea base and the entire turbine is recovered, much in the same manner as it is deployed. Each turbine will be connected to shore by a separate power cable. These cables will also provide power for monitoring instrumentation and fiber optic communication with the turbine and monitoring instrumentation. 


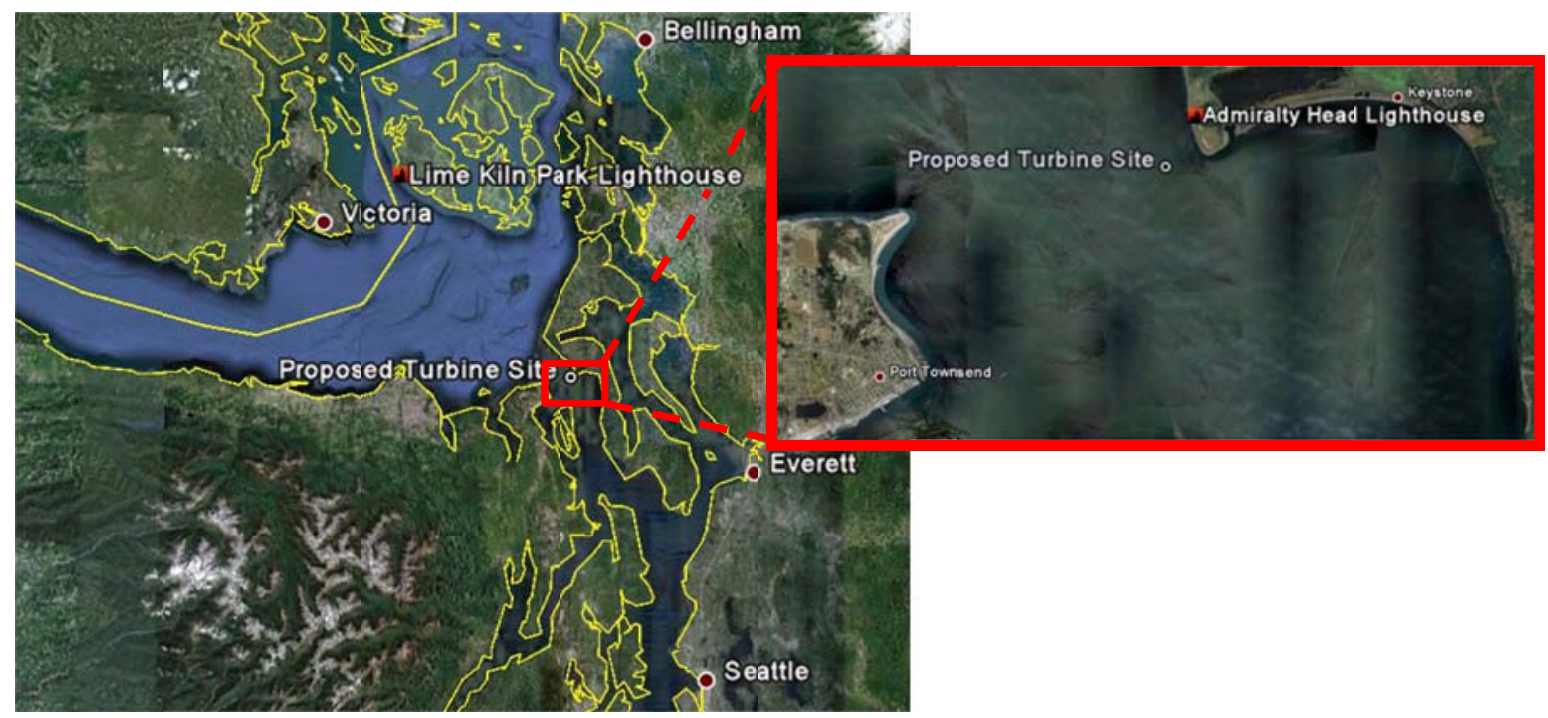

Figure 2 - Puget Sound, Washington (USA) and detail of turbine deployment site. 


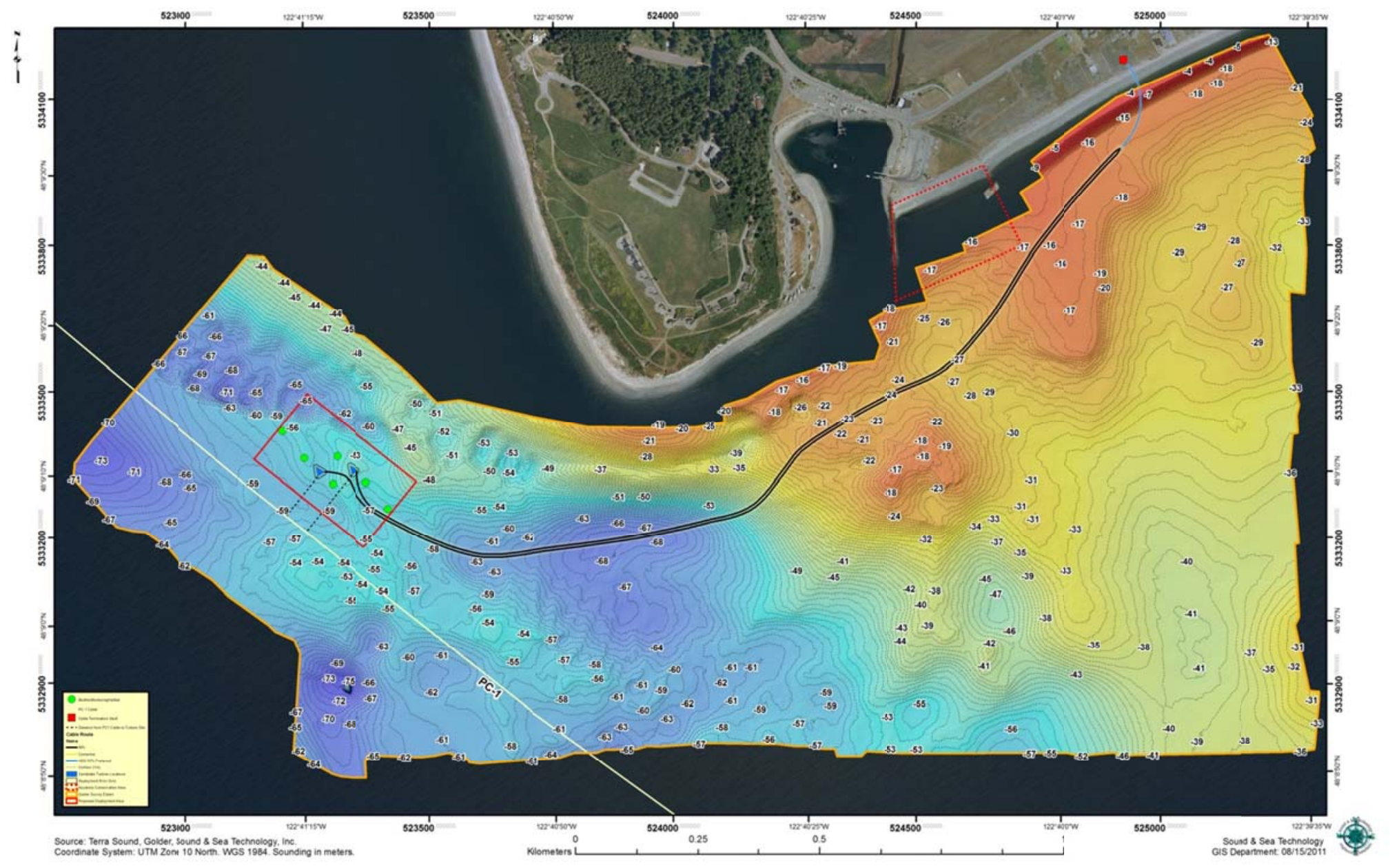

Figure 3 - Turbine deployment location in northern Admiralty Inlet. Blue triangles denote turbines, each of which is connected back to shore via a separate power cable. Dashed red polygon to the east of Keystone Harbor is a marine protected area. 


\subsection{Project Team}

The project team consists of Public Utility District No. 1 of Snohomish County (the District), the University of Washington Northwest National Marine Renewable Energy Center (UW-NNMREC), Sea Mammal Research Unit, Ltd. (SMRU, Ltd.), and Pacific Northwest National Laboratory (PNNL). The project was conducted collaboratively with individuals from each institution contributing to each of the tasks.

The team members and their roles were:

\section{Public Utility District No. 1 of Snohomish County:}

- Craig Collar, Project Director: overall technical and management direction

- Jessica Spahr, Project Manager: technical coordination, financial management, and reporting University of Washington, Northwest National Marine Renewable Energy Center:

- Brian Polagye, Principal Investigator: technical direction on site characterization studies, turbine sound analysis, and marine mammal presence/absence and response to noise; data analysis and interpretation

- Jim Thomson, co-Principal Investigator: direction of all field operations, technical direction on site characterization studies

- Chris Bassett, Graduate Researcher: collection, analysis, and interpretation of acoustic data from Admiralty Inlet; collection, analysis, and interpretation of vessel traffic data

- Joe Graber, Graduate Researcher: evaluation of infrared cameras for detection and classification of marine mammals

- Robert Cavagnaro, Graduate Researcher: analysis of harbor porpoise echolocation data to identify underlying factors

- Joe Talbert, Engineer: design and maintenance of instrumentation packages

- Alex de Klerk, Engineer: design and maintenance of instrumentation packages

- Capt. Andy Reay-Ellers: vessel operator for R/V Jack Robertson for all data collection and instrumentation deployment/recovery

Sea Mammal Research Unit, Ltd:

- Jason Wood, co-Principal Investigator: assessment of marine mammal behavior from echolocation data; experimental design

- Dom Tollit, co-Principal Investigator: assessment of marine mammal behavior from echolocation data; experimental design

\section{Pacific Northwest National Laboratory:}

- Andrea Copping, co-Principal Investigator: technical direction for laboratory studies of turbine noise effects

- Tom Carlson, co-Principal Investigator: technical direction for laboratory studies of turbine noise effects

- Michele Halvorsen, co-Principal Investigator: technical direction and implementation of laboratory studies of turbine noise effects 
While not officially part of the project team, this effort benefited tremendously from interactions with:

- NOAA National Marine Fisheries Service: Keith Kirkendall, Alicia Bishop, Alison Agness, Marla Holt, and Brad Hanson

- OpenHydro, Ltd: Sue Barr

- Scottish Association for Marine Science (SAMS): Caroline Carter

- Sandia National Laboratories: Jesse Roberts

- Washington State Parks

\subsection{Summary Goals and Accomplishments}

The project objectives are structured around four task areas, each with subtasks. Goals and accomplishments are summarized in Table 1. The following sections provide a more detailed description of each task, the approaches taken, results obtained, and lessons learned. 
Table 1 - Project Goals and Results

\begin{tabular}{|c|c|c|}
\hline Task Area & Goal & Accomplishment \\
\hline \multicolumn{3}{|c|}{ Task 1: Site Monitoring (UW-NNMREC Lead) } \\
\hline \multirow[t]{2}{*}{$\begin{array}{l}\text { - Stand-alone Instrumentation } \\
\text { Package }\end{array}$} & $\begin{array}{l}\text { Assemble a second instrumentation } \\
\text { package and upgrade an existing } \\
\text { instrumentation package. Deploy } \\
\text { and recover instrumentation } \\
\text { packages six times. }\end{array}$ & $\begin{array}{l}\text { Assembled two second generation } \\
\text { instrumentation packages. Six } \\
\text { deployments and recoveries, with } \\
\text { near- } 100 \% \text { data return from all } \\
\text { instruments. }\end{array}$ \\
\hline & (not a proposed goal) & $\begin{array}{l}\text { Identification of sources of } \\
\text { underwater noise at tidal energy } \\
\text { sites and role of tidal currents in } \\
\text { production of sound. Identified best } \\
\text { practices for integration of passive } \\
\text { and active acoustic monitoring } \\
\text { systems. }\end{array}$ \\
\hline \multirow[t]{2}{*}{$\begin{array}{l}\text { Shore-based Infrared } \\
\text { detection of marine } \\
\text { mammals }\end{array}$} & $\begin{array}{l}\text { Detect marine mammals using } \\
\text { infrared camera. }\end{array}$ & $\begin{array}{l}\text { Demonstrated ability of infrared } \\
\text { cameras to detect marine } \\
\text { mammals. }\end{array}$ \\
\hline & (not a proposed goal) & $\begin{array}{l}\text { Identified the physics underlying the } \\
\text { detection, demonstrated capability } \\
\text { for auto-detection algorithms to } \\
\text { reduce review time, and identified } \\
\text { parameters governing detection } \\
\text { effectiveness. }\end{array}$ \\
\hline $\begin{array}{l}\text { - Shore-based Vessel traffic } \\
\text { monitoring }\end{array}$ & $\begin{array}{l}\text { Log ship traffic using an AIS receiver } \\
\text { to improve understanding of } \\
\text { contribution of ship noise to } \\
\text { ambient noise. }\end{array}$ & $\begin{array}{l}\text { Two years of vessel traffic } \\
\text { monitoring in Admiralty Inlet. } \\
\text { Measurement and modeling } \\
\text { indicates that vessel traffic accounts } \\
\text { for } 90 \% \text { of the temporal variability } \\
\text { in ambient noise. }\end{array}$ \\
\hline \multicolumn{3}{|c|}{ Task 2: Turbine Noise Source (UW-NNMREC Lead) } \\
\hline \multirow[t]{2}{*}{ - Sound propagation test } & $\begin{array}{l}\text { Deploy an acoustic projector to } \\
\text { simulate the sound profile of a tidal } \\
\text { turbine to evaluate the acoustic } \\
\text { footprint of a tidal energy project. }\end{array}$ & $\begin{array}{l}\text { Single-tone sound propagation } \\
\text { experiment. }\end{array}$ \\
\hline & (not a proposed goal) & $\begin{array}{l}\text { Analysis of turbine sound } \\
\text { measurements and development of } \\
\text { a probability-based framework for } \\
\text { assessing detection of turbine } \\
\text { sound by marine mammals. }\end{array}$ \\
\hline
\end{tabular}


(Table - Continued)

\begin{tabular}{|c|c|c|}
\hline $\begin{array}{l}\text { - Interpret presence and } \\
\text { behavior of marine mammals }\end{array}$ & $\begin{array}{l}\text { Statistical analysis of click data from } \\
\text { echolocation hydrophones. } \\
\text { Interpretation of secondary data, } \\
\text { including marine mammal } \\
\text { vocalizations recorded by ambient } \\
\text { noise hydrophones (Task } 1 \text { ), land- } \\
\text { based observers, and shore-based } \\
\text { infrared cameras. }\end{array}$ & $\begin{array}{l}\text { Statistical analysis of click trains } \\
\text { identified factors influencing } \\
\text { presence/absence of harbor } \\
\text { porpoise, and while diel activity was } \\
\text { identified as a significant factor, } \\
\text { unexplained variability limit the } \\
\text { practical use of click trains to study } \\
\text { the underlying factor influencing } \\
\text { behavior of harbor porpoise. }\end{array}$ \\
\hline & (not a proposed goal) & $\begin{array}{l}\text { Identification of "landmark" } \\
\text { sequences which may be suitable } \\
\text { for characterizing interactions } \\
\text { between harbor porpoises and } \\
\text { turbines, post-installation. } \\
\text { Evaluation of responsiveness of } \\
\text { harbor porpoise to existing } \\
\text { anthropogenic noise. Evaluation of } \\
\text { behavioral state through inter-click } \\
\text { interval. }\end{array}$ \\
\hline \multicolumn{3}{|c|}{ Task 4: Effect of Turbine Noise on Aquatic Species (PNNL Lead) } \\
\hline $\begin{array}{l}\text { - Dose-response experiments } \\
\text { on juvenile Chinook salmon }\end{array}$ & $\begin{array}{l}\text { Expose juvenile Chinook salmon to a } \\
\text { "dose" of turbine noise representing } \\
\text { probable exposure and evaluate } \\
\text { changes to hearing and barotrauma. }\end{array}$ & $\begin{array}{l}\text { Exposed juvenile Chinook salmon to } \\
\text { a "worse than worst-case" acoustic } \\
\text { dose and determined this causes } \\
\text { minor, recoverable injury and no } \\
\text { changes to hearing. }\end{array}$ \\
\hline
\end{tabular}




\section{Task 1: Site Monitoring}

The objective of this task was to demonstrate approaches for monitoring tidal energy sites using a combination of instrumentation placed on shore and on the seabed. The information gained from these monitoring activities is necessary to characterize the physical and biological environment at tidal energy sites for several user groups:

- Site developers require information about tidal currents to optimize power generation from arrays and information about the ecological and social uses of sites to minimize conflict;

- Device developers require information about tidal currents to ensure device survivability; and

- Regulatory agencies require information about the ecological and social uses of sites to establish the context for tidal energy development.

For the purposes of this study, the data collected under this task informed analysis under Task 2 (§ 3 ) and Task 3 (§ 4).

Several novel approaches were demonstrated in achieving the objectives of this task:

1. The use of autonomous bottom-mounted instrumentation packages to characterize the spatial and temporal variations in the biological and physical environment at tidal energy sites;

2. The use of shore-based infrared cameras to extend the capabilities of shoreline observations of marine mammals; and

3. The use of a shore-based receiver station to establish long-term trends in commercial vessel traffic.

This task was led by UW-NNMREC.

\subsection{Sea Spiders: Infrastructure and Equipment}

\subsubsection{Objectives}

The objective of this task was to deploy and recover instrumentation packages six times over the period of performance, with servicing intervals of three months. The first generation package (Sea Spider Mark I) was deployed two times (Feb - May 2010 and May - Aug 2010) and two second generation packages (Sea Spider Mark II) were deployed four times (Aug - Nov 2010, Nov - Feb 2011, Feb - May 2011, and May - Aug 2011). We achieved near-100\% data return on all deployments (i.e., instruments deployed correctly and recorded for the duration of the deployment). For cases in which two Sea Spiders were simultaneously deployed, one Sea Spider was positioned at the probable turbine installation site while the second was positioned elsewhere in Admiralty Inlet to characterize the extent of spatial variability. With experience, instrumentation deployments within $10 \mathrm{~m}$ of the intended target were achieved.

\subsubsection{Approach and Results}

During 2009, NNMREC designed, built and deployed its first generation instrumentation package, the Sea Spider (Mark I). The Sea Spider is a lead-ballasted fiberglass frame (Oceanscience, Ltd. Sea Spider) equipped with redundant acoustic release systems. Autonomous instrumentation is attached to the frame through bolts or clamps. The systems are deployed from a research vessel and lowered to the seabed by a winch. Once they have landed on the seabed, the packages are acoustically released. During recovery, a surface vessel sends a coded pulse to one of the acoustic releases on the Sea Spider, which releases a float to the surface. This float trails a recovery line that connects, at the other end, to a pick 
point near the center of mass for the Sea Spider. A winch takes up the slack in the trailing line and then recovers the Sea Spider and ballast back to the surface. As such, nothing remains behind on the seabed. Images of the Mark I Sea Spider (SS \#01) and Mark II Sea Spiders (SS \#02 and \#03) and a listing of instrumentation are shown in Figure 4 and an annotated image of SS \#02 is shown in Figure 5. The Mark II Sea Spiders incorporated several learnings from the experience with the Mark I packages:

- $200 \mathrm{lbs}$ of additional ballast to maintain platform stability on the seabed. As discussed in the Lessons Learned section, velocities near the seabed can approach $3 \mathrm{~m} / \mathrm{s}$, placing very high loads on the instrumentation package. The increased ballast also necessitated reinforcement of the fiberglass frames. The Mark II Sea Spider frames were customized, at modest incremental cost, by Oceanscience, Ltd.;

- Modular instrumentation mounts (green panels) to accommodate instrumentation changes anticipated over the course of the deployment. Instrumentation was directly attached to the Mark I Sea Spider frame. Consequently, whenever new instrumentation was added, holes needed to be drilled in fiberglass frame. Additionally, surfaces oriented in the horizontal plane or vertical plane are preferred for instrumentation mounting, while the majority of surfaces on the fiberglass frame are at an incline.; and

- Upgraded acoustic releases which can communicate status back to a surface vessel to simplify recovery operations. As discussed in the Lessons Learned section, the Mark I Sea Spiders used "receive-only" acoustic releases, which contributed to several long recovery operations in 2009 and early 2010.

In air, the Mark I Sea Spider weighed approximately 650 lbs and the Mark II Sea Spiders weighed approximated $850 \mathrm{lbs}$. 


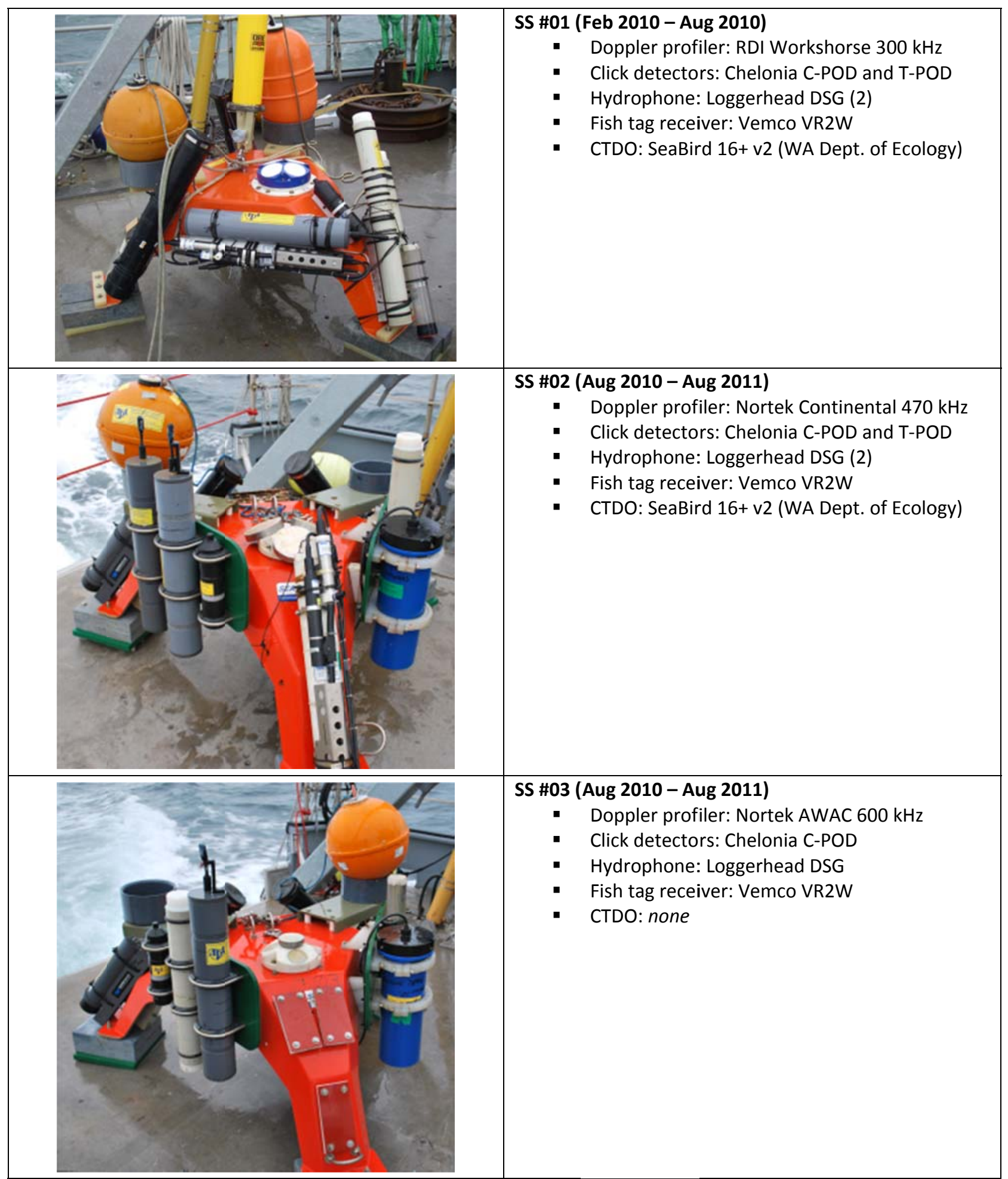

Figure 4 - Sea Spider instrumentation packages deployed over the course of this project (note: red panels on SS $\# 03$ are a static test of a foul release coating conducted in partnership with Hempsel, S.A.) 


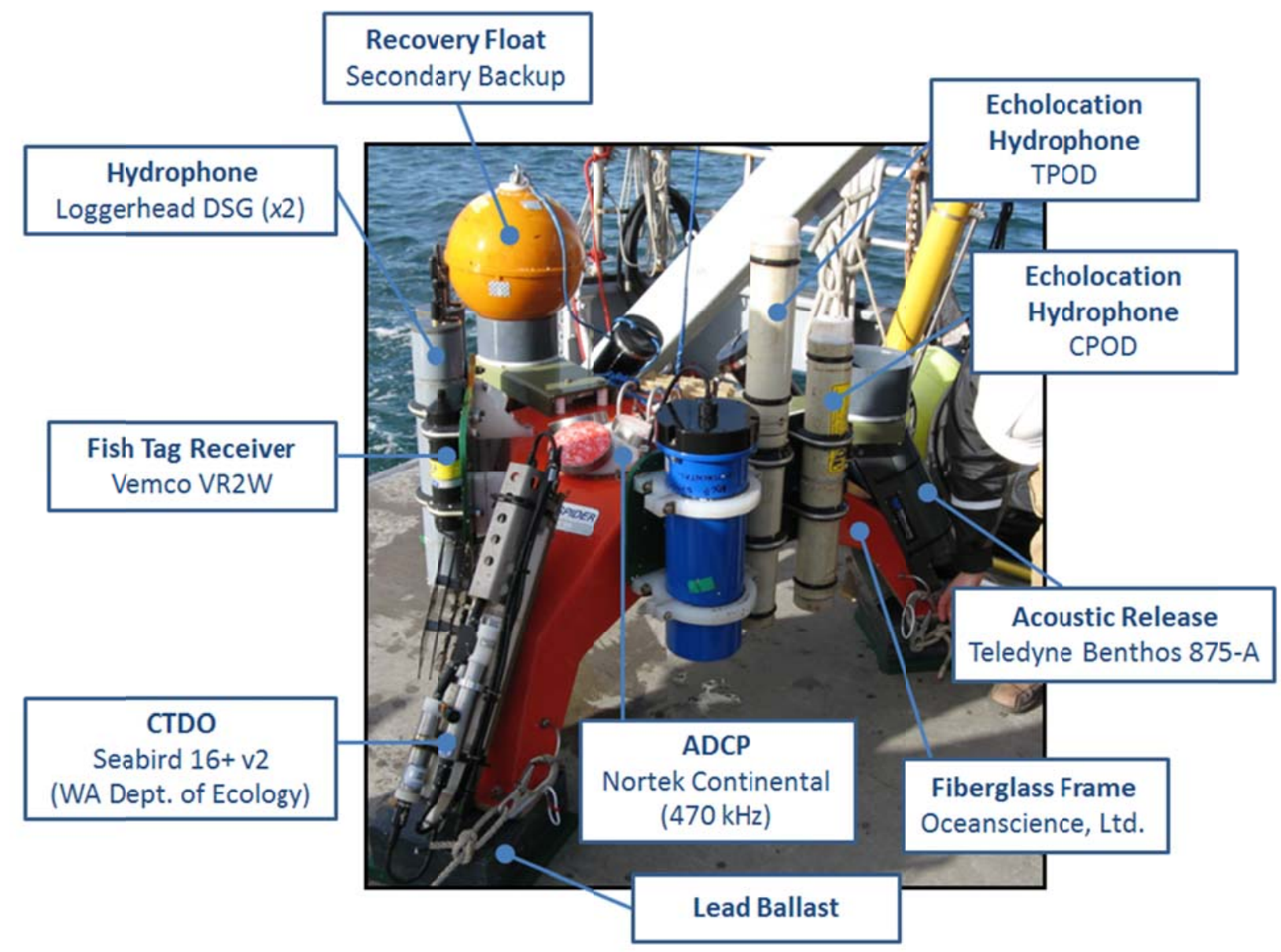

Figure 5 - Sea Spider (SS\#02 Mark II) after recovery with instrumentation and infrastructure as annotated. For this project, all Sea Spiders were deployed from the R/V Jack Robertson, a research vessel owned and operated by the University of Washington's Applied Physics Laboratory. The Jack Robertson is a 60' vessel with a single screw and bow thruster. The working load on its A-frame is approximately 10 tons. Sea Spiders were deployed in Admiralty Inlet at the locations shown in Figure 6 and described in Table 2 for the objectives summarized in Table 3. In summary, SS \#01 was deployed at two options that, at the time, were under consideration for turbine deployment. Once the Mark II Sea Spiders entered service in August 2010, SS \#02 was deployed each time at the same location - the proposed turbine deployment site for turbine \#1. Sequential deployments were all within a $20 \mathrm{~m}$ radius and continuous for nearly one year, excluding several days every three months when instrumentation was out of the water for data offload and servicing. This served to assess long-term temporal variability at a single location. SS \#03 was used to explore spatial variability in currents, ambient noise, and marine mammal activity. The first deployment was to the west of Admiralty Head in the eddy field that forms on ebb tide. This assessed sound production from sediment transport, large-scale turbulence, and surf on the beach. The second deployment was to the east of Admiralty Head directly beneath the ferry lane. As discussed in $\S 4.2$, the information from this deployment was used to assess the capabilities of C-PODs to quantify avoidance behavior from broadband sources of sound louder than tidal turbines (the passenger ferry that traverses between Keystone Harbor on Whidbey Island and Port Townsend on the Kitsap Peninsula). The third 
deployment was in the center of the shipping lanes in Admiralty Inlet. This is a potential site of longerterm interest for tidal energy development. The fourth, and final, deployment was in close proximity to SS \#02 at the site of the second proposed turbine to quantify short-range spatial variability.

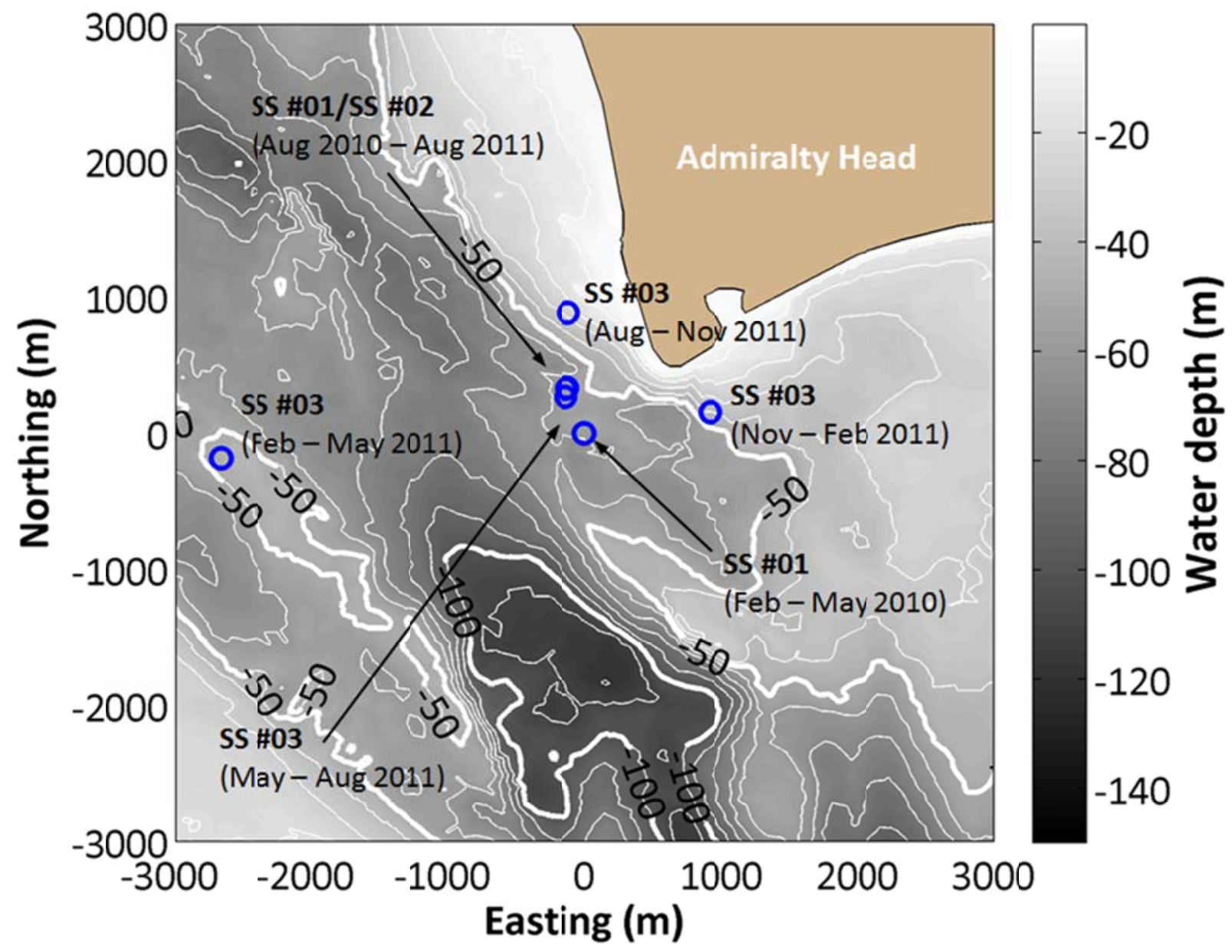

Figure 6 - Sea Spider deployment locations

Table 2 - Sea Spider deployment details

\begin{tabular}{|l|c|c|c|c|c|}
\hline Platform & Dates & Duration (days) & Depth $(\mathbf{m})$ & Latitude & Longitude \\
\hline SS \#01 & $\begin{array}{c}2 / 11 / 2010- \\
5 / 4 / 2010\end{array}$ & 82 & 56 & 48.1501 & -122.6862 \\
\hline SS \#01 & $\begin{array}{c}5 / 6 / 2010- \\
8 / 17 / 2010\end{array}$ & 64 & 58 & 48.1531 & -122.6879 \\
\hline SS \#02 & $\begin{array}{c}8 / 18 / 2010- \\
8 / 9 / 2011\end{array}$ & 356 & 59 & 48.1530 & -122.6880 \\
\hline SS \#03 & $\begin{array}{c}8 / 18 / 2010- \\
11 / 8 / 2010\end{array}$ & 83 & 27 & 48.1581 & -122.6878 \\
\hline SS \#03 & $\begin{array}{c}11 / 10 / 2010- \\
2 / 10 / 2011\end{array}$ & 92 & 48 & 48.1515 & -122.6738 \\
\hline SS \#03 & $\begin{array}{c}2 / 13 / 2011- \\
5 / 9 / 2011\end{array}$ & 85 & 49 & 48.1486 & -122.7221 \\
\hline SS \#03 & $5 / 11 / 2011-$ & & & & \\
\hline & $8 / 9 / 2011$ & 90 & 61 & 48.1525 & -122.6881 \\
\hline
\end{tabular}


Table 3 - Sea Spider deployment objectives

\begin{tabular}{|c|c|c|c|c|c|c|}
\hline & $\begin{array}{l}\text { Feb - May } \\
2010\end{array}$ & $\begin{array}{l}\text { May - Aug } \\
2010\end{array}$ & $\begin{array}{l}\text { Aug - Nov } \\
2010\end{array}$ & $\begin{array}{l}\text { Nov - Feb } \\
2011\end{array}$ & $\begin{array}{l}\text { Feb - May } \\
2011\end{array}$ & $\begin{array}{l}\text { May - Aug } \\
2011\end{array}$ \\
\hline SS \#01 & $\begin{array}{l}\text { Alternate } \\
\text { turbine site }\end{array}$ & & & & & \\
\hline SS \#02 & & $\begin{array}{l}\text { Proposed } \\
\text { turbine site } \\
\text { (turbine \#1) }\end{array}$ & $\begin{array}{l}\text { Proposed } \\
\text { turbine site } \\
\text { (turbine \#1) }\end{array}$ & $\begin{array}{l}\text { Proposed } \\
\text { turbine site } \\
\text { (turbine \#1) }\end{array}$ & $\begin{array}{l}\text { Proposed } \\
\text { turbine site } \\
\text { (turbine \#1) }\end{array}$ & $\begin{array}{l}\text { Proposed } \\
\text { turbine site } \\
\text { (turbine \#1) }\end{array}$ \\
\hline SS \#03 & & & $\begin{array}{l}\text { Eddy field - } \\
\text { sources of } \\
\text { underwater } \\
\text { noise } \\
\text { associated } \\
\text { with strong } \\
\text { currents }\end{array}$ & $\begin{array}{l}\text { Ferry route - } \\
\text { harbor } \\
\text { porpoise } \\
\text { responsiveness } \\
\text { to noise }\end{array}$ & $\begin{array}{l}\text { Central inlet } \\
\text { - macro- } \\
\text { scale } \\
\text { variability }\end{array}$ & $\begin{array}{l}\text { Proposed } \\
\text { turbine site } \\
\text { (turbine \#2) }\end{array}$ \\
\hline
\end{tabular}

Data return rates were near $100 \%$ for Sea Spider deployments, a considerable success given the harsh environments the instruments were deployed in. The data products from these deployments have informed several analyses. Those related to ambient noise and marine mammal activity are detailed in $\S$ 2.2 and $\S 2.3$, respectively. Also of considerable interest to project development is the observed spatial variability in tidal currents, as described in Polagye and Thomson (submitted).

\subsubsection{Lessons Learned}

\section{Sea Spider Stability}

As previously stated, in air, each Sea Spider weighs approximately $850 \mathrm{lbs}$. In water, buoyancy decreases this to approximately $650 \mathrm{lbs}$. The Sea Spiders are tripods, with three feet in contact with the seabed. Analysis of orientation (heading, pitch, and roll) sensors on the Doppler profilers indicate that during most deployments, the Sea Spiders rotate on the order of tens of degrees during the first spring tide following deployment. Because the Sea Spiders rest on a layer of cobbles, it is hypothesized that the feet are slipping over the cobbles or, perhaps, the cobbles under the feet are slipping over each other. Rotation likely ceases when the Sea Spider is oriented along the axis of minimize drag or the feet have dug into the cobble layer sufficiently to arrest motion. Two instructive cases related to platform stability are presented here.

Analysis of orientation data, along with pressure sensor and recovery coordinates, suggest that during the May-August 2010 deployment, SS \#01 was moved 90 meters to the northwest of its deployment location around the $64^{\text {th }}$ day of deployment. While it is not unusual for strong currents to rotate the tripod on the seabed as the feet slide across cobbles, this degree of motion was unusual. Examination of the ADCP data (velocity and direction) indicated that tripod movement occurred during a turbulent spike in current velocity exceeding $2.8 \mathrm{~m} / \mathrm{s}$ in close proximity to the seabed. This incident suggested that the ballast on the Mark I Sea Spider was marginally sufficient to resist the strongest tidal currents. As no significant movement was observed for the Mark II Sea Spiders (deployed at the same location), the 200 $\mathrm{lb}$ increase in ballast between generations appears to be have been sufficient to address this concern. This incident highlights the need for instrumentation platforms deployed for tidal energy site 
characterization to be heavily ballasted, maintain a low center of mass (to resist overturning moments), and have a minimized drag profile. In general, ballasting requirements will be site-specific, depending on the tidal currents, platform drag, seabed composition, water depth, and wave climate. For example, an even heavier tripod deployed by a research group in the Bay of Fundy was recently flipped over (and flipped back) by what appears to be wave-induced currents associated with the passage of a hurricane (10 m swell in 60 m of water). Conversely, platforms lighter than the Sea Spiders have been successfully deployed and recovered at other tidal energy sites.

In February 2011, when the R/V Jack Robertson came on station to recover SS \#02 and SS \#03, the recovery float for SS \#02 was already on the surface. Subsequent assessment indicated that the float deployed prematurely due to a structural failure in the release package. It is likely that the buoy was on the surface and recovery line fully extended for several tidal cycles. During this time, the drag on the line and float would have been considerable. In spite of this, the Sea Spider does not appear to have shifted appreciably on the seabed (as confirmed by the recovery location and lack of rotation recorded by the ADCP heading sensor). Cleats added to the tripod feet in November 2011 (metal U-channel) may have helped to increase resistance to movement/rotation. Previously, the contact surface had been a hard plastic. A cleated contact surface is recommended as a best practice for cobble or sediment seabeds. A different approach may be preferable for bedrock seabeds.

\section{Effectiveness of Fish Tag Receivers}

Each of the Sea Spiders was equipped with a Vemco VR2W fish tag receiver. These are capable of detecting tagged fish at a range of approximately $200 \mathrm{~m}$. Because each tag has a unique identifier, if the tag ID can be located in a research database, the species and life history of the tagged fish can be determined. However, over the course of this project, there were limited tagging efforts undertaken in Puget Sound. Consequently, very few tags were detected. Those that were detected were not archived in public research databases and, therefore, no species identification was possible. This suggests that opportunistic detection of tags is not, necessarily, an effective strategy for assessing species composition in the vicinity of a tidal energy project (see further discussion in $\S 6.3$ regarding the NOPP project to develop these type data).

\section{Instrumentation Compatibility}

The cost of deploying and recovering instrumentation packages is sufficiently high to motivate packaging a full suite of characterization tools onto a single platform. However, this presents the possibility of one instrument interfering with another. Several cases in which this occurred and strategies to mitigate this interference are described here:

- Doppler profiler and broadband hydrophone: While the frequency of the Doppler profilers (300 $\mathrm{kHz}$ minimum) is substantially higher than the sampling frequency of the broadband hydrophone $(80 \mathrm{kHz})$, sound from the Doppler profiler can be recorded by the broadband hydrophone. This can occur because of sound produced by profiler away from the center frequencies within the sampling range of the hydrophone or because high frequency sound is aliased to lower frequencies ${ }^{1}$. This interference can be mitigated by staggering data collection

\footnotetext{
${ }^{1}$ The Loggerhead DSG is equipped with a hardware anti-aliasing filter, but this is not completely effective at removing high frequency sound, particularly high intensity sound at close proximity to the instrument.
} 
for the Doppler profiler and hydrophone. While data collection is asynchronous, internal clock drift was never substantial enough to result in overlapping data collection when instruments were configured for staggered collection. This interference does, however, place a fundamental limit on the duty cycle for Doppler profilers and broadband hydrophones on the same platform. However, due to memory limitations for hydrophones, a low duty cycle is generally required.

- CTDO pump noise and broadband hydrophone:-The conductivity and dissolved oxygen sensors on a SeaBird $16+v 2$ are designed for water to be pumped across the sensors. This improves accuracy and reduces biofouling over long deployments. However, the noise from the pump is detectable by the hydrophone and of moderate intensity, given the close proximity of the pump to the hydrophone element. This interference can be minimized by increasing the separation between the pump and hydrophone within the limits of the platform size and, in postprocessing, by identifying and removing recordings contaminated by pump noise. The pump signature is sufficiently unique that identification and removal is not difficult. Further, because of power constraints, the pump will operate on a relatively low duty cycle during long-term deployments (e.g., pumping for several seconds every 30 minutes during a 90 day deployment).

- Platform noise and broadband hydrophone: High currents can produce self-noise on the instrumentation platform by rattling shackles or recovery floats. This noise is low frequency and will only be apparent if the hydrophone is equipped with a flow shield to attenuate flow noise (further discussion in § 2.2). These sources of noise can be mitigated by padding contact surfaces or otherwise restraining hardware. However, at current speeds above $2 \mathrm{~m} / \mathrm{s}$, some platform noise is likely inevitable for the Sea Spider package. A trawl-proof platform (e.g., an enclosed platform with ports for recovery floats and instrumentation) may have a lower selfnoise profile during strong currents, but makes it more difficult to implement a modular architecture (i.e., a hole needs to be cut for each sensor).

- Doppler profiler and Click Detector: Doppler profiler sound may, in some cases, be detected by a cetacean click detector. This interference is extremely sensitive to the relative orientation of instruments and their configuration. This is discussed further in $\S 2.3$, but, as a best practice, a short-term deployment (i.e., 1-2 days) is recommended to assess the potential for interference when a new package is put into service or the Doppler profiler configuration is changed.

\section{Biofouling}

While all Sea Spider deployments were beneath the photic zone, moderate biofouling was routinely observed on instrumentation packages during recovery, with strong seasonal and inter-annual variability. This biofouling never affected instrumentation performance, but does highlight the challenge that long-term instrumentation deployments for post-installation project monitoring will face. For acoustic measurements, covering transducers with a thin layer of zinc oxide (diaper rash cream has a high zinc oxide content) proved effective for suppressing biofouling. In general, fouling was most pronounced in crevice spaces and on uncoated surfaces (e.g., PVC instrument cases). Post-recovery images for several Sea Spiders are shown in Figure 7. 


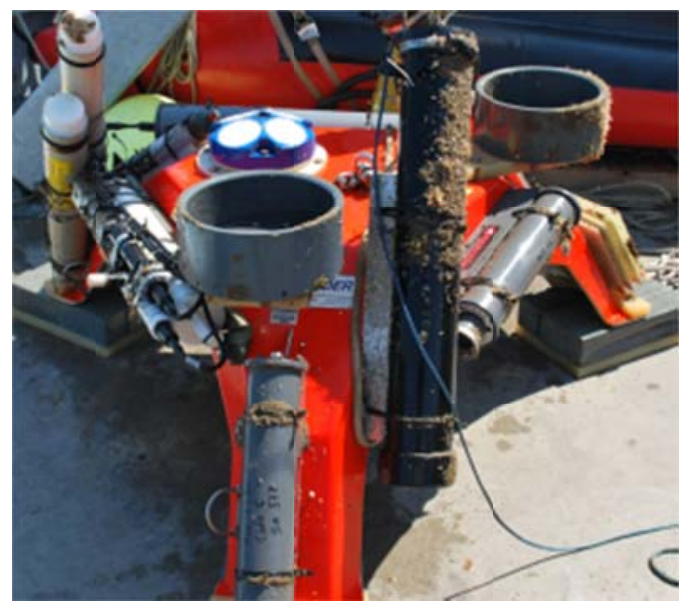

(a) SS \#01 - August 2010

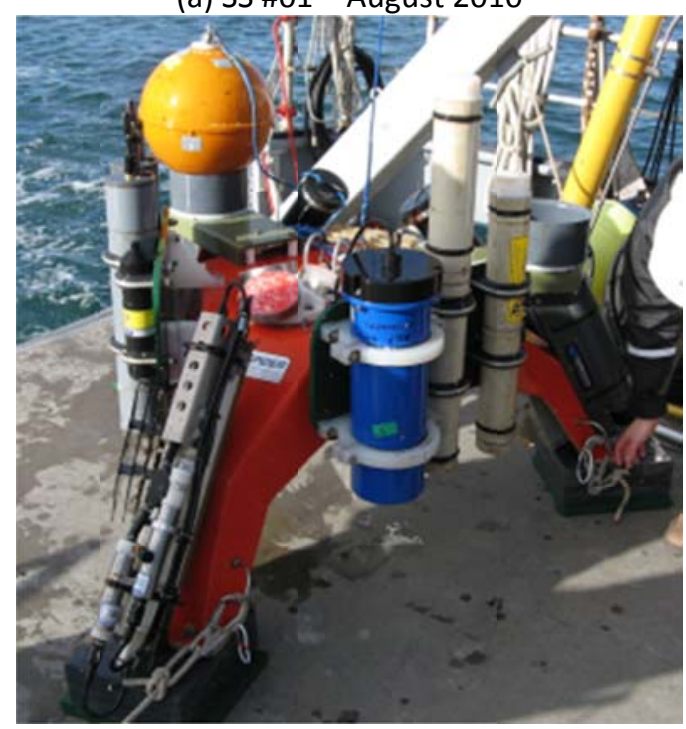

(c) SS \#02 - November 2010

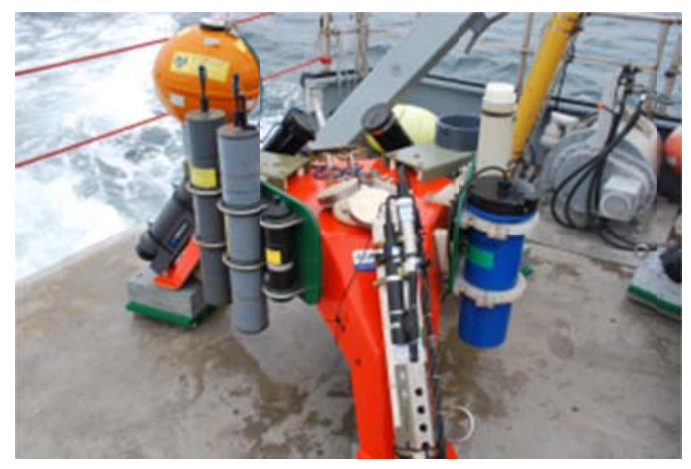

(b) SS \#02 -May 2011

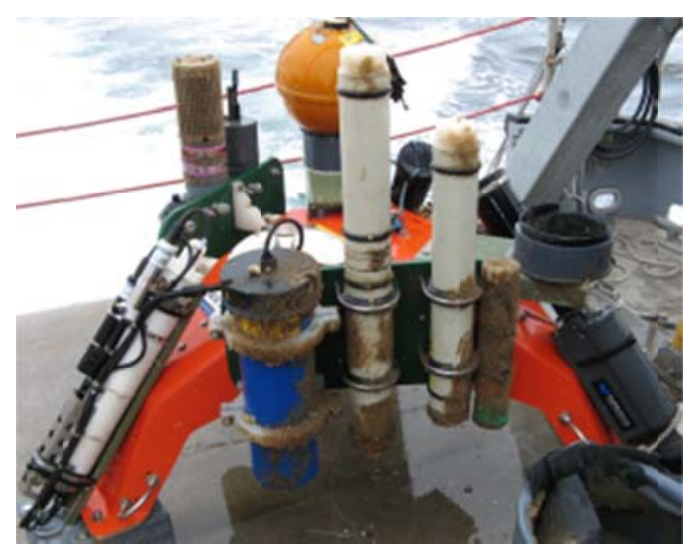

(d) SS \#02 - August 2011

Figure 7 - Sea Spider biofouling

While biofuling was most significant during the May to August time period, inter-annual variability was also pronounced. From April 2009 - May 2010 various materials and coatings were deployed for static biofouling tests on SS \#01. In general, the results suggested that smooth surfaces were not likely to develop significant fouling, with edges and crevices at much higher risk. However, between May and August 2010, many smooth surfaces experienced significant bioufling. The primary macro-fouling appeared to be a red algae, which then acted as an aggregation site for krill and sediment. Barnacles also colonized a higher percentage of surfaces than during the same period in the previous year. As discussed in $\S 6.3$, this motivated a collaboration with Hempel, S.A. to conduct static testing of antifouling coatings during subsequent Sea Spider deployments.

\section{Stainless Steel Corrosion}

Upon recovery, stainless steel corrosion was typically observed on at least $50 \%$ of all hardware - crevice corrosion at interfaces with composites or plastic being the most common. Consequently, the majority of the 316 stainless steel hardware on the tripods was replaced during each recovery/redeployment cycle. While this type of preventative action is possible when the service interval is three months, 
crevice corrosion has the potential to cause more serious hardware failures over longer intervals (i.e., 12 year service interval for a hydrokinetic turbine). One solution to this challenge is to use titanium hardware, which has excellent corrosion resistance. However, the cost of titanium is quite high and hardware sizes more limited than for $\mathbf{3 1 6}$ stainless steel. Alternatively, galvanized hardware, which is lower cost and corrodes more predictably than 316 stainless steel may be preferable. It is possible that periodic low-oxygen intrusions over the Admiralty Inlet sill from the Pacific Ocean may worsen corrosion at this specific location. Several examples of crevice corrosion of 316 stainless steel on Sea Spider hardware are presented in Figure 8.

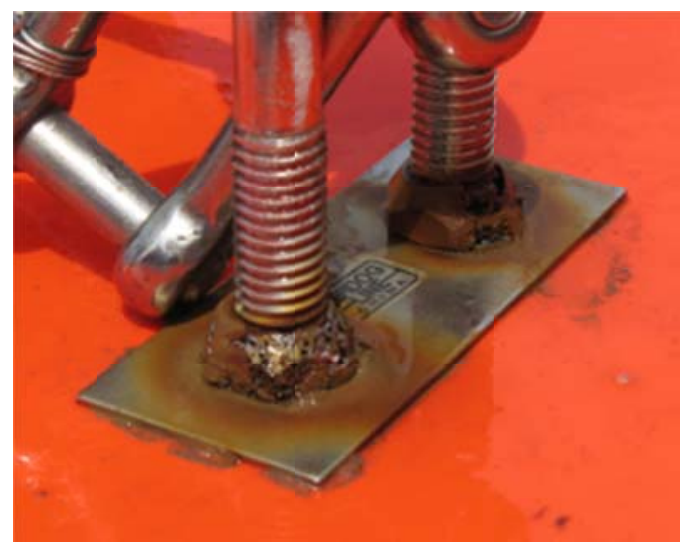

(a) SS \#01 - May 2009 (1 month deployment, Nylock nuts on reverse side starved stainless steel of oxygen)

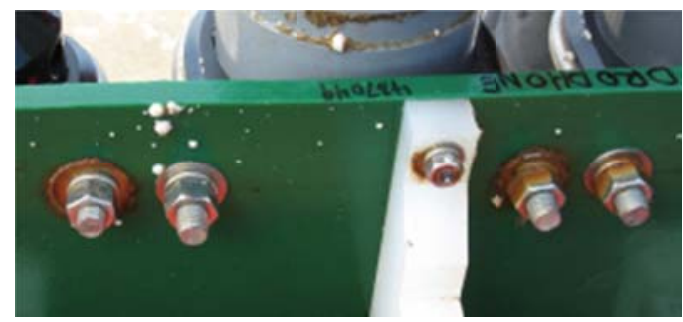

(c) SS \#03 - November 2010 (3 month deployment) Figure 8-Crevice corrosion

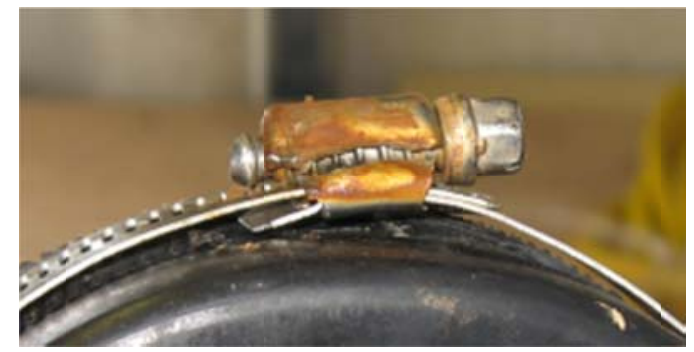

(b) Stainless steel hose clamp

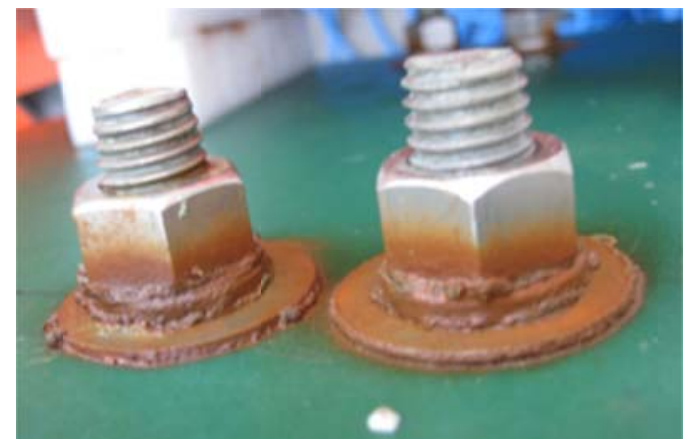

(d) SS \#02 - February 2011 (3 month deployment)

\section{Acoustic Releases}

The Mark II Sea Spiders incorporated acoustic releases which were able to both receive and transmit (i.e., releases can communicate back to deck box on surface). The Mark I Sea Spider incorporated acoustic releases which were only able to receive commands. During recovery operations this contributed to ambiguity about the state of the tripod. If a release code had been transmitted and a recovery float did not appear on the surface, the release might not have received the release code, the release might have received the code but a mechanical problem prevented float release, or the tripod could have been transported by currents out of the project area. This ambiguity contributed to a number of delays in tripod recovery during field operations in 2009 and 2010. The recovery procedure for the Mark II Sea Spiders involves sending a coded pulse to wake up the release (which is acknowledged by the release), a coded pulse to arm the release (which is also acknowledged), and a final pulse to release the float (which is also acknowledged). This allows for much more effective trouble 
shooting during recovery operations. While "receive-only" releases are less expensive, "transmit and receive" releases are a recommended best practice and less costly over the lifetime of the release (e.g., higher release cost offset by lower vessel costs for recovery).

The Sea Spider incorporates a redundant recovery system. During recovery operations for the Mark I Sea Spider in August, 2010, the primary float did not surface after multiple attempts. The backup release did function correctly and the Sea Spider was recovered. Upon retrieval, it was determined that the primary release mechanism had functioned correctly, but that the float was connected to the wrong end of the retrieval line. Consequently, the float buoyancy was insufficient to pull cordage from the line canister (more than 100 pounds of force would have been required). This problem was caused by operator error during preparation for deployment and is a relatively easy (though uncommon) mistake to make. This reinforces the need for redundant recovery systems as there are several potential points of failure in each release system, but it is unlikely that both would simultaneously fail.

\section{Deployment Operations}

Due to the spatial variability in the tidal current resource, it is desirable to deploy instrumentation packages within $10 \mathrm{~m}$ of their intended targets. Truly slack water does not occur at deep water tidal energy sites due to the phase difference in tidal currents between the surface and the seabed (i.e., while the currents are slack at the surface, they will likely still be ebbing or flooding near the seabed). Consequently, appreciable currents are likely during instrumentation deployment. This can be dealt with by anchoring the deployment vessel or deploying instrumentation from a "live boat". The former option requires a three-point mooring be established at the deployment site, which can be quite challenging given the mass of the anchors required to hold station in strong currents. For this study, all deployments were conducted from a live boat, which is, in our experience, preferable to static deployments ${ }^{2}$.

For live boat deployments, the R/V Jack Robertson would come on station approximately 30 minutes before predicted slack water. As described in Polagye et al. (2010) and Polagye and Thomson (submitted), current predictions based on harmonic constituents are imperfect due to the aharmonic response caused by topography and bathymetry. Once tidal currents are between 0.5 and $1 \mathrm{~m} / \mathrm{s}$ throughout the water column and decelerating, deployment operations begin. The vessel makes an initial drift over the proposed deployment site for the captain to judge the competing effects of windage, currents, and wave action, then the vessel sets up for a drift and the Sea Spider is lowered over the side. The research vessel drifts towards the intended deployment site as the Sea Spider is lowered (approximately 5 minutes to reach the bottom in $60 \mathrm{~m}$ of water), with the captain making minor course adjustments with prop and bow thruster to keep the deployment line clear of the transom. Once the package is within $5 \mathrm{~m}$ of the seabed (determined by a combination of depth sounder and line marking), lowering is suspended until the research vessel is within $15 \mathrm{~m}$ of the intended location. If the research vessel is drifting wide of this target, the package is brought back to the surface and the vessel resets for a second attempt ${ }^{3}$. Once within $15 \mathrm{~m}$ of the intended location, the package is lowered to the seabed.

\footnotetext{
${ }^{2}$ In 2009, as part of initial ROV surveys of the seabed, a three point anchor was set on one occasion. Several hours of ship time to set up and break down the anchoring system, with no regard for the precise location of the vessel. Once the mooring had been established, ROV operations were restricted to the immediate times of slack water due to the phase differences in currents between surface and seabed.

${ }^{3}$ This was, in practice, never required due to the skill of the APL ship captains.
} 
Once the tension goes out of the deployment line, line continues to be paid out until the acoustic release is triggered (and the Sea Spider released) to avoid dragging the Sea Spider across the seabed. Release location is recorded by a GPS with an antenna next to the block. Package weight is sufficient to limit wire angle to a few degrees.

During earlier deployments, attempts were made to verify Sea Spider deployment with a dive camera inline with the deployment line. This, however, is not a recommended practice. While it does provide additional certainty, it introduces another moving part into the operation and can delay the release of the package once landing has occurred (i.e., delay of up to a minute while a camera operator verifies the landing and communicates with the rest of the team). Because rapid release of the package is essential once landing has occurred, provided that the seabed has been well-characterized during prior surveys, in our experience, the cost and complexity of visual conformation exceeds the benefits.

\subsection{Bottom-Mounted Instrumentation: Ambient Noise}

\subsubsection{Approach}

As described in Bassett et al., (submitted), each Sea Spider was equipped with at least one broadband hydrophone and recording system (Loggerhead instruments, DSG). The hydrophone is an HTI-96-Min with an internal pre-amplifier. The hydrophones have an effective sensitivity of $-166 \mathrm{~dB}$ re $1 \mu \mathrm{Pa} / \mathrm{V}$. The frequency response of the hydrophone and data acquisition system is flat ( $\pm 3 \mathrm{~dB}$ ) from $20 \mathrm{~Hz}$ to $30 \mathrm{kHz}$. Digitized 16-bit data are written to a SD card. The following ambient noise analysis pertains to data from four deployments of three months duration (May 7, 2010 to May 9, 2011). The sampling frequency was $80 \mathrm{kHz}$ on a one-percent duty cycle (7 seconds continuous recording every 10 minutes).

Each recording was post-processed into windows containing $65,536\left(2^{16}\right)$ data points with a $50 \%$ overlap. Windows were weighted by a Hann function and a Fast Fourier Transform (FFT) was applied. Resulting spectra were then scaled to preserve total variance. Recordings with pump noise (CTDO) or float noise were removed and the remaining observations stratified by current velocity.

\subsubsection{Results}

In describing ambient noise measurements at tidal energy sites, there has been a healthy debate as to the production of sound by strong currents. Arguments range from the assertion that currents do not produce any true, propagating noise and to the assertion that they produce high intensity noise. While apparently conflicting, both are correct over a specific range of frequencies. Certainly, the awareness of this issue has grown within the marine and hydrokinetic community over the past two years and the finer points of the debate are likely to persist for the foreseeable future. At present, our most complete understanding of noise sources within Admiralty Inlet are, as follows:

- Strong currents indirectly produce relatively high intensity (i.e., one-third octave levels exceeding $120 \mathrm{~dB}$ - as high as $140 \mathrm{~dB}$ ) and high frequency (i.e., frequencies greater than $1 \mathrm{kHz}$ ) sound by mobilizing gravel and shell hash on the seabed (Bassett et al., in prep). While the seabed in Admiralty Inlet is principally composed of stationary cobbles, smaller material is mixed in around the margins and periodically mobilized. Sound production starts at high frequency (smallest material mobilized by weakest currents) and expands down into the $1-10 \mathrm{kHz}$ decade during strong currents. The intensity of this sound is, broadly, proportional to the square of the current velocity in a one-third octave band. This is true, propagating sound and appropriately included in a noise budget for a tidal energy site. 
- Strong currents advected across a hydrophone element give rise to turbulent pressure fluctuations that are interpreted as high intensity noise at lower frequencies (i.e., frequencies less than $1 \mathrm{kHz}$ ). This is not, however, a source of propagating sound. Rather, it is equivalent to "sound" one hears when someone blows across a microphone or when one is riding a bike downhill at high speed. This pseudo-sound is apparent only to the local receiver (i.e., the hydrophone) and is not appropriately included in an ambient noise budget.

Support for this description of current-induced sound is provided by measurements from a pair of Loggerhead DSG broadband hydrophones deployment on a Sea Spider in Admiralty Inlet. A flow shield constructed of high porosity open-cell foam was used to shield one hydrophone from strong currents (effectively creating a quiescent zone around the hydrophone element), while the other hydrophone remained unshielded (Figure 9). As shown in Figure 10, the flow shield suppressed most of the noise increase at frequencies below $750 \mathrm{~Hz}$ observed on the unshielded hydrophone during periods when near-seabed currents exceed $1 \mathrm{~m} / \mathrm{s}$. Outside of those periods, each hydrophone recorded equivalent levels of sound, indicating that the flow shield effectively reduces pseudo-sound without attenuating propagating sound. These results suggest that most of the noise increase at frequencies below $750 \mathrm{~Hz}$ is pseudo-noise and should not be included in a characterization of ambient noise levels.

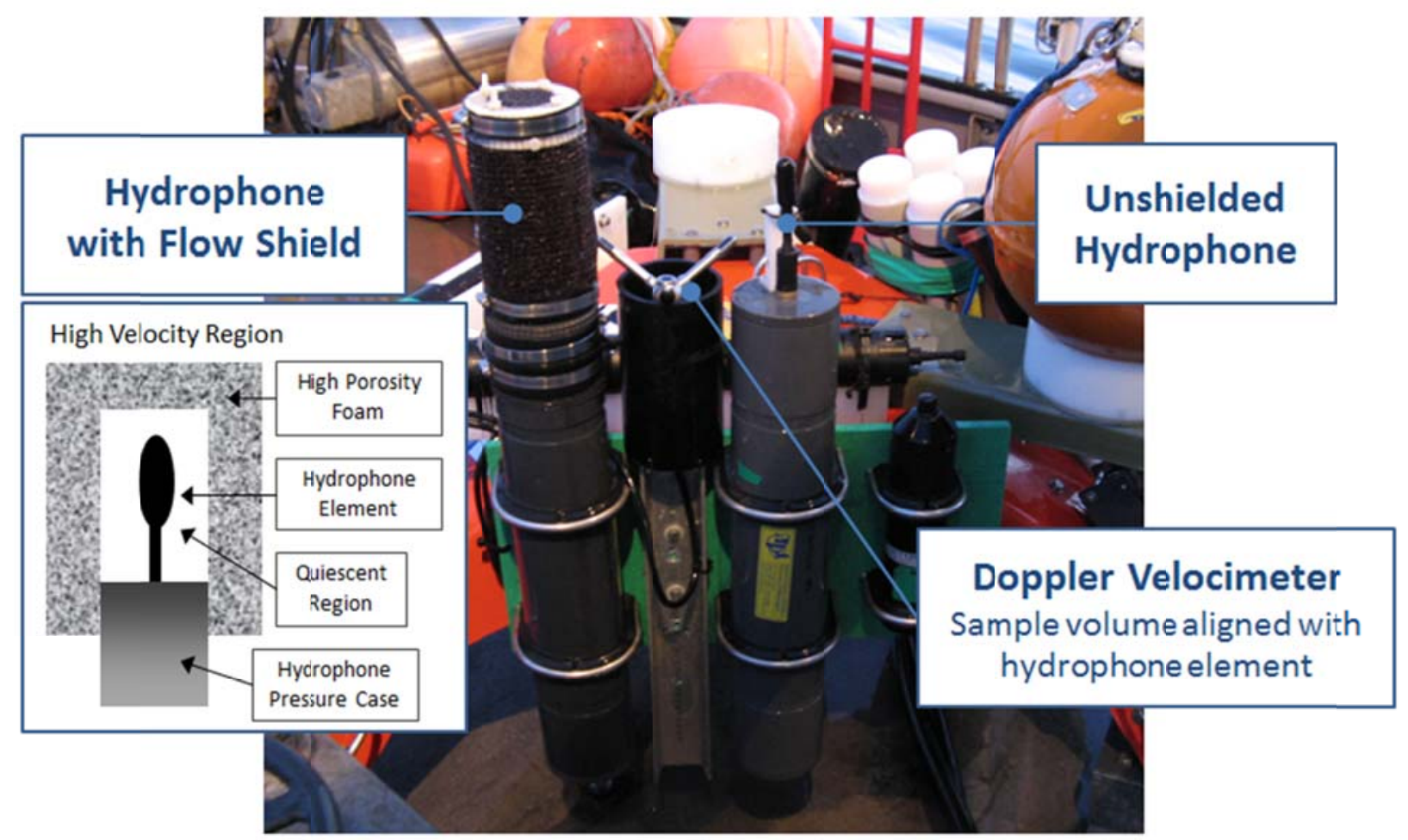

Figure 9 - Flow shield test configuration (SS \#04) 

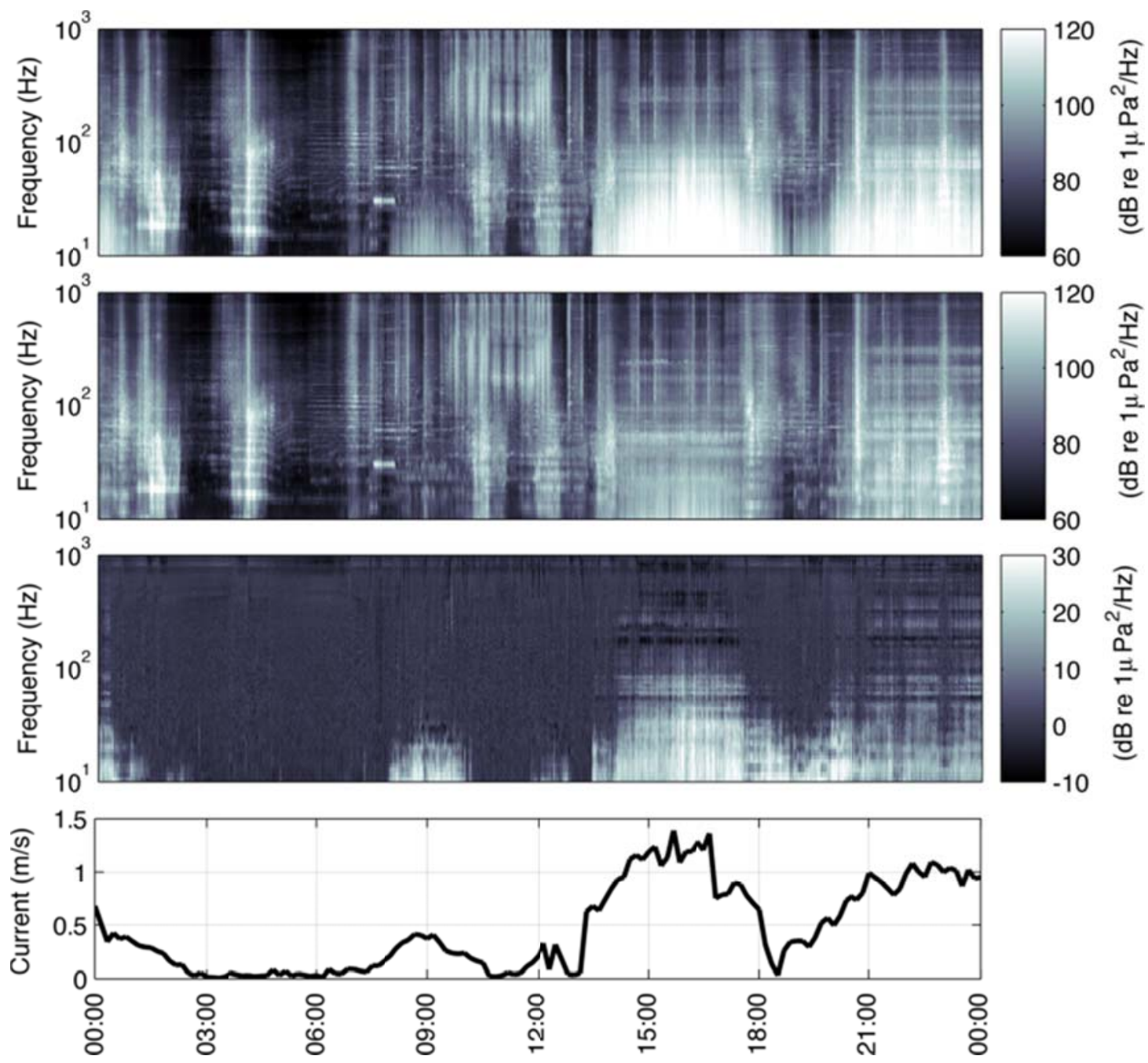

Figure 10 - Preliminary flow shield results. Panel 1: spectrogram of recorded noise over a 24 hour period from the unshielded hydrophone. Panel 2: co-temporal spectrogram for hydrophone with flow shield. Panel 3: difference in sound intensity (in dB) for the two configurations. Panel 4: tidal currents at hydrophone height recorded by a Doppler velocimeter.

Other sources of propagating sound include:

- Vessel traffic: As demonstrated in Bassett et al., (submitted) vessel traffic accounts for $90 \%$ of the temporal variability in broadband ambient noise in Admiralty Inlet. Vessel noise intensity is highest at frequency below $1 \mathrm{kHz}$, but when currents are weak and bedload noise is negligible, vessel noise is observed at frequencies up to $30 \mathrm{kHz}$.

- Rain: Rainfall produces propagating sound at frequencies between 10 and $30 \mathrm{kHz}$. While detectable, this does not contribute substantially to the ambient noise budget at this location.

- Marine mammals: Marine mammal vocalizations can occur over a broad range of frequencies. Most vocalizations detected in Admiralty Inlet are associated with killer whales (low frequency cetaceans being relatively uncommon). While striking, they are intermittent and do not contribute substantially to the ambient noise budget at this location.

The temporal variability in ambient noise levels are visualized in Figure 11 and Figure 12 . These distributions exclude periods with depth averaged currents greater than $0.4 \mathrm{~m} / \mathrm{s}$. This excludes sound 
produced by bedload transport (but also pseudo-sound) and are consequently biased somewhat low. Distributions are shown both for broadband $(0.02-30 \mathrm{kHz})$ sound pressure levels and M-weighted sound pressure levels (Southall et al., 2007) by marine mammal functional group. In general, Admiralty Inlet is a relatively noisy location, with broadband sound pressure levels exceeding National Marine Fisheries Service criteria for Level B harassment of marine mammals ( $120 \mathrm{~dB})$ almost $50 \%$ of the time. Because the ambient noise budget for Admiralty Inlet is dominated by vessel traffic (Bassett et al., submitted), the temporal trends in ambient noise levels shown in Figure 12 largely reflect temporal trends in vessel traffic (e.g., the minimum in ambient noise around 0400 reflects a common lull in commercial shipping traffic).

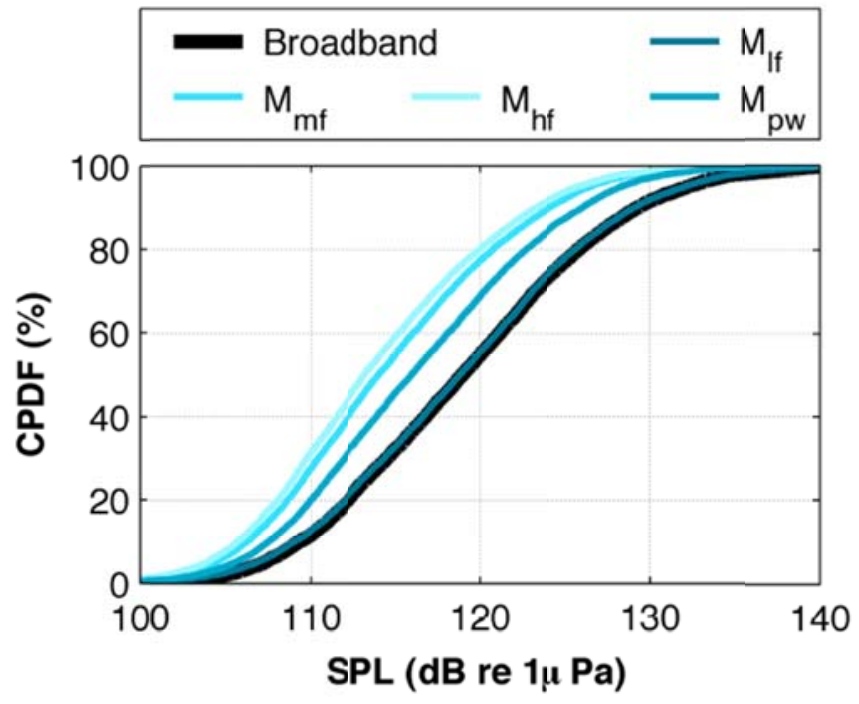

Figure 11 - Cumulative probability distribution function of unweighted broadband SPLs $\mathbf{0 . 0 2}$ - $30 \mathrm{kHz}$ ) and $\mathrm{M}$-Weighted cumulative probability distribution functions for pinnipeds in water and low-, mid-, and high-frequency cetacean marine mammal functional groups (source: Bassett et al., submitted). 

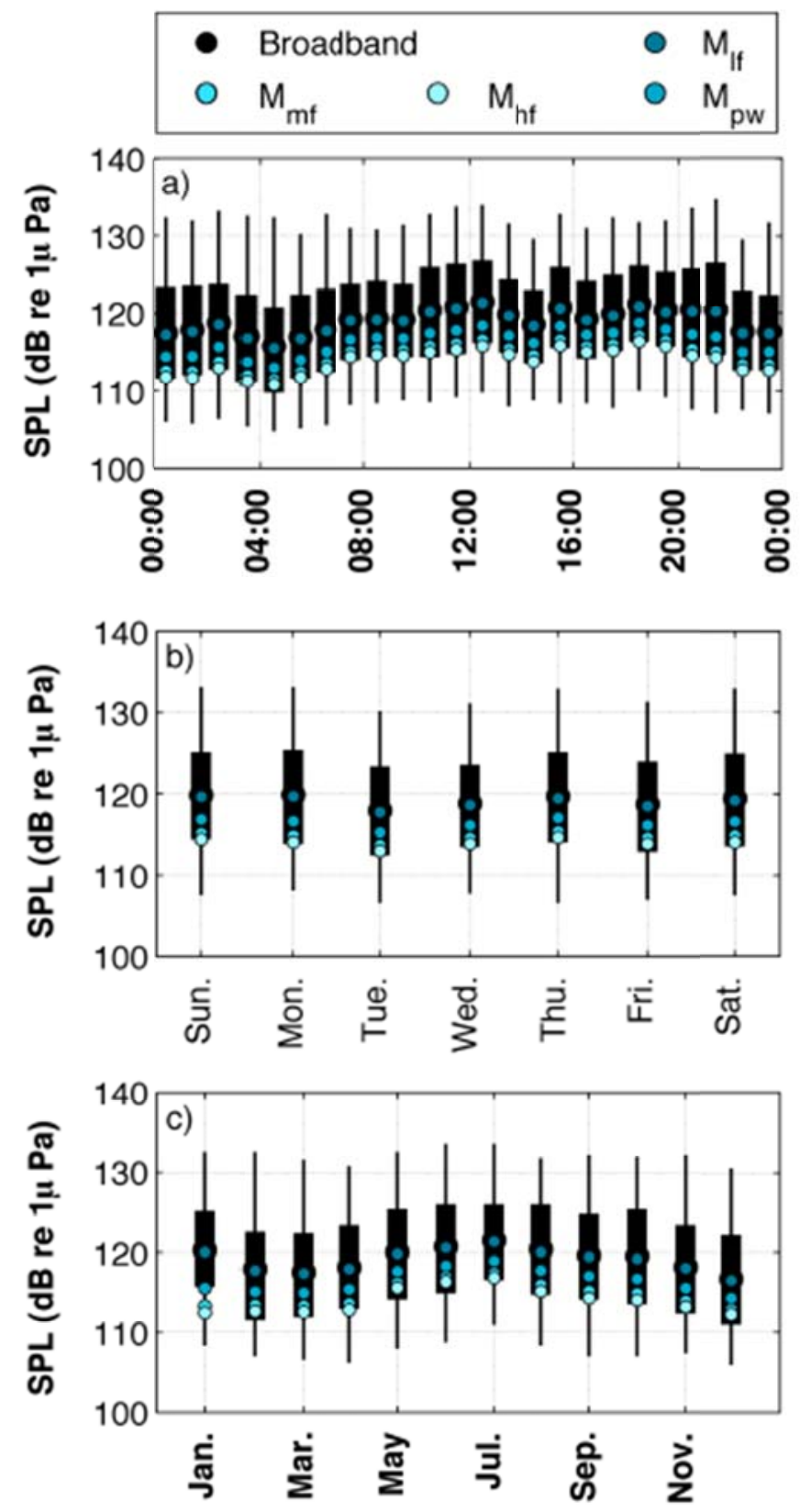

Figure 12 - Hourly (a), daily (b) and monthly (c) average broadband (0.02 - $30 \mathrm{kHz}$ ) and Mweighted sound pressure levels. The box plots show the range for the $25 \%$ to $75 \%$ thresholds and the whiskers show the range for the $5 \%$ to $95 \%$ thresholds for broadband SPLs (source: Bassett et al, submitted).

\subsection{Bottom-Mounted Instrumentation: Marine Mammal Echolocation}

\subsubsection{Approach}

Click detectors are specialized hydrophones that continuously monitor for high frequency $(>40 \mathrm{kHz})$ signals that may be associated with marine mammal cetacean echolocation. Such signals may also be generated by active sonars or sediment transport. The instrument stores only the properties of clicks, not the raw waveform of the signal. This project utilized two click detectors, both manufactured by 
Chelonia, Ltd., the T-POD and the C-POD. The T-POD is the first generation instrument and detects clicks using analog bandpass filters corresponding to the echolocation frequencies of target cetacean species. The T-POD scans each channel in sequence and stores the click information for subsequent classification. T-PODs have been used in a number of studies to monitor the acoustic effects of wind farm construction (Thompson et al., 2010; Brandt et al., 2011). The C-POD is the successor to the T-POD and utilizes on-board digital signal processing to identify clicks. Consequently, the C-POD is able to monitor for a broader range of cetacean activity than the T-POD (i.e., frequencies of interest need not be specified prior to deployment) and report additional properties of the clicks. However, there is relatively limited experience with the C-POD, as compared to the T-POD. This project deployed a T-POD (one of the last units produced by Chelonia, Ltd.) and a C-POD simultaneously on one of the tripods to assess the relative effectiveness of the new instrument. Since harbor porpoise echolocation is directional (Au et al., 1999) a point-wise comparison of instruments (either T-POD to C-POD or C-POD to C-POD) is not possible (i.e., the same echolocation click may not be received by both instruments, even when in close proximity) and comparisons must be made on a statistical basis.

Upon recovery, click information is offloaded from the instruments and then post-processed by Chelonia, Ltd. software (tpod.exe or cpod.exe) to identify click trains (series of clicks associated with biological or anthropogenic sources). Over the course of this project, Chelonia released several new versions of the cpod.exe software which fundamentally improved the classifier effectiveness. However, as shown here, the software has a strong effect on results and care must be taken in comparing results between studies using the same instrument, but different software versions. The classifier software is essentially a black box but, in principle, takes information about the recorded clicks (such as frequency, inter-click interval, intensity, and bandwidth) and compares this against click train properties for a variety of cetaceans in an attempt to automatically classify the click origin. Those that are suspected to be biological in origin are assigned a quality based on the match - low, medium, or high. General practice is to perform analysis only on medium or high quality detections. Low quality detections are only used when animal abundance is so low as to preclude sufficient information for statistically relevant analysis (not the case for Admiralty Inlet).

Post-classification echolocation data is presented and analyzed using a metric of Detection Positive Minutes (DPM). DPM (alternatively referred to as Porpoise Positive Minutes, PPM) are defined as a minute in which at least one high or medium quality porpoise click train is classified. DPM specifically refer to narrow-band high frequency (NBHF, porpoise) detections in the context of this study. DPM are a commonly used unit for measuring cetacean echolocation (e.g., Kyhn et al., 2008). Counting intervals of time with confirmed detections reduces the chance for bias created by particularly vocal animals (Mellinger, et al., 2007). Therefore, the use of this metric strengthens the assumption of independence of observations for statistical inference testing and modeling. DPM provide no resolution for identifying the number of animals present. Conclusions can only be drawn on presence or absence and relative echolocation activity without a co-temporal visual observation study (e.g., as described in Kyhn et al, 2012). No focal animal tracking observations with sufficient location accuracy were available for this 
study ${ }^{4}$. DPM are reported and analyzed over deployment days and hours. DPM per hour ranges from 0 to a maximum of 60 - indicating no minutes with confirmed click train detections in an hour or all minutes with at least one confirmed detection, respectively. DPM per day are similarly defined over a range of 0 to 1440 . For reasons discussed in $\S 2.3 .3$, only harbor porpoise DPM are presented here. All of this does, perhaps, beg the question - why not simply use a recording hydrophone to capture click train data along with all other ambient noise and identify echolocation activity with open-source algorithms in post-processing? The answer lies in the required bandwidth to conduct such studies. Harbor porpoise echolocation frequencies are around $120 \mathrm{kHz}$. Resolving signals at this frequency requires a sampling frequency of at least $240 \mathrm{kHz}$ - more likely $300 \mathrm{kHz}$ to prevent problems associated with signal detection close to the Nyquist cut-off ( $1 / 2$ the sampling frequency). Assuming hydrophone data is digitized with 16-bit resolution, 90 days of continuous monitoring would require more than 4 TB of storage. High-end recording hydrophones (e.g., JASCO Applied Sciences Advanced Multi-channel Acoustic Recorder, AMAR has 2 TB of storage) approach this requirement, but post-processing and archiving of this volume of data is non-trivial. The C-POD and T-POD, on the other hand, monitor continuously, but store only information about the click trains, such that 90 days of monitoring requires less than $4 \mathrm{~GB}$ of data storage and post-processed time series of classified trains are on the order of 0.1 $\mathrm{GB}$, simplifying data archiving and analysis.

\subsubsection{Results}

\section{Comparison of C-POD and T-POD Results}

Figure 13 shows a comparison of porpoise detection positive minutes per day (medium or high quality detections) for a one year period from May 2010 - May 2011. For the four underlying deployments, the same C-POD and T-POD units were used (prior research by Kyhn et al. (2008) indicates that relative sensitivity differences between T-POD instruments exist) and the instrumentation package (SS \#02) was deployed at approximately the same geographic coordinates. Comparisons are shown between version 1 of the C-POD classifier, version 2 of the C-POD classifier, and the T-POD classifier. All instruments show the same relative trends in echolocation activity (which are described further in $\S 4.1$ ). However, in absolute terms, the results are significantly different. Version 2 of the C-POD classifier significantly increased porpoise detections relative to Version 1. The C-POD was, in fact, initially less sensitive than its T-POD predecessor when using the Version 1 classifier, but Version 2 of the classifier has significantly improved upon this and the C-POD now appears to have superior sensitivity to the T-POD.

\footnotetext{
${ }^{4}$ The District did position marine mammal observers on Admiralty Head in 2009 and 2010 to evaluate presence/absence of marine mammals. However, tracking the trajectory of harbor porpoise relative to the instrumentation packages deployed at this time were not undertaken as part of that study.
} 

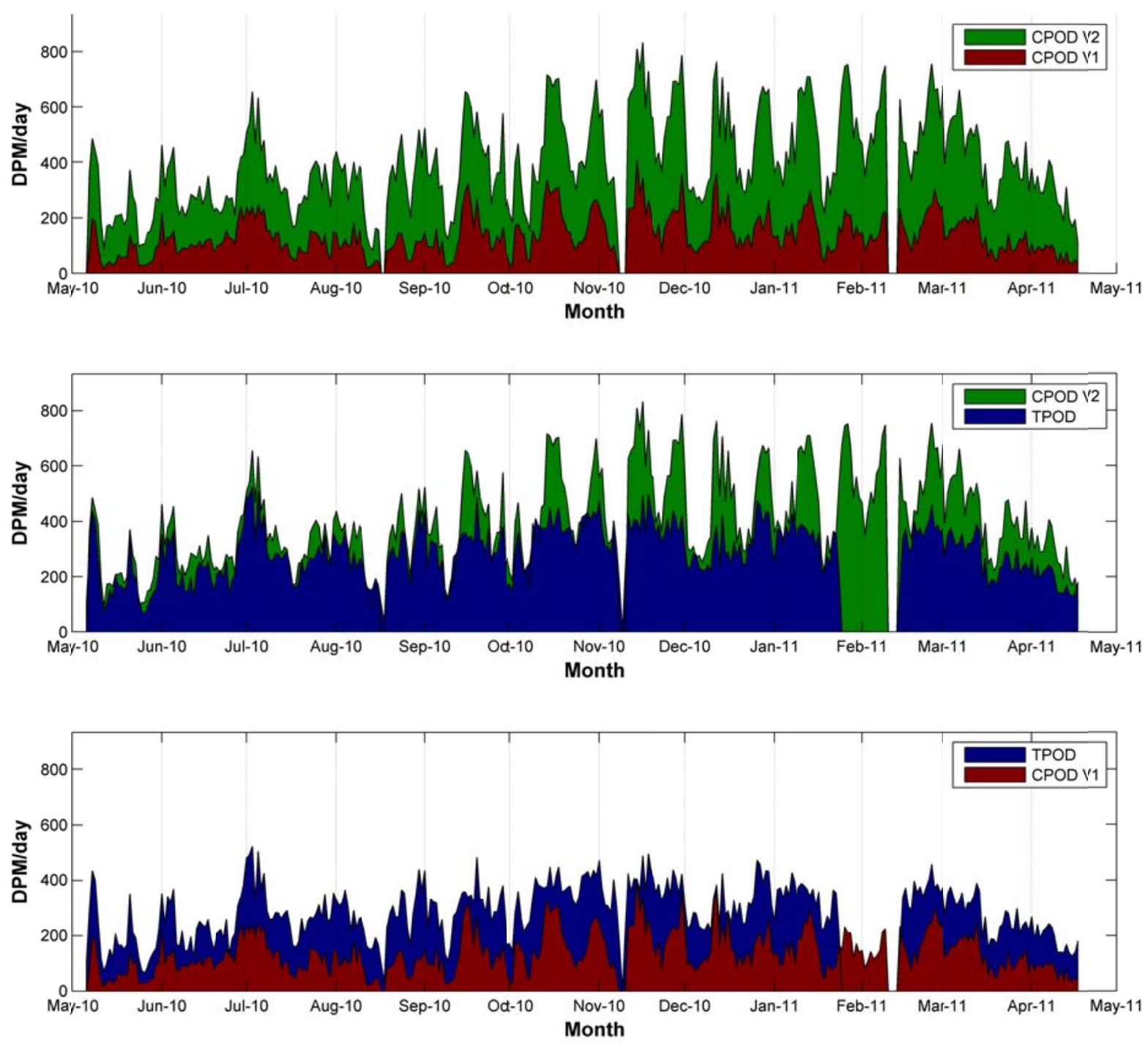

Figure 13 - Porpoise detection positive minutes per day, as classified by different instrument/software combinations.

\section{Spatial Variability}

Table 4 shows average detection positive minutes per day for each instrumentation package deployment. Quantitative analysis of spatial trends throughout is not possible (due to both interference between the C-PODs and Doppler profilers on some platforms as well as seasonal trends in echolocation activity), but a qualitative description is possible. Echolocation activity is generally high in the vicinity of Admiralty Head (defined as the proposed deployment site and the areas to the east and west of the headland). In particular, as shown in Figure 14, echolocation activity is much higher near the headland in Admiralty Inlet than in the Bay of Fundy (or Strangford Lough - not shown). Echolocation activity appears to be much lower in the center of the channel. This is likely due to variations in habitat and prey abundance between the areas close to the headland and the center of Admiralty Inlet. 
Table 4 - Temporal-spatial variability in porpoise detection positive minutes per day. Asterisk denotes significant interference between the C-POD and Doppler profiler on the instrumentation platform (§ 2.4.3).

\begin{tabular}{|l|l|l|l|l|l|l|}
\hline & $\begin{array}{l}\text { Feb - May } \\
2010\end{array}$ & $\begin{array}{l}\text { May-Aug } \\
2010\end{array}$ & $\begin{array}{l}\text { Aug - Nov } \\
2010\end{array}$ & $\begin{array}{l}\text { Nov - Feb } \\
2011\end{array}$ & $\begin{array}{l}\text { Feb - May } \\
2011\end{array}$ & $\begin{array}{l}\text { May - Aug } \\
2011\end{array}$ \\
\hline SS \#01 & $170^{*}$ & 293 & & & & \\
\hline SS \#02 & & & 401 & 490 & 410 & 380 \\
\hline SS \#03 & & & 297 & 452 & $34^{*}$ & $224^{*}$ \\
\hline
\end{tabular}

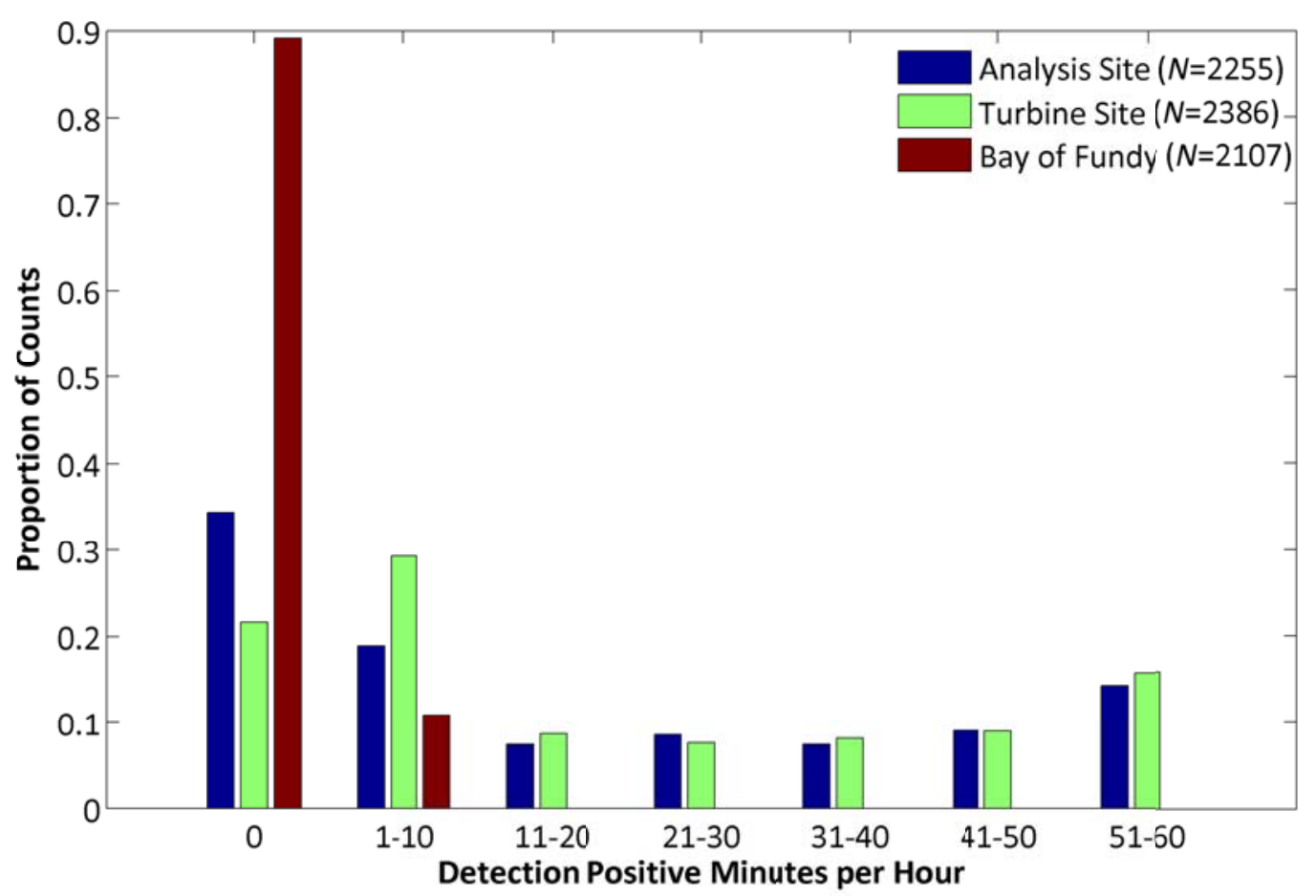

Figure 14 - Detection positive minutes per hour: Admiralty Inlet - turbine deployment site, Admiralty Inlet noise habituation study site (§ 4.3), Bay of Fundy (source: UW-NNMREC and SMRU, Ltd.)

\subsubsection{Lessons Learned}

\section{C-POD Deployments in High Current Environments}

C-PODs have relatively few configuration settings exposed to the user. However, it is possible to set the "buffer size" and the high pass filter frequency. The buffer size defines the maximum number of clicks that can be logged during a single minute before the C-POD will discontinue recording until the next minute starts. This is a protective measure from a data storage standpoint. Clicks detected by the C-POD may be biological in origin, or may be associated with sonar activity or natural ambient sources (such as sediment movement). Because the C-POD has finite storage capacity, if a non-biological source is producing "clicks" in the vicinity of the instrument, it is crucial that these not fill the available storage within a short time. Similarly, the high pass filter sets the minimum frequency for click detection.

Initial C-POD deployments had a relatively high number of "clipped minutes", that is, minutes in which the buffer limit was reached before the end of the minute. A strong relation between clipping and current velocity was observed (i.e., clipping was more prevalent during strong currents). We now understand that this is caused by high frequency (e.g., > $20 \mathrm{kHz}$ ) sound produced by mobilization of sediment, gravel, and shell hash on the cobbled seabed (Bassett et al., in prep). The solution to this problem (arrived at through a test of multiple C-PODs with different filter and buffer settings) was to 
increase the high pass filter frequency from $20 \mathrm{kHz}$ to $40 \mathrm{kHz}$. This reduced the number of clipped minutes, without significantly reducing the number of porpoise detections (the more bandwidth the CPOD has to work with, the greater the chance of making a high-quality porpoise classification). This does, however, likely reduce the ability of the classifier to detect Southern Resident killer whales, which echolocate at frequencies closer to the high-pass filter cut-off (i.e., around $50 \mathrm{kHz}$ ) than harbor porpoise. The alternative is, of course, to increase the buffer limit. However, tests indicated that increasing the buffer limit would result in the storage capacity of the C-PODs being exceeding prior to deployment and would cause gaps in the data set.

\section{Doppler Profiler Interference}

Per manufacturer disclaimer, C-PODs are sensitive to interference by active sonars and Chelonia, Ltd. does not recommend placing these on the same platform as a Doppler profiler. That being said, unless the instruments are co-located trends in presence/absence of marine mammals that may be associated with the strength of tidal currents cannot be ascertained. Such information is crucial to establishing probable exposure to turbine stressors that may also vary with current velocity (e.g., sound produced by the turbines).

Over the course of this project, C-PODs were deployed on platforms with three models of Doppler profiler (a $300 \mathrm{kHz}$ RDI Workhorse, a $470 \mathrm{kHz}$ Nortek Continental, and a $600 \mathrm{kHz}$ Nortek AWAC). As part of a separate project, C-PODs have also been deployed with a $1000 \mathrm{kHz}$ Nortek AWAC. During that experiment, three C-PODs were deployed on a Sea Spider (SS \#04) in the configuration shown in Figure 15. This package was deployed in Admiralty Inlet within a few hundred meters of SS \#02 and SS \#03 from June to August 2011. For the first 30 days of the deployment, the Doppler profiler was switched off. For the second 30 days of the deployment, the Doppler profiler sampled continuously at $1 \mathrm{~Hz}$. All three C-PODs were configured with the same buffer and filter settings. For the first 30 days, all three CPODs detected a statistically similar number of harbor porpoise echolocations. However, once the Doppler profiler switched on, C-POD \#3 did not detect further echolocation activity, while detections for C-PODs \#1 and \#2 were relatively unchanged. C-PODs \#2 and \#3 are nearly equivalent distance and orientation relative to the Doppler profiler, which supports the manufacturer assertion that active sonar interference has strong spatial sensitivity and can be significant.

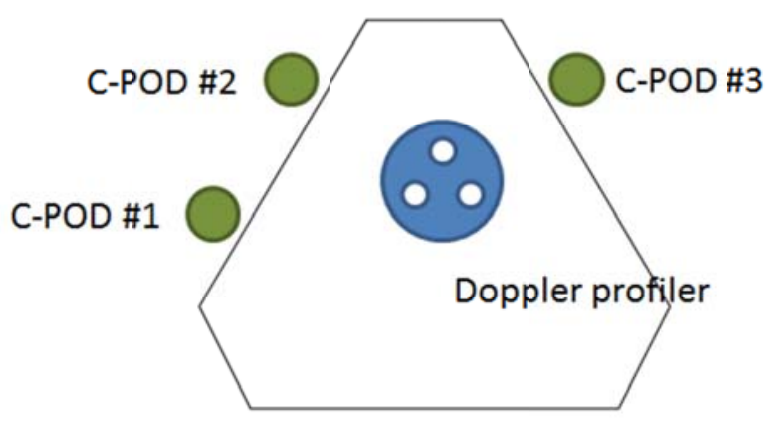

Figure 15 - C-POD/Doppler profiler interference test configuration (top view)

In light of these results, UW-NNMREC and Chelonia, Ltd. developed a post hoc test for Doppler profiler interference. Click trains from each instrument were processed using standard techniques and then re- 
processed using a high-pass filter from $120-160 \mathrm{kHz}$. The high-pass filtering degrades the number of high quality click train classifications and manual review suggests that the classifier reliability is significantly compromised (i.e., results are not as suitable for quantitative analysis as unfiltered processing). If the Doppler profile has not interfered with the C-POD, the average number of detection positive minutes per day will be similar for the filtered and unfiltered data (i.e., within $\pm 10 \%$ ). If interference is occurring, these metrics will vary by up to $100 \%$. Using this technique, UW-NNMREC confirmed that no appreciable interference occurred with the $470 \mathrm{kHz}$ Nortek Continental. Only moderate interference is indicated for one deployment with the $300 \mathrm{kHz}$ RDI Workshop and the first two deployments on SS \#03 with the $600 \mathrm{kHz}$ Nortek AWAC (i.e., filtered and unfiltered results vary by less than 25\%), but during the last two, significant interference is indicated (i.e., filtered and unfiltered results vary by more than $50 \%$ ). The sole difference between the deployments with the Nortek AWAC was the sampling configuration for the AWAC in terms of ping interval.

These results suggest that Doppler profilers and C-PODs can be deployed on the same platform without interference, but requires careful planning. We recommend that if these instruments are to be placed on the same platform that a short test deployment be conducted in an area with known harbor porpoise echolocation activity (i.e., deployment for 1-2 days). The high-pass filter test described above can then be applied to evaluate whether interference has occurred. If interference occurs, C-POD orientation relative to the profiler should be adjusted and the process repeated until low-interference operation is achieved. This test is time consuming and would be required even for changes in the sampling configuration for the profiler, even if instrument orientation does not change.

Inter-instrument Comparability

In-situ comparisons between C-PODs, even those on the same platform is challenging given the focused beam pattern of porpoise echolocations. This is compounded by the presence of active sonars on the Sea Spiders, which may subtly affect click train detections. However, over the course of this study and other, similar activities, in Admiralty Inlet funded under separate awards, a few C-PODs were observed to be consistently biased in echolocation detections (both high and low). SMRU, Ltd. and Acadia University have had the same experience in C-PODs used for studies in the Bay of Fundy. While Chelonia, Ltd. maintains that sensitivity is calibrated in their laboratory and there is not a difference between instruments, prior research has demonstrated inter-instrument variability for T-PODs (Kyhn et al., 2008). We suspect that similar variability may exist for C-PODs and recommend that procedures be developed for field calibration of instrument sensitivity. Rotation of PODs within a sampling scheme may provide an alternative means to assess inter-instrument sensitivity variability.

\section{Detection of Southern Resident Killer Whales}

A significant advantage of the C-POD over the T-POD is its ability to monitor for echolocations over the full instrument bandwidth. In order to detect killer whales with a T-POD, one or more of the five channels needs to be configured to bandpass killer whale echolocation signals. However, a T-POD configured exclusively in this manner will not detect harbor porpoise echolocation. Splitting the channels between harbor porpoise and killer whales allows for detection of both species, but at lower duty cycle than if all channels were allocated to one species. The C-POD, however, can detect either species in a continuous manner. 
Over the course of this study, very few medium or high quality "dolphin" detections were made by the classifier. A "dolphin" detection in Admiralty Inlet would likely be a Southern Resident killer whale. This lack of detections is likely a combination of three factors. First, Southern Residents are much less common than harbor porpoise in Admiralty Inlet, averaging approximately 40 transits per year (Wood et al., 2009). Second, by adjusting the high pass filter on the C-POD to mitigate the problem of sedimentinduced "click trains" the classification algorithm would be less likely to automatically identify killer whale click trains, even if they are logged by the instrument. Finally, the C-POD classifier is, presently, most accurate for porpoises (POD stands for POrpoise Detector) and Chelonia, Ltd. has relatively little experience with classifying killer whale echolocations. Manual review of C-POD data at times when killer whales were known to be present in Admiralty Inlet reveals probable killer whale click trains that are not usually classified (though at least one confirm classification occurred during initial C-POD deployments in 2009). This information has been passed along to Chelonia, Ltd. to be incorporated in newer versions of the software that may be better suited to detecting killer whale echolocation.

\subsection{Shore-based Infrared Monitoring of Marine Mammals}

The objective of shore-based infrared monitoring of marine mammals was to detect marine mammals based on the relative difference between their bodies and the water surface. As described in Graber et al. (2011), infrared imaging is able to produce striking representations of marine mammals and enable efficient, automated detection algorithms but it is actually a difference in emissivity that produces the apparent temperature difference between the marine mammals and the water surface.

\subsubsection{Approach}

Infrared and visual imagery were collected at Lime Kiln Park, Washington from July 6 - July 9, 2010. Three cameras in a protective housing were mounted to the railing of the Lime Kiln Park lighthouse (Latitude $48^{\circ} 30^{\prime} 57^{\prime \prime} \mathrm{N}$ Longitude $123^{\circ} 9^{\prime} 9^{\prime \prime} \mathrm{W}$ ) at a height of 13 meters above sea level. The cameras were positioned to face west towards, Victoria $B C$ and had an incidence angle with the water surface of $72^{\circ}$. The infrared camera used is a FLIR ThermoVision A40M uncooled microbolometer with an $18 \mathrm{~mm}$ lens (7.5-14 $\mu \mathrm{m}, 37^{\circ}$ horizontal field of view, $320 \times 240$ pixels).

The collected footage was reviewed to identify whale sitings and those sections were exported from Streams 5 DVR recording software to 16 bit binary format (.raw). The binary files were then read into MATLAB for analysis. Footage of whales was separated into sections of 3 minutes or less (<1350 frames) to enable efficient processing. To identify stationary pixels (due to sensor or lens drift), the mean image was calculated by taking the mean pixel value over all frames within each section. The mean image was then removed from each frame, resulting in an image corrected for drift in the mean. Care was taken to ensure each section of footage has at least 200 frames without whales, so the mean image is not significantly biased by the temperature increase associated with whales surfacing. The pixel value of the corrected frames was then translated from "counts" associated with the FLIR's raw signal to temperature contrast $\left({ }^{\circ} \mathrm{C}\right)$ by using a calibration equation relation supplied by the manufacturer.

\subsubsection{Results}

During the four days of field observations, Southern Resident killer whales (SRKW) passed Lime Kiln Park 11 times. Out of these 11 passes, 8 were recorded with the IR camera. During daylight hours the recording on all cameras was initiated by reports of whales in the area by the Orca Network or the 
Whale Museum's hydrophone array. Nighttime footage was recorded throughout the night and reviewed the next morning. Figure 16 shows an example of footage recorded at 3:48 on July $7^{\text {th }}$.

As shown in Figure 1, the dorsal fin, blow, and body were all distinguishable in the recorded infrared footage. Of these three potential detection targets, the dorsal fin is the only one with a fairly predictable relative angle to the sea surface. Although the angle between the fin and sea surface varies from fin to fin, they remain relatively close to $90^{\circ}$.

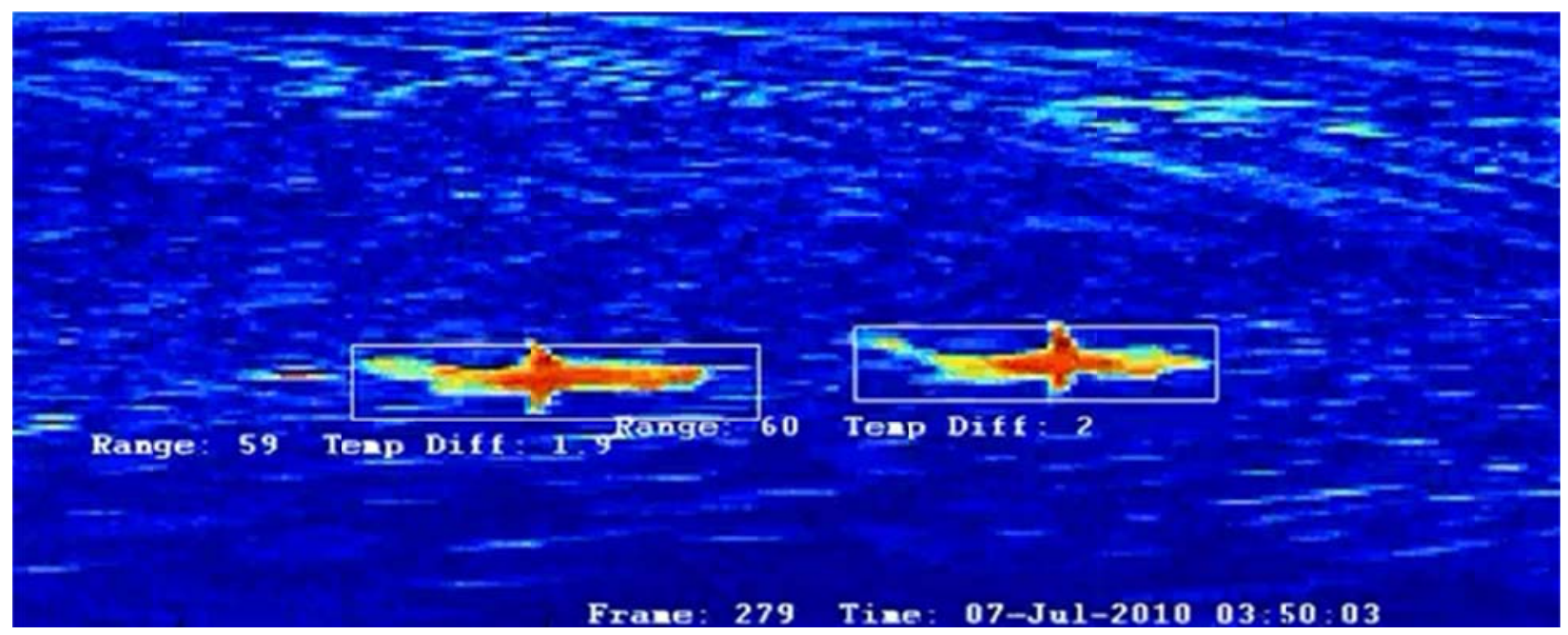

Figure 16 - Infrared imagery of Southern Resident killer whales recorded from Lime Kiln State Park on San Juan Island including the output of the automated detection algorithm. Whales are distinguished from background variations and highlighted with a bounding rectangle. Range and temperature contrast between the whales and water surface are also displayed.

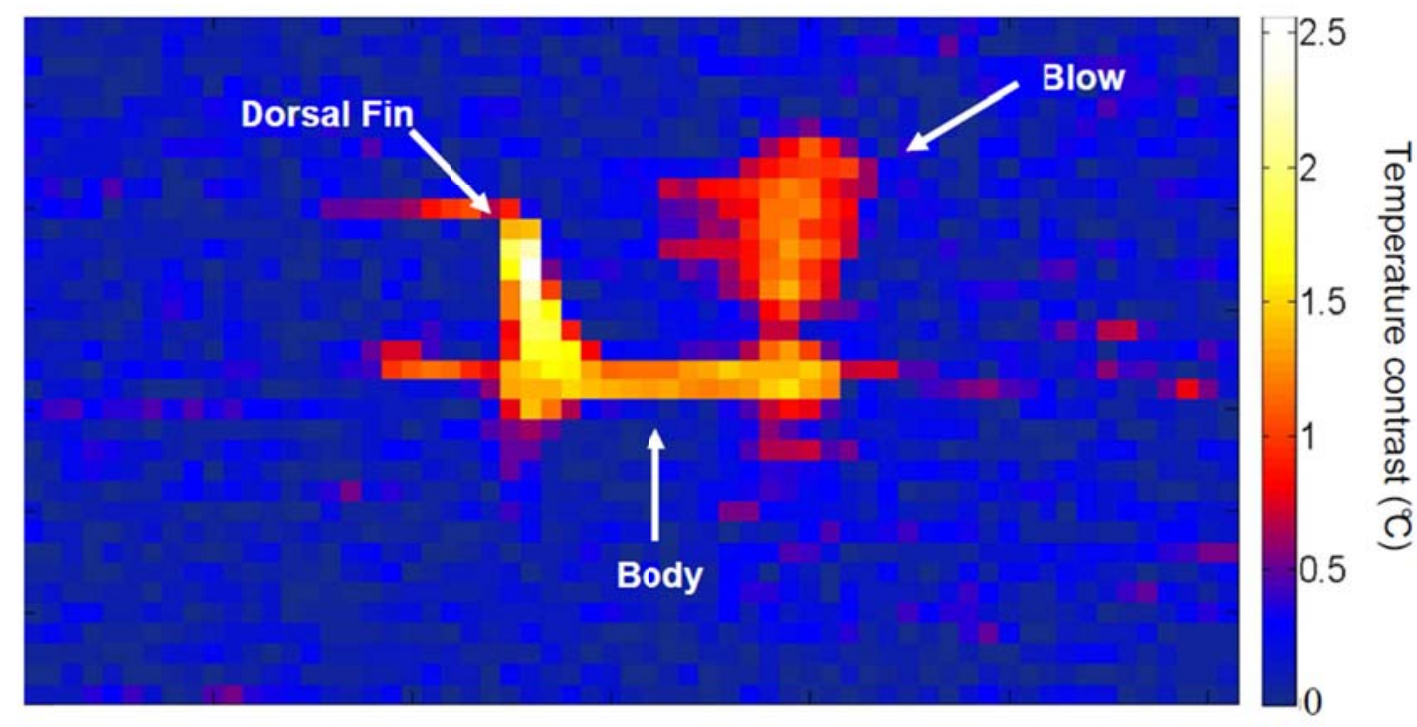

Figure 17 - Infrared image of potential targets for cetacean detection. Color map has been adjusted to enhance visual contrast. Color bar shows temperature contrast from the sea surface mean $\left({ }^{\circ} \mathrm{C}\right)$.

All detections are shown in Figure 18. With the camera system used for this test (FLIR A40M with a wide angle lens), detections at ranges greater than $150 \mathrm{~m}$ were not common and high-quality detections were limited to a range of less than $100 \mathrm{~m}$. This limitation is imposed by camera resolution, the lens field of view, and number of pixels required to positively detect a target. The image shown in Figure 17 is at 
close range and is composed of 10's of pixels. At further range, targets consist of only a few pixels and detection is more difficult.

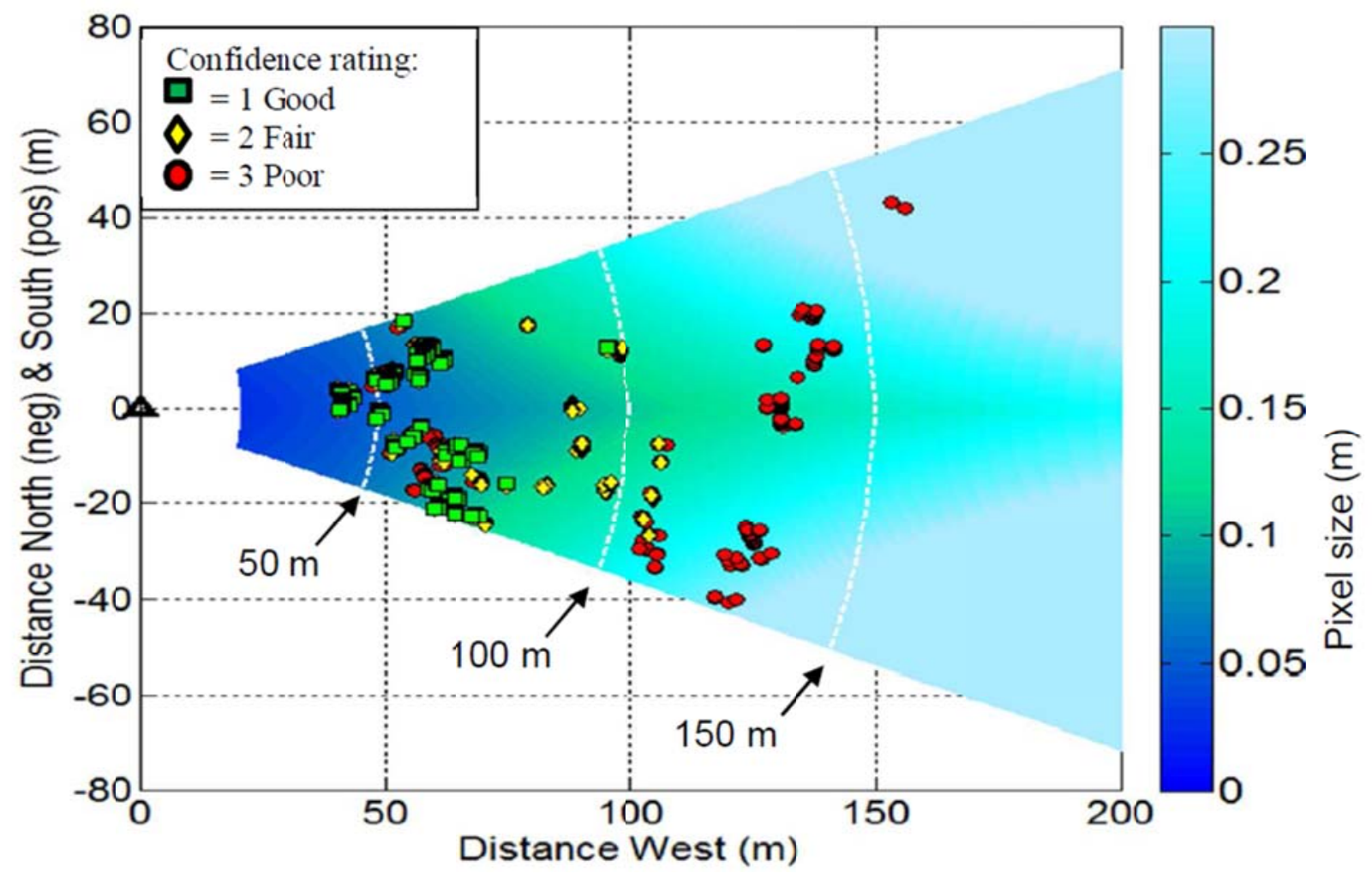

Figure 18 - Southern Resident killer whale detections over a three day observation at Lime Kiln State Park, San Juan Island, Washington. Color contours denote pixel size in meters. Each colored dot (red, yellow, green) denotes a detected Southern Resident killer whale on the surface. Dot color denotes detection confidence (source: Graber et al., 2011).

For the District's project in Admiralty Inlet, Graber et al. (2011) estimates that an infrared camera would improve the availability of shore-based observations to $67 \%$ of the time, relative to $39 \%$ for visual cameras (accounting for reduced availability depending on visible light, sea state, and fog). However, detection requires at least two pixels per target and classification on the order of ten pixels per target. The current generation of infrared cameras generally have a maximum resolution of $640 \times 480$ pixels (one manufacturer offers a 1024 x 1024 pixel camera). Given that the project site lies $1 \mathrm{~km}$ offshore, it is likely possible to detect marine mammals using an infrared camera and narrow angle lens, but not classify then. Classification using infrared cameras would require (1) multiple cameras, (2) a scanning survey methodology sweeping the project area, or (3) a foveal view system in which a camera with a wide angle lens is used to detect targets and direct a camera with a very narrow angle lens to achieve classification. None of these approaches is ideal and all would be costly to implement.

\subsubsection{Lessons Learned}

Infrared spectrum optics can detect marine mammals with greater availability than visual spectrum optics. Unfortunately, the resolution of the current generation of infrared cameras is low in comparison to visual spectrum cameras and the cost is substantially higher (i.e., \$20-\$50k for a $640 \times 480$ infrared camera versus $\$ 3 \mathrm{k}$ for a machine vision optical camera with $2452 \times 2056$ resolution). The image contract 
for marine mammals observed by infrared cameras is, however, significantly higher than for visual spectrum cameras. As discussed in Graber et al. (2011), marine mammals have a high apparent temperature contrast relative to the water, not because their skin is much warmer in absolute terms, but because their bodies are at a higher incidence angle than the water surface (i.e., a fin is nominally at a $90^{\circ}$ incidence angle to the water surface). Consequently, their emissivity is much higher than the water surface and an apparent temperature difference is observed. This high contrast can be exploited by automated image processing (a basic algorithm is presented in Graber et al.) to detect, with high accuracy, targets in the field of view. These detections could then, in theory, be compared against cotemporal observations with a wide-angle, high resolution optical spectrum camera to identify the target. This could be used as a pre-processing step to reduce the effort (either software or manual) required for marine mammal detection and classification using visual spectrum camera observations.

\subsection{Shore-based Vessel Traffic Monitoring}

The US Coast Guard requires all vessels exceeding 300 tons gross weight and those carrying passengers to be equipped with Automatic Identification System (AIS) transponders. AIS transmissions are primarily used for real-time collision avoidance, but, if transmissions are logged by a receiver, they can be used to assess vessel traffic patterns. The objective in deploying a receiver was to better understand the contribution of vessel traffic noise to ambient noise levels at this site.

\subsubsection{Approach}

Automatic Identification Systems operate on frequencies adjacent to VHF channels used for maritime communications. As such, the range of an AIS receiver is constrained similarly to other radio signals by line of site to the transmission source and weather conditions. Washington State Parks granted permission for an AIS antenna and receiver to be deployed on the historic Admiralty Head lighthouse. The lighthouse is the highest point on the Whidbey Island side of Admiralty Inlet and affords an excellent view. Under most conditions, it was possible to receive AIS transmissions to a range of $20 \mathrm{~km}$. A receiver and logging system is relatively inexpensive and easy to assemble. The system for this project consisted of:

- AIS receiver (class A and B signals, e.g., Comar AIS-2-USB \$400)

- AIS antenna (e.g., Shakespeare 5250-AIS \$100)

- Low-cost desk top computer with upgraded hard disk storage ( $\$ 600)$

- Misc. cables (e.g., USB, Ethernet $\sim 30)$

The receiver logs approximately $5 \mathrm{MB}$ of ship traffic each day, which is straightforward to process and archive, even on an annual basis.

While vessels are underway, they broadcast their MMSI number (a unique identifier), location, speed, and heading up to twice per second. They also transmit descriptive information (e.g., flag, draft, length, vessel class) once every six minutes. A Python software package (NOAA data version 0.43 ) was used to decode AIS transmissions into at flat text format for further manipulation. These transmissions were then aggregated into one minute intervals for further statistical processing.

\subsubsection{Results}

The recorded AIS transmissions provide considerable insight into vessel traffic patterns in Admiralty Inlet over a range of time scales. Figure 19 shows vessel traffic patterns for a one month period (June, 2010) 
in close vicinity to Admiralty Head. Blue lines denote ferry traffic (Washington State ferries - KeystonePort Townsend route), while white lines denote other commercial and passenger traffic. The red triangle denotes the area under consideration for tidal energy development by Snohomish Public Utility District. This visualization demonstrates one of the leading rationales for siting the project off Admiralty Head namely the site is not outside of ferry and commercial shipping lanes and infrequently traversed by other traffic (primarily slower moving tugs). This information was used by the District and Sound \& Sea Technology to perform a navigational risk assessment for the Coast Guard in response to stakeholder concerns.

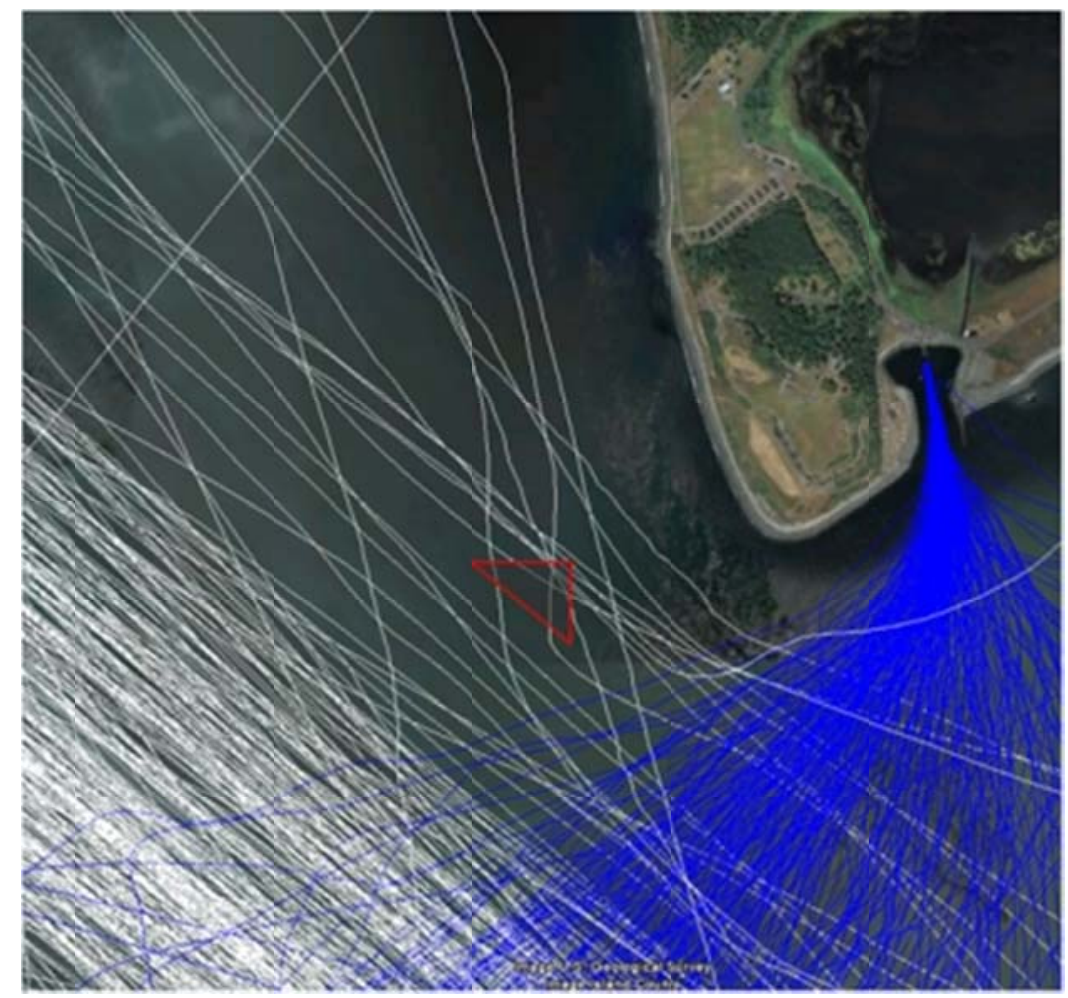

Figure 19 - Vessel traffic patterns off Admiralty Head. White lines are commercial shipping traffic, blue lines are ferry traffic, and the red triangle is the region being investigated by Snohomish Public Utility District for tidal energy development. Vessel tracks are for June $\mathbf{2 0 1 0}$ and are representative of typical monthly traffic.

Figure 20 shows ship track density for one year of observations in the project area. Densities are presented in terms of "vessel-minutes", that is, the number of minutes that vessels of a particular class (i.e., cargo, tug or tanker) spent within a $100 \mathrm{~m} \times 100 \mathrm{~m}$ grid cell. Long-term ship traffic patterns are evident. For example, the federal traffic separation zone in Admiralty Inlet is clear, with the separation between northbound and southbound lanes. Nearly all cargo traffic through Admiralty Inlet is coming from the Pacific, whereas tanker traffic diverges, with some traffic headed towards the Straits of Juan de Fuca and other traffic headed north to the refineries near Anacortes. Finally, passenger ship traffic is dominated by the cross-channel route between Admiralty Head and Port Townsend. 

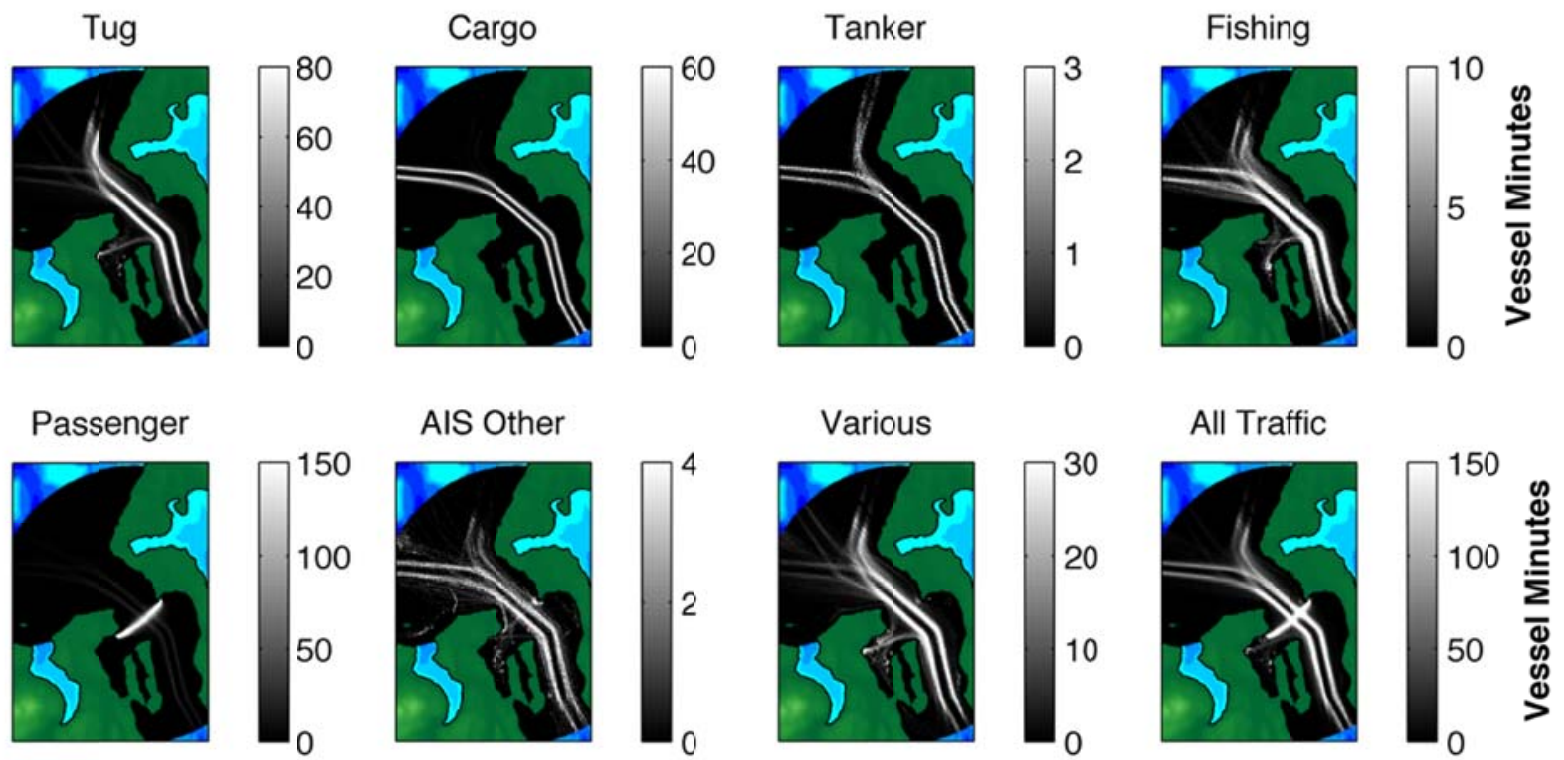

Figure 20 - Ship traffic density map plotted on a $100 \mathrm{~m} \times 100 \mathrm{~m}$ horizontal grid. Each subplot represents an area with the dimensions of $\mathbf{2 8} \mathrm{km}$ by $\mathbf{4 0} \mathrm{km}$ (source: Bassett et al., submitted)

In Bassett et al. (submitted), AIS and hydrophone data are combined to develop a vessel noise budget for Admiralty Inlet (as has been done for a few other areas around the United States with high traffic densities) and assess the contribution of vessel noise to ambient noise. A simple model to represent the contribution of vessel noise to ambient noise is presented, based solely on vessel type and distance to the receiver. As shown in Figure 21, the model envelope captures $90 \%$ of the temporal variability in ambient noise for Admiralty Inlet suggesting that during all but the quietest periods, vessel noise dominates ambient noise in Admiralty Inlet. 


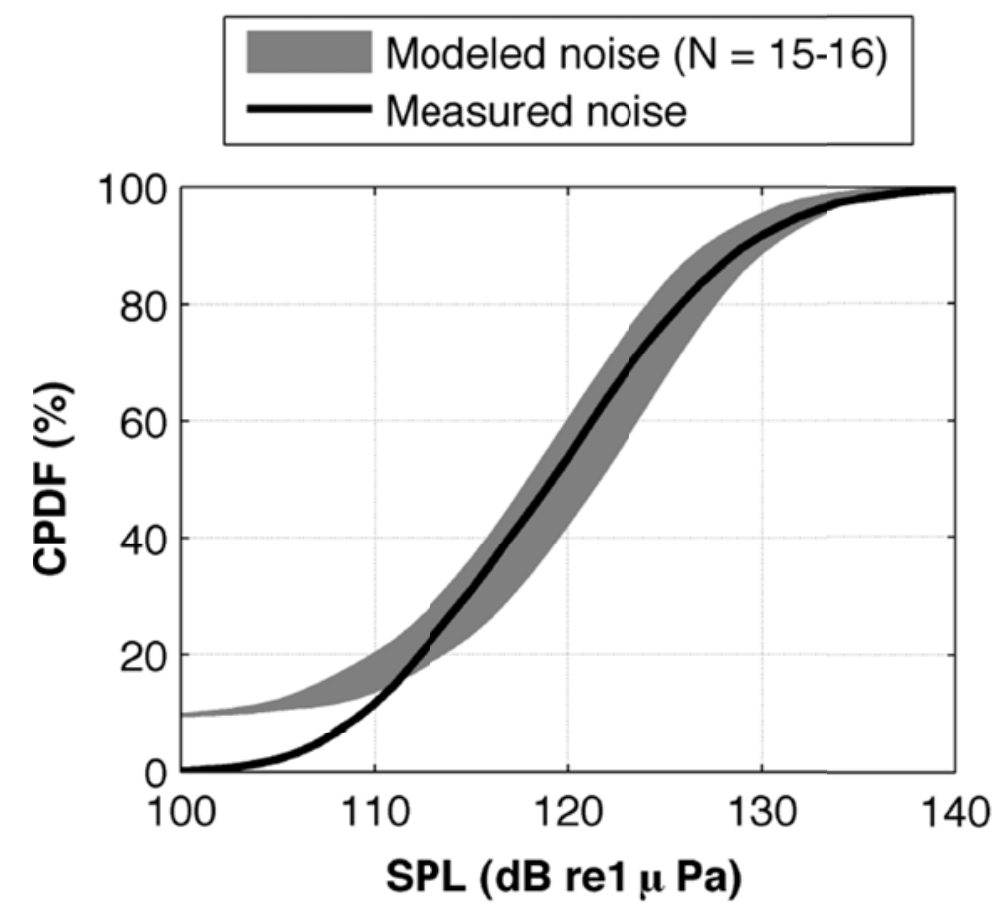

Figure 21 - Cumulative probability distributions of underwater ambient noise in study area for measurements (all ambient noise sources) and the model for vessel noise. The gray envelope of modeled noise represents predicted received levels using a transmission loss coefficient of 15 to 16.

\subsubsection{Lessons Learned}

This project demonstrates the value of collecting and archiving AIS data for vessel traffic around marine and hydrokinetic energy sites. First, these data can inform siting decisions that minimize stakeholder conflict or enable developers to proactively identify conflicts with specific stakeholder groups. For example, in Admiralty Inlet, most vessel traffic through the project area is associated with tug and barge traffic, rather than commercial shipping. This information allowed the District to conduct a navigational risk assessment for the pilot project for a relatively narrow set of vessel types. Second, these data provide essential context for interpreting pre-installation acoustic measurements. In the case of the Admiralty Inlet, at frequencies below $1 \mathrm{kHz}$, ambient noise is dominated by vessel traffic sources. Finally, these data can help to structure post-installation acoustic monitoring activities. In the case of Admiralty Inlet, these data suggest that acoustic characterization of the turbine be undertaken during the early morning hours (i.e., temporal minimum in ambient noise shown in Figure 12) to minimize masking of turbine sound by other anthropogenic sound sources. These data can be collected autonomously and at low cost using off-the-shelf components.

Note, however, the not all users correctly program their AIS transponders, which can confound interpretation of data. For example, a small number of vessels improperly program their MMSI number, and therefore, vessel information (length, draft, type, etc.) cannot be verified against available databases. More common are improperly assigned vessel length or vessel type. This is generally more of problem from small tugs, fishing vessels, and recreational craft making voluntary use of AIS than for large commercial vessels (cargo and tankers). 


\section{Task 2: Turbine Sound}

The objective of this task was to provide guidance on the expected sound profile for the District's pilot project to enable regulatory decision making and to inform Task 4 experiments (effect of sound on marine animals). The intended approach was to deploy an acoustic projector within the project area to simulate the noise signature of a hydrokinetic turbine (i.e., conduct a playback experiment) in order to evaluate the consequences of non-uniform sound propagation in Admiralty Inlet. Though the objectives were achieved through a combination of analysis and in situ experiments with a tonal source, the simulated playback approach proved untenable for reasons described in $\S \mathrm{X}$. While knowledge of turbine noise has advanced over the course of this study, significant uncertainties remain that are only likely to be resolved through post-installation monitoring of pilot projects.

In order to understand the outcomes of this task, it is helpful to lay out the timeline for how understanding of turbine sound has evolved over the course of the project. At the time this study began, the best (and only) estimate for the source level of sound produced by an OpenHydro turbine was a figure of $162 \mathrm{~dB}$ re $1 \mu \mathrm{Pa}$ at $1 \mathrm{~m}$ (Subacoustech, 2008). This was a broadband estimate, integrating measured turbine sound over all frequency bands. The National Marine Fisheries Service (NMFS) considers Level $B$ harassment of marine mammals to occur when broadband received levels ${ }^{5}$ exceed 120 $\mathrm{dB}$ re $1 \mu \mathrm{Pa}$. Consequently, a playback at this source level would require an Incidental Harassment Authorization (IHA) from NMFS. Because marine mammal hearing is frequency dependent, as is the response of underwater speakers, pursuit of an IHA required more than a broadband estimate (both to specify the sound exposure for marine mammals and specify the equipment used to produce this exposure). However, by the time discussions regarding a playback experiment began in early 2010 with NMFS, OpenHydro had concluded that the towed hydrophone methodology was likely flawed (in retrospect, a correct conclusion) and planned to undertake additional measurements of turbine sound at the European Marine Energy Center (EMEC, $6 \mathrm{~m}$ turbine) and in the Bay of Fundy (10 $\mathrm{m}$ turbine). At the time, the District's project consisted of a pair of $10 \mathrm{~m}$ turbines and measurements from a device of the same scale in the Bay of Fundy were considered preferable.

Measurements from the Bay of Fundy were not, however, productive. Anecdotally, the initial survey technique involved holding station with a survey vessel with the hydrophone streamed out behind. This badly contaminated the measurement of turbine noise with engine noise and flow noise. Drifting measurements undertaken in $\mathbf{2 0 1 0}$ were also unsuccessful as the turbine blades had experienced a structural failure in late 2009 due to higher than expected loads. This was not, however, apparent until the turbine was recovered in late 2010 (well after the noise survey had been undertaken) because the turbine was not grid connected, acoustic communications had been lost shortly after deployment, and tidal conditions in the Bay of Fundy are significantly extreme as to complicate even basic maintenance intervention with an ROV.

The blade failure on the $10 \mathrm{~m}$ OpenHydro turbine had two direct impacts on this project. First, in late 2010 attention turned to interpreting experimental results from noise monitoring of the $6 \mathrm{~m}$ OpenHydro turbine at EMEC and scaling those results up to estimate source levels for a pair of $10 \mathrm{~m}$ turbines in

\footnotetext{
${ }^{5}$ Received levels are sound level interpreted by a receiver, biological or mechanical (i.e., a hydrophone). Received levels are lower than source levels due to spreading and absorption of acoustic power.
} 
Puget Sound. This was completed in January 2011 and provided the first complete look at the spectrum of turbine noise. It also demonstrated that a number of significant uncertainties remained in the understanding of the turbine sound profile. For example, because no simultaneous measurements of ambient noise were undertaken, the contribution of received levels from ambient noise sources and turbine noise sources could not be directly determined. Further, as discussed in $\S X$, it was not possible to establish a relation between the turbine sound profile and power generation state (i.e., if the turbines would generate more or less sound when tidal currents were higher or lower than during the measurements at EMEC). Measurements indicated that the highest intensity turbine sound occurs at frequencies below $1000 \mathrm{~Hz}$, with tonal clusters at frequencies around $15 \mathrm{~Hz}, 160 \mathrm{~Hz}$, and $500 \mathrm{~Hz}$. Low frequency sound is difficult to produce in a controlled manner. Consequently, the decision was made to decouple the question of sound propagation in Admiralty Inlet from the question of the turbine sound profile. In doing so, a relatively high frequency acoustic source $(10 \mathrm{kHz})$ could be operated at sufficiently low intensity (less than $120 \mathrm{~dB}$ ) to gain insight into sound propagation in the project area without the need for an IHA. NMFS concurred with this approach in its response to a Biological Opinion in the summer of 2011. In August, 2011, source propagation tests were conducted in Admiralty Inlet.

The second effect of the blade failure in the Bay of Fundy was a change to the Admiralty Inlet pilot project. During the summer of 2011, the District and OpenHydro determined that the turbines to be used in Admiralty Inlet should be $6 \mathrm{~m}$, rather than $10 \mathrm{~m}$ variants. This was based on an analysis of the structural loading data obtained from the Bay of Fundy and comparison to expected loads in Puget Sound. In the first quarter of 2012, NNMREC undertook an analysis of turbine sound based on the $6 \mathrm{~m}$ turbines at EMEC and combined this with the understanding of ambient noise in Admiralty Inlet to produce a probabilistic estimate of turbine noise as it pertains to detectability by marine mammals. The draft version of this analysis was included with the District's FERC license filing on March 1, 2012. Submission of this analysis (authored by NNMREC, SMRU Ltd., OpenHydro, and NMFS) is expected in the second quarter of this year.

Our understanding of turbine noise continues to evolve and, while significant progress has been made since 2010, a number of questions remain that will need to be addressed through thoughtful monitoring of pilot projects. Here, we summarize the sound profile of an OpenHydro turbine, the development of a framework to assess the effects of turbine noise in Admiralty Inlet, and the results from the tonal sound propagation test in Admiralty Inlet.

\subsection{Turbine Sound Profile}

To date, there has been no comprehensive characterization of tidal turbine noise. Some acoustic data have been collected (Davidson and Mallows, 2005; Verdant Power, 2010; Ocean Renewable Power Company, 2011), but generally lack context (e.g., quantification of ambient noise in the absence of turbine operation). This limited data set is, in part, attributable to the challenge of collecting acoustic data in such high velocities, as described in this report. Polagye et al. (in prep) includes a reanalysis of data collected by the Scottish Association for Marine Science from a $6 \mathrm{~m}$ OpenHydro turbine operating at the European Marine Energy Center (Figure 22). 


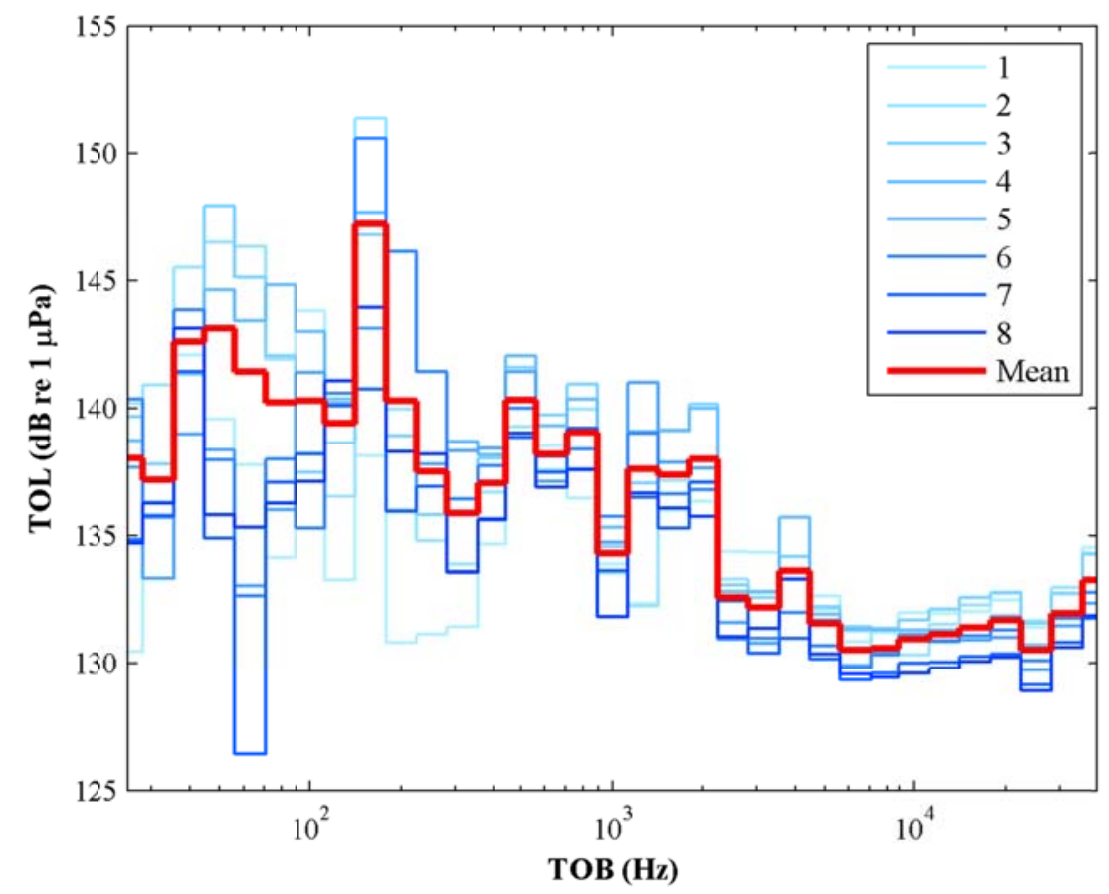

Figure 22 - One-third octave source levels from measurements of an OpenHydro turbine at EMEC (source: Polagye et al. in prep)

These measurements were obtained at a single operating state and in uncertain ambient noise conditions. For example, the increase in the spectrum beyond $10 \mathrm{kHz}$ may well be associated with rain (it was raining lightly during data collection) or bedload transport (Bassett et al., in prep). In Polagye et al. (in prep) the full spectrum of received sound is assumed to be associated with the turbine and the hypothesis that turbine sound is likely to scale with power generation state (Davidson and Mallows, 2005; Hazelwood and Connelly 2005). Measurements from EMEC at a single power generation state are, therefore, scaled according to predicted power generation in Admiralty Inlet (using the current profiler data from Task 1) to obtain the distribution of source levels shown in Figure 23.
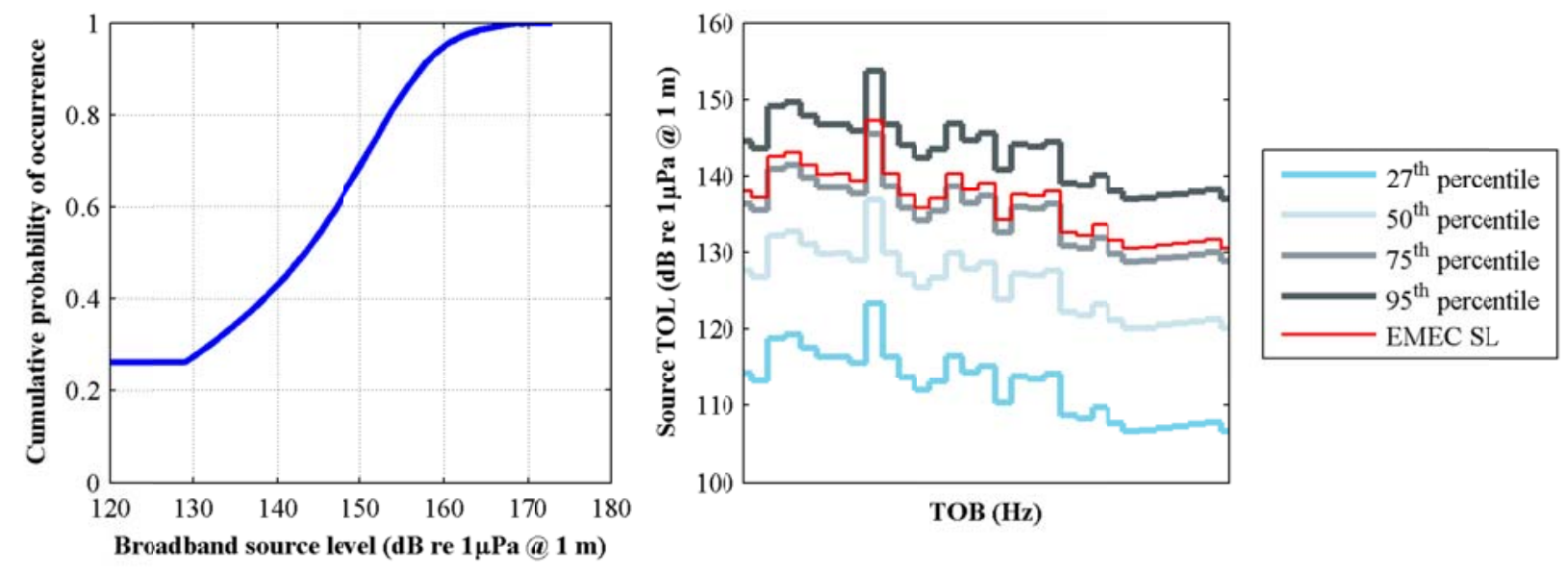

Figure 23 - Probability distribution of turbine source levels. (left) Broadband ( $25-25000 \mathrm{~Hz}$ ). (right) One-third octave source levels for select percentiles. Turbine operation begins at the $27^{\text {th }}$ percentile currents. The red line denotes the turbine source level estimated from measurements at EMEC (source: Polagye et al. in prep). 
Consequently, if this hypothesis holds true, received levels of sound in Admiralty Inlet will be a strong function of tidal current velocity, as shown in Figure 23. Addressing the validity of this hypothesis is a central component of the District's proposed post-installation acoustic monitoring plan.
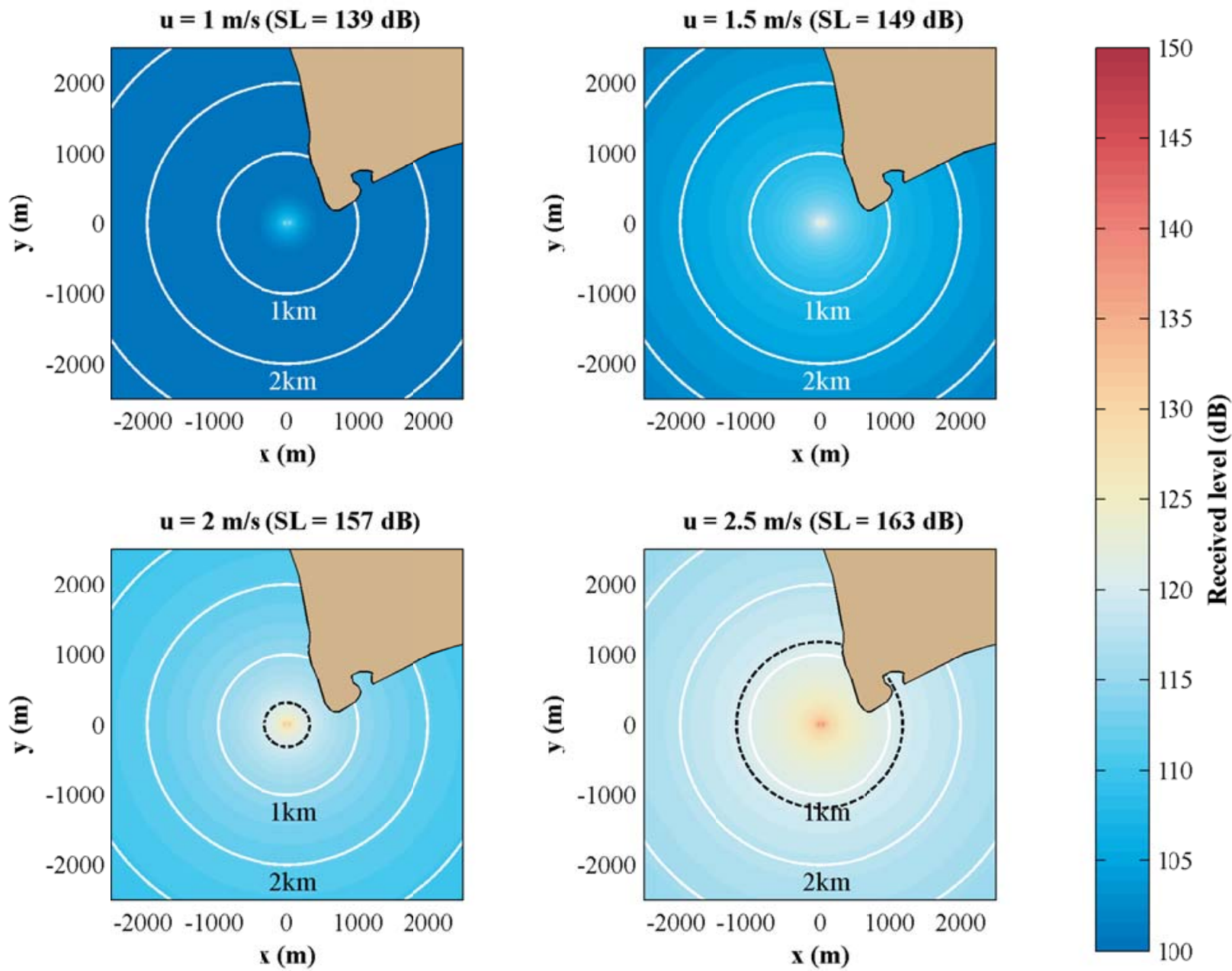

Figure 24 - Broadband ( $25-25000 \mathrm{~Hz}$ ) received levels at four inflow velocities ( $30 \mathrm{~m}$ depth relative to surface). Dashed black contour denotes the $120 \mathrm{~dB}$ isobel (regulatory harassment threshold at this site).

\subsection{Estimating Effect of Turbine Noise for the Admiralty Inlet Demonstration Project}

Given that turbine sound intensity (and perhaps frequency) are likely to vary in time with tidal state and site-specific ambient noise has been demonstrated to vary in time ( $\$ 2.2$ ), marine mammal detection of turbine sound will be probabilistic, as discussed in Polagye et al. (in prep). Namely, detection of turbine sound (and potential behavioral response) will depend on marine mammal hearing thresholds, position relative to the turbines, current velocity, and ambient noise variability (to the first order, a function of vessel traffic). For example, as shown in Figure 25Figure 25 when these factors are all accounted for, the probability of a mid-frequency cetacean (such as a Southern Resident killer whale) detecting turbine noise is highest in the one-third octave band centered at $500 \mathrm{~Hz}$, but detection is only probable within a few hundred meters of the turbine. Further, the zone of sound detection is likely greater than the zone of behavioral response. This suggests that marine mammal observations for the District's pilot project 
should focus on the immediate vicinity of the turbine deployment area and interpret observed behavior in the context of "signal excess" of turbine sound (received levels relative to ambient noise levels). Other turbine variants or turbines with higher power output may ensonify a larger area and warrant widerscale monitoring.
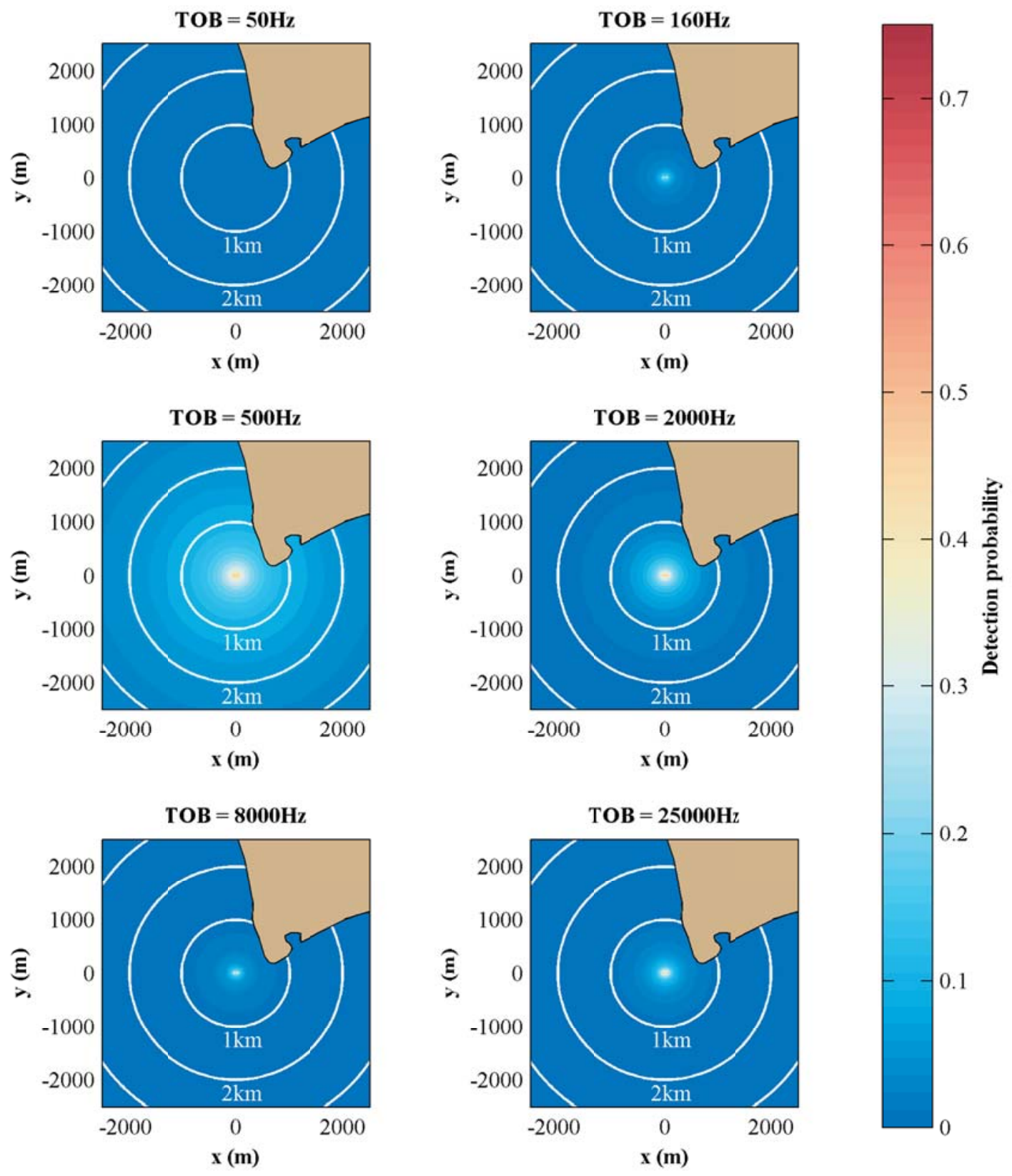

Figure 25 - Probability of mid-frequency cetacean (killer whale) detecting turbine noise $(30 \mathrm{~m}$ depth relative to surface) (source: Polagye et al. in prep)

\subsection{Tonal Sound Propagation in Admiralty Inlet}

\subsubsection{Approach}

The objectives of the tonal propagation experiment were twofold: 
1. To obtain information about site-specific sound propagation in Admiralty Inlet that could be used to assess whether turbines generate omnidirectional or directional sound during post installation studies.

2. To compare drifting hydrophone data collection (two types) against bottom deployed hydrophones in order to evaluate the effectiveness of these approaches for post-installation monitoring of turbine noise.

Proper measurement of acoustic transmission losses is dependent on reliable source levels from the projector. Prior to fieldwork, the acoustic projector system was calibrated in a tank at the Applied Physics Laboratory. An Agilent 33220A Arbitrary Waveform Generator connected to the full-length cable and the source was used to generate source functions. The output was monitored with an oscilloscope connected to a Navy Standard calibration hydrophone one-meter form the source. The calibration procedure was used to create a curve of acoustic source levels versus voltage input from the function generator.

Two research vessels, the R/V Jack Robertson and the R/V Inferno, were used in the field campaign for deployment of the acoustic source and the deployment/recovery of passive acoustic monitoring instrumentation, respectively.

The R/V Inferno powered the acoustic source using a battery to produce a clean signal. The acoustic source was connected to a 50-meter cable and to the function generator. Weights were attached to the source cable to reduce the line angle and a cable fairing was used to reduce cable strum. During playbacks, 40 meters of cable (referenced to the surface) were deployed. An Onset HOBO U20 water level data logger mounted on the cable just above the source was used to log the source depth and account for line angle due to the current. Playbacks consisted of a $10 \mathrm{kHz}$ pure sine wave on a $50 \%$ duty cycle (10 seconds on, ten seconds off) continuously during passive acoustic monitoring drifts to allow for measurements of ambient noise conditions between playbacks.

The R/V Jack Robertson was used for the deployment and recovery of three passive acoustic monitoring systems: three Sea Spiders deployed in May 2011 (and recovered at the conclusion of the propagation test), a near-surface drifter, and two cabled hydrophones. As described in $\S 2.1$, each tripod was equipped with a Loggerhead DSG, a self-contained system consisting of a Hi-Tech (96-min) hydrophone, an internal preamplifier, and a data acquisition. The effective frequency response of the systems is -166 $\mathrm{dB}$ re $1 \mathrm{~V} / \mu \mathrm{Pa}$. The duty-cycles were limited by the available memory based on the deployment durations. Two systems recorded at $80 \mathrm{kHz}$ on a $50 \%$ duty-cycle (30 seconds every minute). The final system recorded at $80 \mathrm{kHz}$ on a 100\% duty-cycle. For this experiment, SS \#02 and \#03 (described previously) were used, as well as SS \#06, a platform developed under funding for a separate project. The second system that was used was a drifter (SWIFT) allowing acoustic measurements near the surface while drifting with the current. As with the Drifting Ears approach described in $\S 3.1$, this minimizes contamination of recordings by flow noise. The SWIFT (Thomson, 2011), was also equipped with a QStarz BT-Q1000 GPS and accelerometer, a GoPro Hero video camera for monitoring surface conditions in the vicinity of the drifter, a Kestral 4500 NV anemometer, and a Garmin Astro for real-time tracking of the drifters. Each SWIFT was also equipped with a Loggerhead DSG, programmed at the beginning of each day to continuously record one-minute files at $80 \mathrm{kHz}$. 
The final passive acoustic monitoring system was two cabled hydrophones deployed directly from the work deck of the R/V Robertson. Two cabled hydrophones (Cetacean Research Technology C55) were connected to an IOtech Personal DAQ 3000 and a Panasonic Toughbook for real-time data acquisition and storage. The hydrophones were deployed at depths of $\mathbf{4 0}$ meters and 20 meters (referenced to the surface). Two Onset HOBO U20 water level loggers were deployed with the hydrophones to monitor the actual depths of the hydrophones. During each drift, data was acquired continuously in 60-second files sampled at $400 \mathrm{kHz}$. Data acquisition was triggered manually at the beginning of each drift. An additional GPS (QStarz BT-Q1000) was collocated with the hydrophone cables on the deck of the R/V Robertson to identify the location of each recording.

Data for each hydrophone was processed separately using comparable algorithms. Each recording was broken up into individual windows with a $50 \%$ overlap, the mean was removed, a Hann Window was applied, and the raw window was scaled to preserve the total variance of the raw signal. A Fast Fourier Transform is applied to each window and the result is squared and properly normalized to produce the pressure spectral density. To identify each playback, one-second averages of the spectra were calculated over the frequency bands that contain noise from the playback to produce one-second sound pressure levels. Each recording was manually processed to identify all recorded playbacks and the mean was calculated for the received sound pressure level of each playback. For each recording containing the signal of the acoustic source, the GPS systems were used to determine the geographic location and to calculate the distance from the source.

\subsubsection{Challenges}

Two significant challenges exist for the use of active acoustics devices in study sound propagation at bathymetrically complex sights: regulatory limitations of acceptable source levels for acoustic sources and obtaining sufficient resolution in space to help account for all variables that impact sound propagation.

Regulations on source levels (currently an IHA is required for broadband source levels exceeding $120 \mathrm{~dB}$ - which can be generated by banging a hammer against the hull of ship), can limit the effective range of propagation experiments. As the source level decreases, the resulting signal-to-noise ratio of the playback to ambient noise levels decreases. In busy urban waterways, ambient noise levels, particularly those with commercial ship traffic are driven by vessel traffic. As was the case in this study, vessel presence limited the effective the range over which measurements of the source projection could be obtained.

Sound propagation is affected by variables including sound speed profiles, bottom type, bottom roughness, wave climate, and bathymetric conditions. Designing an experiment to measure sound propagation in a region with complex bathymetry requires a high level of effort to achieve meaningful resolution. This is further complicated when limitations on source levels result in masking of the source over relatively short distances. Because surveys must be undertaken by free-drifting platforms (else propulsion noise obscures the source), data must be collected in the along channel direction, complicating spatial resolution of transmission losses at different azimuth angles. 


\subsubsection{Results}

A total of 222 data points from the deep cabled hydrophone (depth, $40 \mathrm{~m}$ ), 218 data points from the shallow cabled hydrophone (depth, $20 \mathrm{~m}$ ), and 244 data points from the drifter included identifiable tonal playbacks. Results are normalized in terms of transmission loss (TL)

$$
T L=S L-R L
$$

where $R L$ is the received level at a hydrophone (fixed, cabled, or drifting) and $S L$ is the calibrated source level.

Maps of the cabled hydrophone results and the drifter results are included in Figure 26. The distances on the $x$ and $y$-axis are based on the mean location of the source during the playbacks. As expected, the transmission losses increase with increasing distance from the source. Variations in the received level with distance from the source in the maps, particularly at distances less than 500 meters, is attributed to ambiguity in location of the source ( $40 \mathrm{~m}$ of cable out in directionally varying currents) as well as variations in sound propagation with azimuth angle from the source location.
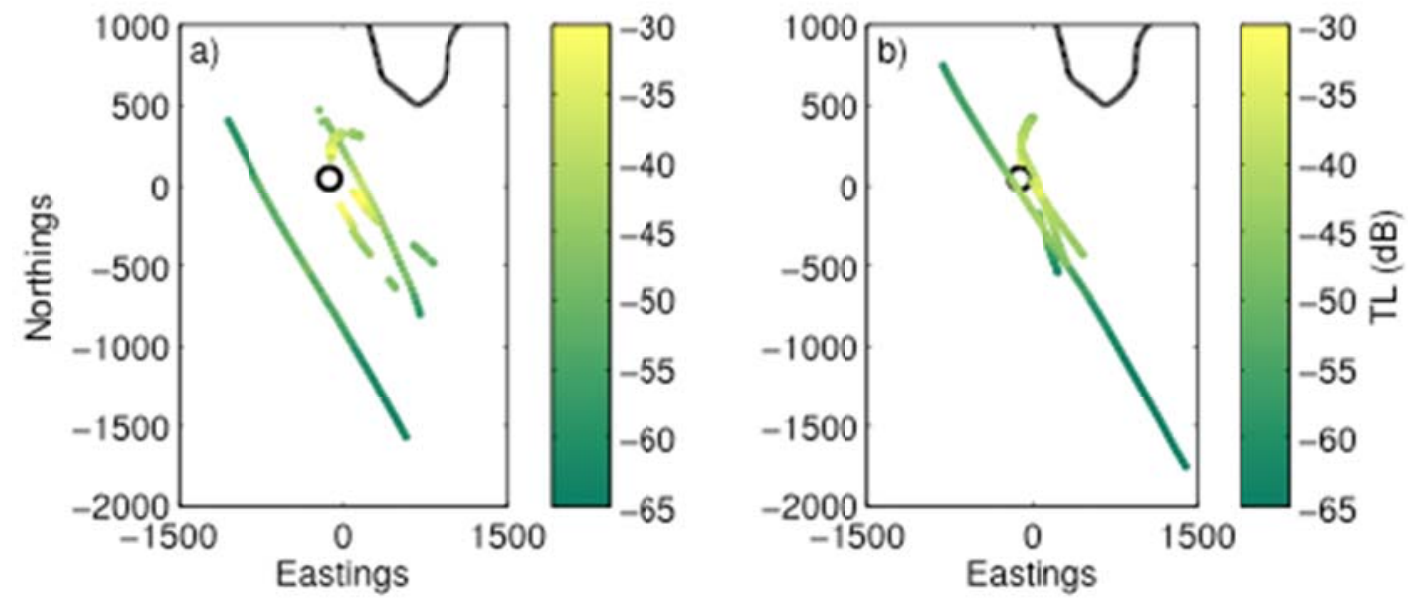

Figure 26 - a) Transmission loss for the cabled hydrophone (depth, $40 \mathrm{~m}$ ). b) Transmission loss for the drifting hydrophone. In both figures, the black circle represents the approximate location of the proposed tidal turbines at the site.

Transmission losses without respect to azimuth angle are calculated in Figure 27. Distances between the source and receiver are calculated based on the surface location of the sources and receivers without accounting for the slant distance. At distances greater than $\mathbf{3 0 0}$ meters, the difference between the surface distance and the slant angle is less than $1 \%$ based on a source depth of $40 \mathrm{~m}$ and difference of 39 meters between the source and receiver depth (surface drifter). 


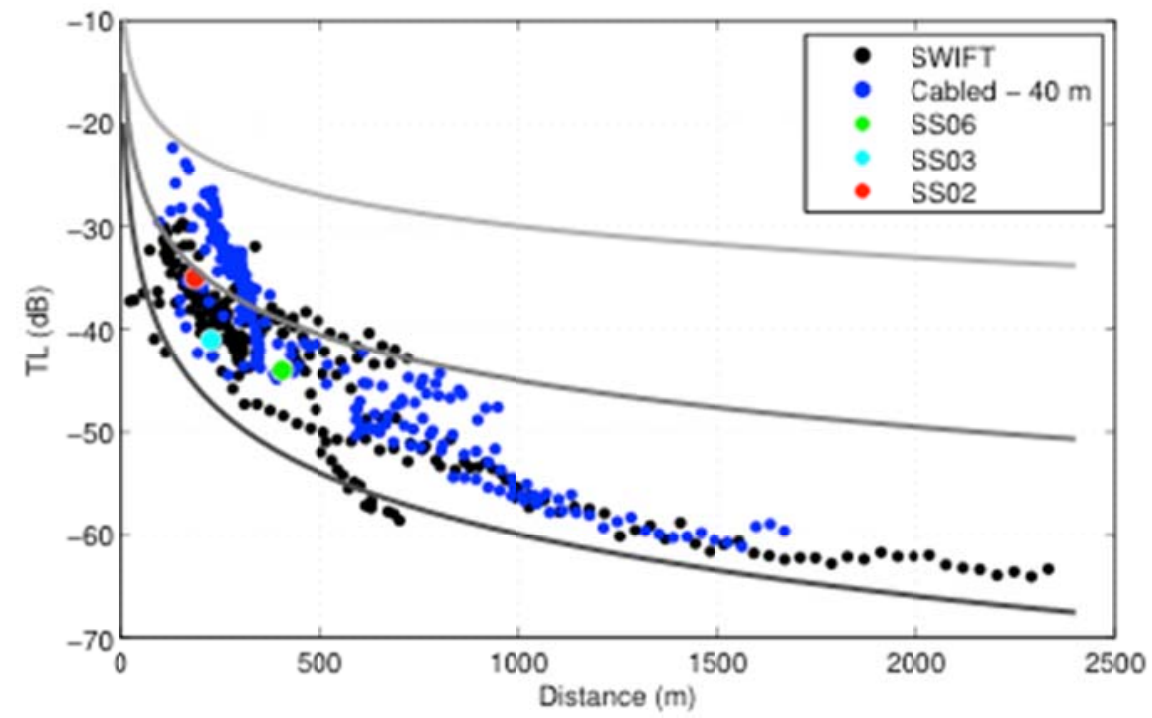

Figure 27 - Transmission losses between source and receiver versus the distance from the source. The gray lines represent transmissions losses with distance based on transmission loss coefficients of 10, 15, and 20.

The transmission losses for the different recording methods show significant variability at distances less than 1000 meters. The variability in this range is likely associated with the transition from spherical spreading $(\mathrm{N}=20)$ to cylindrical spreading $(\mathrm{N}=10)^{6}$. At even shorter ranges $(<500 \mathrm{~m})$, the cabled hydrophone shows smaller transmission losses than the drifter surveys, a difference that can be related, in part, to differences between the slant distance and the horizontal distance. For both cabled and drifter surveys, the most significant outliers that result in lower transmission losses occur during survey around slack tide. During this period the drifter and cabled hydrophone switched directions from ebb to flood while drifting into shallower waters.

At distances greater than 1000 meters, drifter and cabled surveys have similar results suggesting that at greater distances the transmission loss coefficient approaches a value significantly greater than 15 (black line denotes a transmission loss coefficient of 20). Cabled and drifter results suggest significant near-field variability in transmission losses which should be investigated through further analysis of field data and numerical modeling.

\subsubsection{Lessons Learned}

Several challenges were encountered in the course of developing and conducting this experiment that altered the approach taken. The need to specify, with precision, the sound profile of a playback and the equipment required to produce it for regulatory reasons conflicted with significant uncertainty that remains, at present, regarding the true sound profile of a tidal turbine. Consequently, the simplest approach is to use a source level below the current regulatory threshold of $120 \mathrm{~dB}$. This restricts the range at which sound can be detected relative to ambient noise to less than $2 \mathrm{~km}$. For the tonal propagation experiment, $10 \mathrm{kHz}$ was chosen because it represents a local minimum in the ambient noise spectrum and allows for the greatest detection range.

\footnotetext{
${ }^{6}$ Transmission losses may, to a leading order, be approximated as $N \log D$ where $\mathrm{N}$ is the transmission loss coefficient and $D$ is the distance between source and receiver.
} 
Regardless of the sound source and the intensity of sound produced, deploying a sound source for a playback experiment is challenging. Because it was desirable to be able to adjust the source in real time (and only broadcast sound while hydrophones were recording), a cabled deployment was required. This, in turn, necessitated anchoring a surface vessel and allowing the hydrophone to stream out behind. This created spatial ambiguity in the location of the source in strong, turbulent currents. At long ranges, this ambiguity is inconsequential, but at short ranges it can confound interpretation of results (and the low source level decreases the likelihood of a long-range detection). For future experiments of this type, deploying the acoustic source on an autonomous bottom mooring would simplify operations and the interpretation of results, albeit at higher equipment cost. 


\section{Task 3: Presence and Behavior of Marine Mammals}

The objective of this task was to interpret the presence and behavior of marine mammals within the study area using data generated by site monitoring (Task 1). This was achieved through statistical analysis of click data collected by the echolocation hydrophones (specifically, the C-PODs). A secondary objective was to incorporate other data, including marine marine vocalizations, land-based marine mammal observations, and shore-based infrared observations to further this interpretation. This could not be achieved for the following reasons:

- As discussed in $\S 2.3$, Southern Resident killer whale echolocation click trains were not reliably classified by the C-POD software and transits were too few to achieve statistical power. Harbor porpoise, which were readily classified by the C-POD software, do not vocalize at lower frequencies.

- Land-based marine mammal observations took place primarily before data collection for this project was underway due to contracting delays in initiating this effort.

- The evaluation of the infrared camera determined that, using the current generation technology, resolution would be too low to effectively monitor marine mammals in Admiralty Inlet.

Consequently, additional analyses were undertaken to evaluate marine mammal behavior from the collected data:

- Identification of "landmark" sequences denoting harbor porpoise awareness of the Sea Spider.

- A study of the responsiveness of harbor porpoise to an existing anthropogenic noise source in order to investigate methodologies to detecting responsiveness to turbine noise.

- Indirect evaluation of behavioral state through investigation of click train properties, specifically inter-click interval (ICI).

\subsection{Trends in Harbor Porpoise Presence}

\subsubsection{Approach}

Trends in harbor porpoise presence were investigated by a Generalized Linear Model (GLM) with current speed, day/night, tidal stage (neap/spring), sound exposure level (SEL, M-weighted to porpoise auditory sensitivity), months, and seasons as explanatory variables for DPM/hour. GLMs are regression models that fit data following distributions of the exponential family utilizing linear predictors connected to the natural mean of the response variable with a link function (Myers et al., 2002). A general expression for the structure of a GLM with a log link is

$$
\mu=\exp \left(\beta_{0}+\beta_{1} x_{1}+\beta_{2} x_{2}+\cdots+\beta_{n} x_{n}\right)
$$

in which $\mu$ is the expected value of the response to regression coefficients, $\beta$, acting on regressors, $X$. GLMs are frequently used to model cetacean echolocation activity. Khyn et al. (2008) have modeled DPM in response to T-POD detection sensitivity. Tollit et al. (2011) used location and month as predictors in a GLM describing DPM at a proposed tidal energy site in the Bay of Fundy. Variation in $\mathrm{ICI}$ and DPM of Heaviside's Dolphin echolocation were linked to time of day in a study by Leeny, et al. (2011). 
GLM regression is performed on observed DPM per hour to enable investigation of regressors including those with necessary resolution of less than one day (e.g. diel variation). Choice of an applicable exponential distribution for the model is crucial to ensure a good fit. A negative binomial fit approximates the observed distribution of DPM per hour most accurately and was used for modeling. Regressors were prepared for inclusion in the model using Matlab (www.mathworks.com). Time series of DPM derived from the C-POD data, current velocity from the ADCP, and SEL from the hydrophone were filtered to only include hours in which uninterrupted data is available for each. For this analysis, data were derived from four deployments of a single C-POD (ID\# 718) using consistent buffer and filter settings and deployed in the same location for the duration of the study. Further, clipped hours (hours in which at least $25 \%$ of all minutes had full buffers), are excluded to minimize bias associated with noncontinuous observation. Of the 8068 hours (336 days) recorded by the C-POD, applicable hours for modeling are reduced to 6028 (75\%) by clipping and to 5537 (69\%) by the need for intersecting data series for all explanatory variables. Variables for deployment hour, month, and season, water level above MMLW, neap/spring, and time of day (day/night), were generated for the entire span of the deployment and then matched against DPM time-indices. Similarly, current speed, SEL, and the two tidal state series (water level, position within neap-spring cycle) were treated as continuous variables for each hour. Months and seasons were treated as categorical variables, while diel state was a binary variable. To avoid 24 individual categories for an hour of the day regressor, a 5-point spline is fit to the 24 hour cycle, creating 5 categories, each spanning multiple hours.

\subsubsection{Results}

Porpoises are detected in every deployment day, with a minimum of 84 and maximum of 834 DPM per day, and median of 382 DPM per day (Figure 28). This represent a median total of 6.37 hours porpoise presence over the course of a 24 hour day. DPM are henceforth analyzed over deployment hours. When clipped hours are removed, porpoises are detected in 83\% (5018 of 6028) of unclipped hours, with a median of 9 DPM per hour. 60 DPM per hour are observed for 49 hours (0.8\%). Rates of detection are considered high in comparison with other tidal sites (Tollit et al., 2011). 


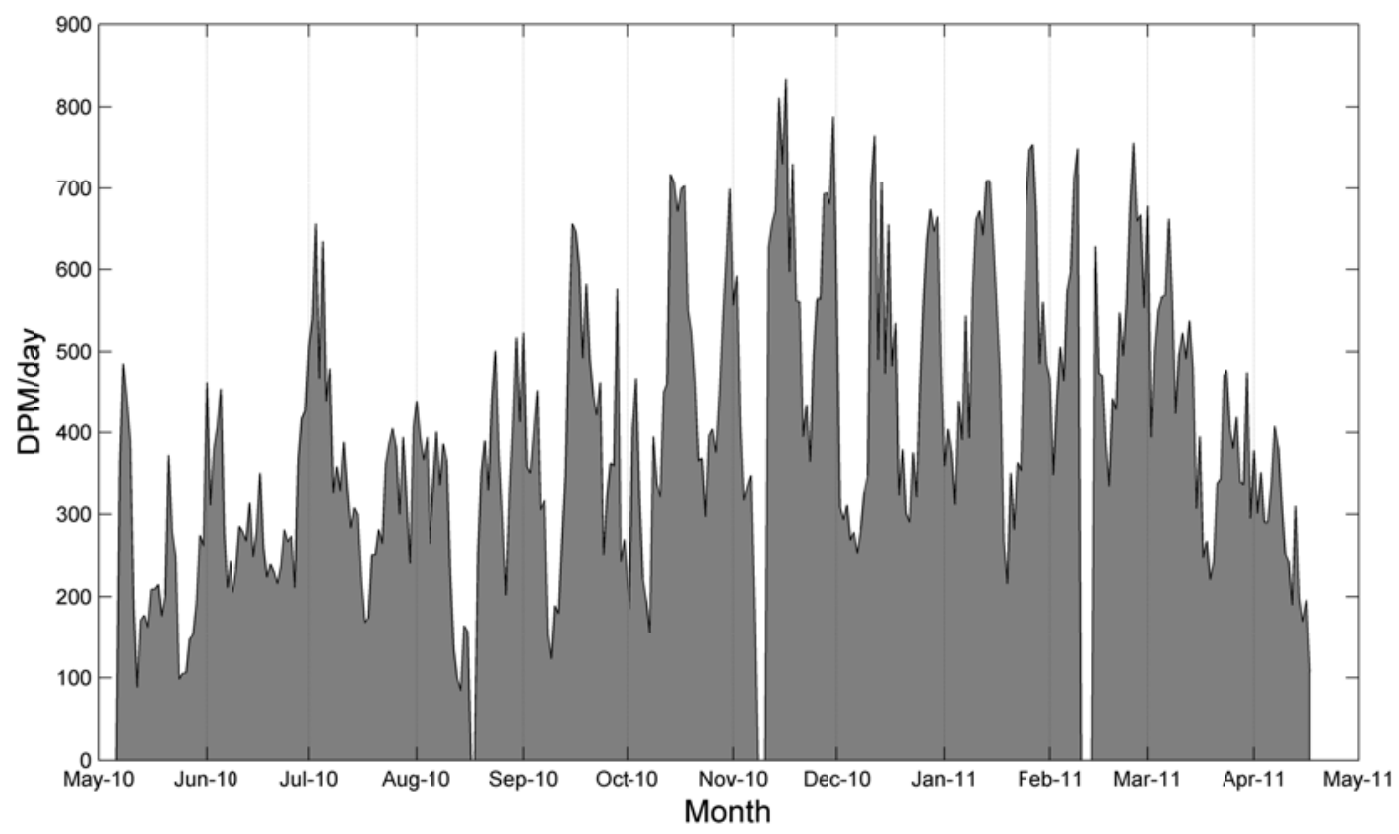

Figure 28 - DPM per day. Gaps in data represent C-POD retrieval and deployment periods

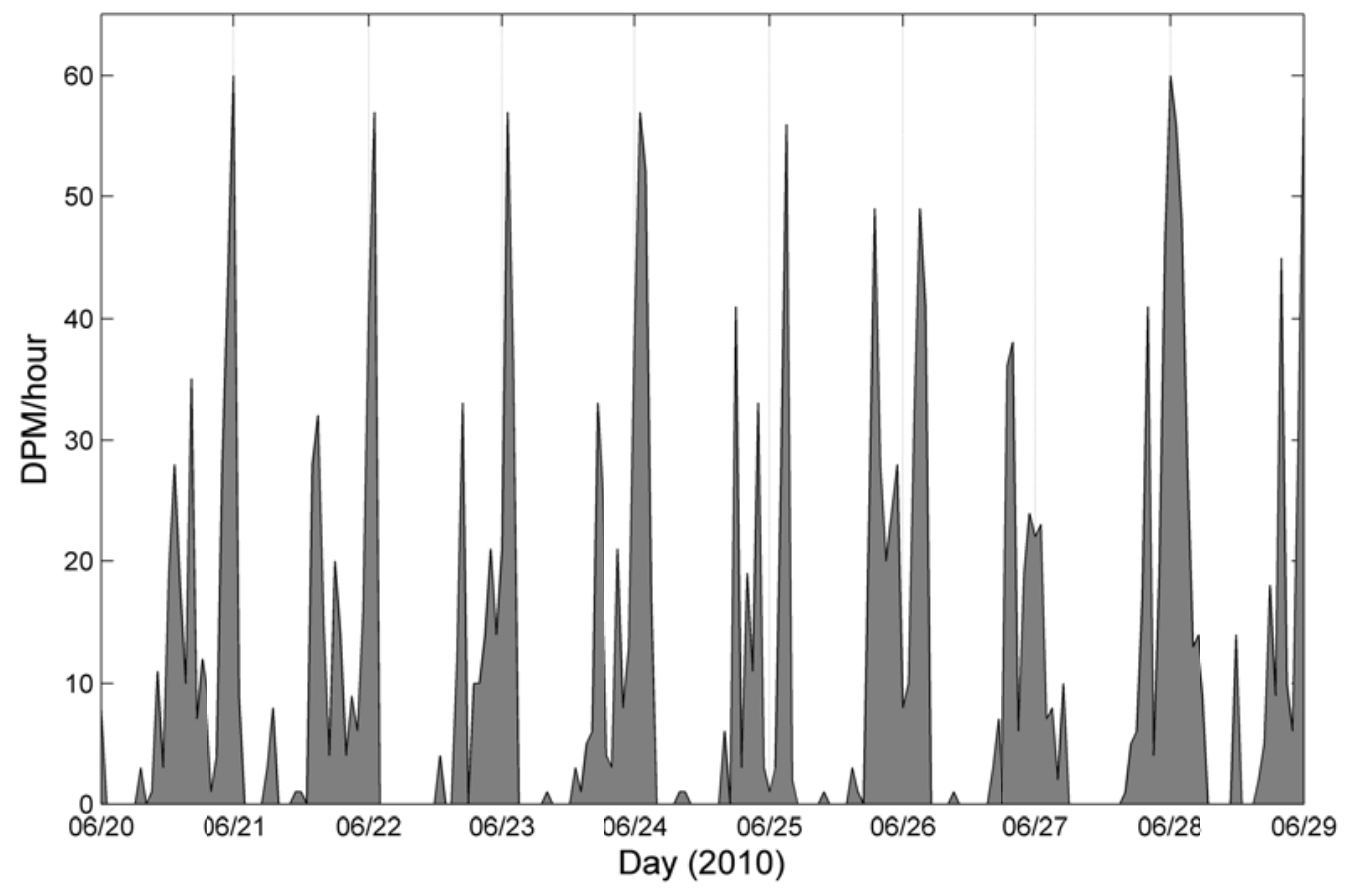

Figure 29 - DPM per hour for nine day sample period

Daily trends in DPM per hour include sharp peaks around midnight and a sharp drop-off in detections followed by relatively low activity until midday (Figure 29). Spectral analysis confirms the existence of 
this trend, with a strong peak at a period of one day, and weaker peaks at fractional day lengths. A peak at 15 days is also clear, suggesting a signal near the periodicity of the neap/spring cycle (Figure 30 ).

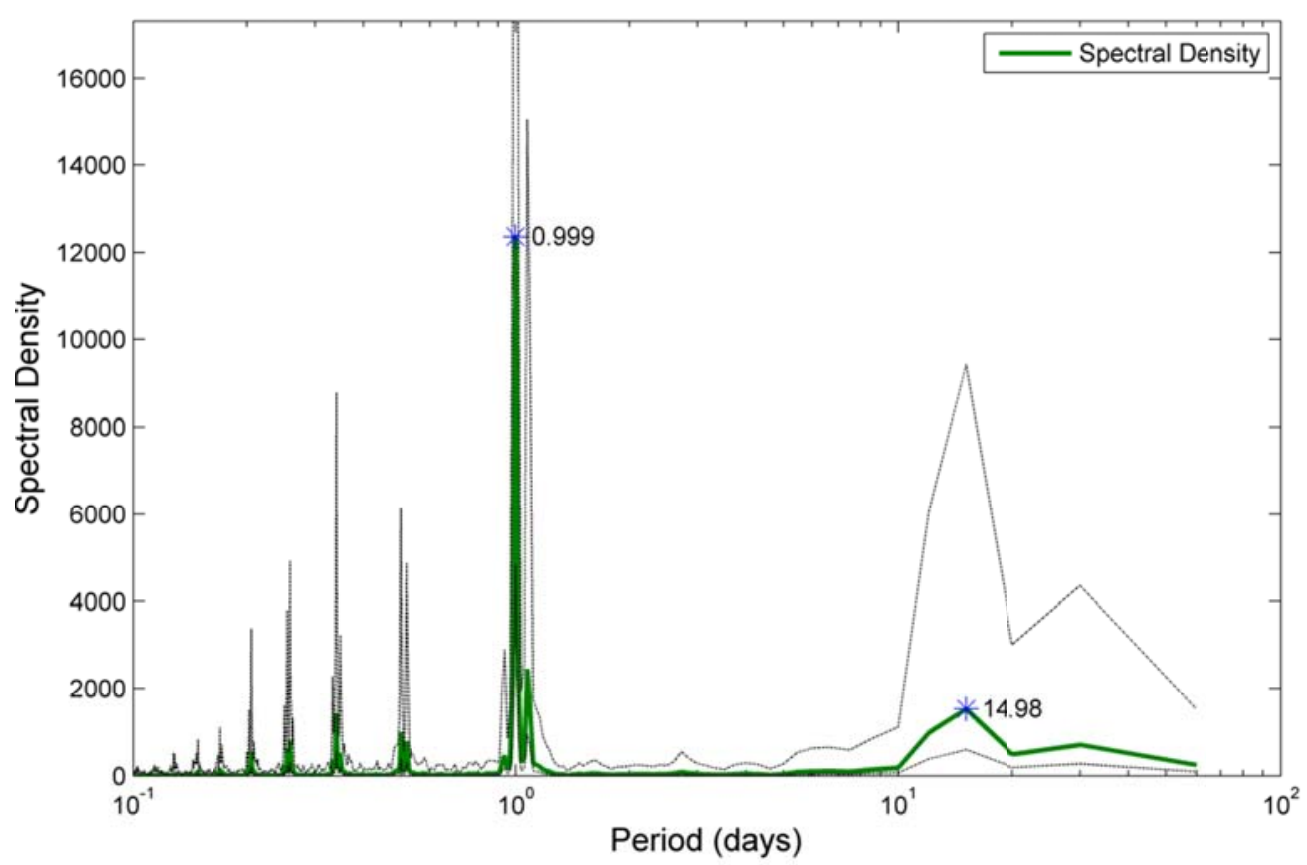

Figure 30 - Periodogram of DPM per hour with 95\% confidence interval (grey line)

In order to assess underlying factors governing presence or absence of harbor porpoise at this location, DPM/hour are grouped by time of day, month, season, and current speed (Figure 31). Trends in DPM were investigated using the Kruskal-Wallis test or Wilcoxon-Mann-Whitney test in the case of 2 sample groupings. Brunner and Puri (2001) describe these nonparametric tests for independent observations, under which "....no specific parametric class of distributions is assumed". As DPM are not normally distributed, this relaxed constraint makes nonparametric testing appropriate. Significant differences in sample medians were inferred using a chi-square statistic.

Variation of DPM with time of day is shown to be significant $\left(\chi^{2}{ }_{1}=1812, p<0.0001\right)$ and accounts for the most variance of all parameters tested, at 30\%, with an average of $31.6 \mathrm{DPM} /$ hour at night and 9.9 DPM/hour during the day. DPM/hour varies significantly with month $\left(\chi_{11}^{2}=170, p<0.0001\right)$, accounting for $2.8 \%$ percent of the variance of the data. Average DPM/hour are highest in January, 2011 (21.3) and lowest in May, 2010 (12.0). Similarly, seasonal variation is significant $\left(\chi_{3}^{2}=108, p<0.0001\right)$ and accounts for $1.8 \%$ of the variance. Average DPM/hour is higher in autumn and winter $(19,20.6)$ than spring and summer $(13.4,17.8)$. Current speed is found to be a significant source of variance $\left(\chi_{6}^{2}=22.1 p<0.002\right)$, but accounting for only $0.4 \%$, meaning that while it is of statistical significance, it is not likely of biological significance (i.e., harbor porpoise presence/absence is not meaningfully correlated with current velocity). 

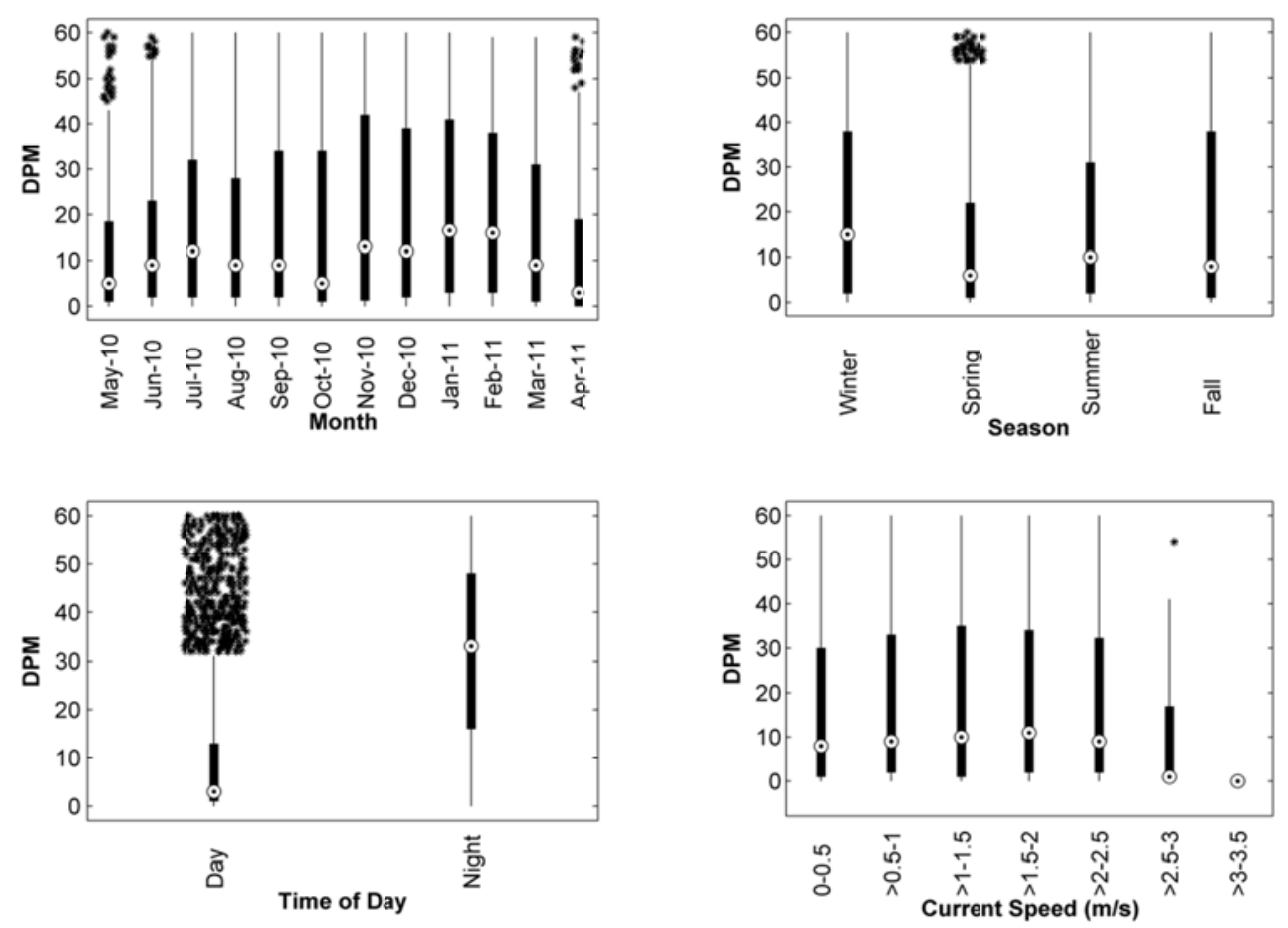

Figure 31 - Boxplots of grouped DPM/hour. Dots above bars represent outliers.

Three GLMs are constructed and compared in the statistical computing package, $R$ (website). A negative binomial GLM with a log link is presented as a "standard" modeling scenario. The second and third models are created by choosing unambiguously "day" and "night" samples from the series and constructing individual negative binomial, log linked GLMs. This split is motivated by the strong disparity in DPM between night and day The "day" series is deployment hours from 11AM through 3PM (PST) and the "night" series spans 9PM through 1AM. Additionally, shipping traffic is relatively consistent through Admiralty Inlet during these periods (Basset, et al., in prep), eliminating a potentially confounding factor. The time of day binary variable is removed from the split models. Results for the full series GLM are presented in Figure 32. The model shows moderate skill in tracking average DPM/hour over long time scales, but fails to capture a number of significant features. 


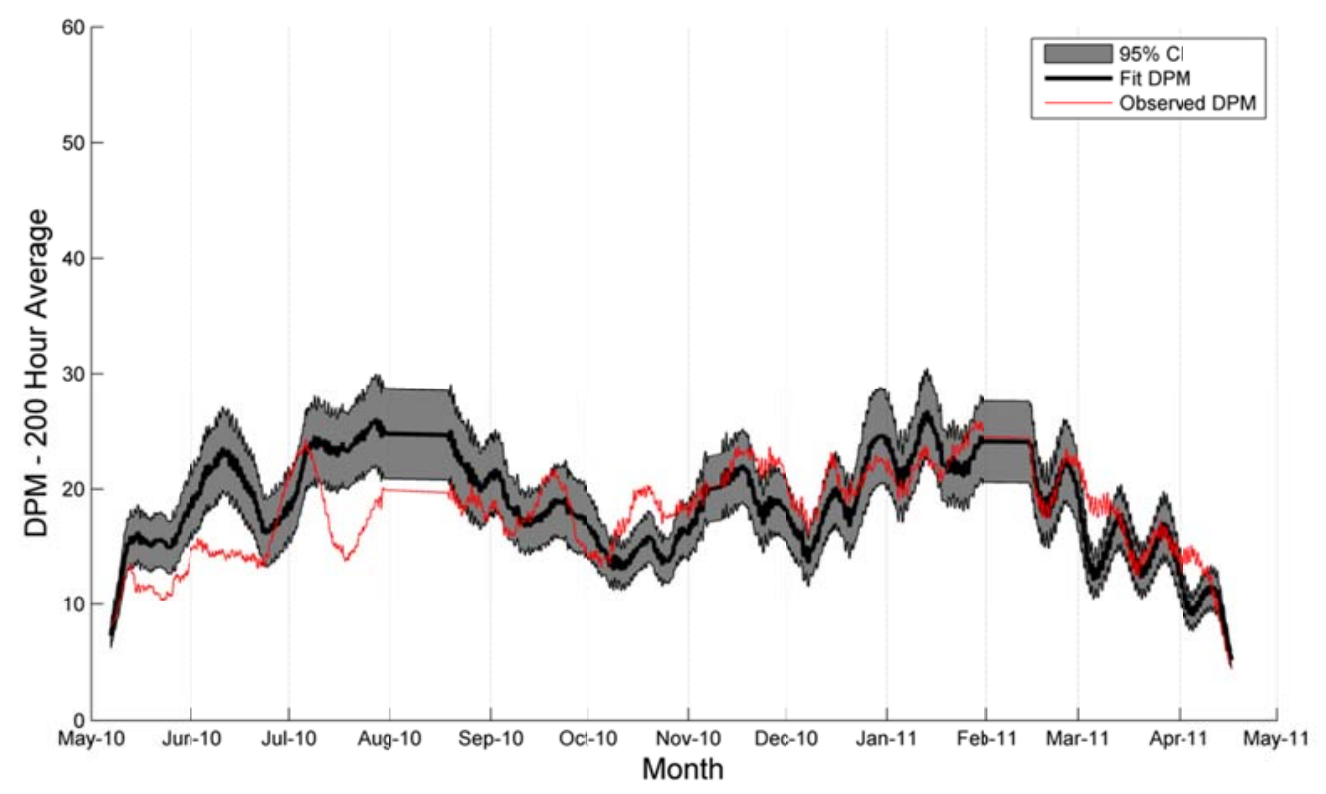

Figure 32 - Full series GLM. Note: the 200 hour running average significantly smoothes model output and gives the impression of better agreement over short time scales than is actually observed.

"Goodness of fit" testing, regressor significance inference, and model comparison are performed by evaluating residuals and deviance $(D)$

$$
D(\beta)=-2 \ln \left[\frac{L(\beta)}{L(\mu)}\right]
$$

where $L(\beta)$ is the likelihood of the fitted model and $L(\mu)$ that of a saturated (regressor-independent) model (Myers et al., 2002). Deviance is approximately $\chi^{2}$ distributed, allowing testing to determine if the fit model is significantly worse than the saturated model. Thus, models with the lowest deviance relative to degrees of freedom are favorable (Myers et al., 2002). Relative regressor importance can be inferred by systematically adding variables to the model and observing their effects on lowering the value of the likelihood ratio. This analysis of deviance is performed in $R$ with the Companion to Applied Regression package's Type II ANOVA function. Patterns in deviance residuals are inspected to determine model inadequacies or suggest "missing pieces", as residuals in an ideally well-fit model should satisfy a normal distribution (Myers et al., 2002). The autocorrelation function in $R$ is utilized to assess trends in the residuals.

The three models are compared for goodness of fit, followed by regressor coefficient and significance analysis. Deviance per degrees of freedom is lowest in the case of the daytime only model, and similarly higher in the cases of the nighttime and full series models (Table 5). $\chi^{2}$-inference testing on the deviance yields significant differences for both the full and nighttime models, and no significant difference if a $\mathrm{p}$-value of $<0.01$ is considered the criterion for rejecting the null hypothesis. This result implies the daytime model predicts DPM/hour better than the other two models. 
Table 5 - Goodness of fit comparison

\begin{tabular}{lcccc}
\hline Model & $\begin{array}{c}\text { Degrees of } \\
\text { Freedom } \\
\text { (DOF) }\end{array}$ & $\begin{array}{c}\text { Residual } \\
\text { Deviance } \\
\text { (D) }\end{array}$ & D/DOF & $\begin{array}{c}\text { p-value } \\
\left(\mathbf{x}^{2}\right)\end{array}$ \\
\hline \hline Full Series & 5512 & 6512 & 1.181 & 0 \\
Split - Day & 1233 & 1341 & 1.079 & 0.017 \\
Split - Night & 1071 & 1255.4 & 1.172 & $<0.001$ \\
\hline
\end{tabular}

Coefficient interpretation can only be performed on continuous and binary regressors, as linear coefficiencts are meaningless when applied to categorical variables (e.g. months). The full model considers all such regressors significant following the above criterion, while the daytime model does not find current speed or tide height to be significant. Tide height is not significant in the nighttime model (Table 6). Agreement of coefficient sign is seen between all three models for current speed, neap/spring, and SEL, higher values of which infulence DPM negatively. Significance and relative importance of all regressors is evalueated by observing the decrease in the likelihood ratio (and therefore deviance) of the model (Table 7).

Table 6 - GLM Coefficient Estimates

\begin{tabular}{c|ccc|ccc|cccc}
\hline \multirow{2}{*}{ Regressor } & \multicolumn{3}{|c|}{ Full Series } & \multicolumn{3}{c|}{ Split-Day } & \multicolumn{3}{c}{ Split-Night } \\
\cline { 2 - 12 } & Coefficient & Std. Error & p-value & Coefficient & Std. Error & p-value & Coefficient & Std. Error & p-value \\
\hline \hline Intercept & 6.147 & 0.421 & $<0.001$ & 7.038 & 1.362 & $<0.001$ & 5.967 & 0.505 & $<0.001$ \\
Current Speed & -0.919 & 0.034 & 0.007 & -0.196 & 0.099 & $0.049 *$ & -0.208 & 0.046 & $<0.001$ \\
Neap/Spring & -0.182 & 0.022 & $<0.001$ & -0.278 & 0.061 & $<0.001$ & -0.192 & 0.037 & $<0.001$ \\
Tide Height & 0.121 & 0.020 & $<0.001$ & 0.179 & 0.077 & $0.020^{*}$ & -0.049 & 0.042 & $0.236 *$ \\
SEL & -0.022 & 0.003 & $<0.001$ & -0.047 & 0.011 & $<0.001$ & -0.016 & 0.004 & $<0.001$ \\
Day/Night & 0.434 & 0.062 & $<0.001$ & NA & NA & NA & NA & NA & NA \\
\hline
\end{tabular}

All regressors are significant in the full model, with hour of the day accounting for the largest drop in deviance relative to degrees of freedom. A model constructed with hour of the day as the only regressor results in a deviance per degrees of freedom of 1.178, indicating slightly better performance than the full model. Current speed, tide height, and season are insignificant in the dayttime model, with months accounting for the strongest change in deviance. In the nighttime model, tide height, season, and hour of the day are not significnat, and neap/spring variation accounts for the largest drop in deviance relative to degrees of freedom (Table 7). 
Table 7 - GLM Analysis of Deviance

\begin{tabular}{|c|c|c|c|c|c|c|c|c|c|}
\hline \multirow[b]{2}{*}{ Regressor } & \multicolumn{3}{|c|}{ Full Series } & \multicolumn{3}{|c|}{ Split-Day } & \multicolumn{3}{|c|}{ Split-Night } \\
\hline & DOF & $\begin{array}{l}\Delta \text { likelihood } \\
\text { Ratio (LR) }\end{array}$ & $p$-value & DOF & $\begin{array}{c}\Delta \text { likelihood } \\
\text { Ratio (LR) }\end{array}$ & p-value & DOF & $\begin{array}{c}\Delta \text { likelihood } \\
\text { Ratio (LR) }\end{array}$ & p-value \\
\hline Current Speed & 1 & 7.1 & $<0.001$ & 1 & 3.430 & $0.064 *$ & 1 & 20.121 & $<0.001$ \\
\hline Neap/Spring & 1 & 62.5 & $<0.001$ & 1 & 17.814 & $<0.001$ & 1 & 26.643 & $<0.001$ \\
\hline Tide Height & 1 & 34.4 & $<0.001$ & 1 & 4.412 & $0.036^{*}$ & 1 & 1.435 & $0.231 *$ \\
\hline SEL & 1 & 45.7 & $<0.001$ & 1 & 18.004 & $<0.001$ & 1 & 15.591 & $<0.001$ \\
\hline Month & 11 & 164.1 & $<0.001$ & 11 & 128.292 & $<0.001$ & 11 & 34.708 & $<0.001$ \\
\hline Season & 3 & 23.9 & $<0.001$ & 3 & 11.185 & $0.010 *$ & 3 & 1.008 & $0.799 *$ \\
\hline Hour & 5 & 2111.7 & $<0.001$ & 3 & 36.375 & $<0.001$ & 3 & 3.693 & $0.297^{*}$ \\
\hline Day/Night & 1 & 44.4 & $<0.001$ & NA & NA & NA & NA & NA & NA \\
\hline
\end{tabular}

In conclusion, while the GLM is able to identify statistically significant underlying factors, it does not provide a satisfactory prediction of porpoise activity with the included regressors. These results suggest unknown factors missing from the analysis (e.g., concentration of prey) or a high degree of random variability.

Additionally, autocorrelation is observed in the deviance residuals at short time lags meaning detections are more likely to occur at times closer to other detections. This calls the assumption of independence of observations into question for all statistical inference testing, and can lead to incorrect estimates of the standard errors of the GLMs. Modeling techniques such as Generalized Estimating Equations (GEE) exist to extend GLMs to handle correlated observations, but require knowledge of observation grouping, which is unknown in this context (Meyers et al, 2002). Modeling results may also be confounded by the correlation between regressor variables. SEL and current speed are known to be linked, while neap/spring variability is also encoded within tide water level. At this time, conclusions can only be drawn as to the relative strength of regressors and their directionality of influence (i.e., presence is more likely during the day than at night).

\subsection{Landmark Activity}

Landmark activity is defined as a sequence of echolocation click trains with linearly decreasing inter-click intervals (ICI). This pattern indicates cetaceans approaching the instrument and actively echolocating at the C-POD, its mooring, or other nearby object (Chelonia user guide). Landmark sequences are identified by cpod.exe software and must be analyzed manually for validity. A typical sequence indicative of landmark behavior recorded during the deployment is depicted in Figure 33. These sequences can be used to roughly estimate the distance at which porpoises becomes aware of their echolocation target (Chelonia user guide). Distance within a landmark sequence is calculated by

$$
D=\frac{(t-10) \times c_{w}}{2}
$$

where $t$ is the $\mathrm{ICl}$ of the sequence measured in milliseconds (minus $10 \mathrm{~ms}$ as an empirical measure of porpoise processing time for the returned signal) and $c_{w}$ is the speed of sound in water $\left(\mathrm{m} \mathrm{s}^{-1}\right)$. The distance is divided by two to account for the two-way travel of the click. 


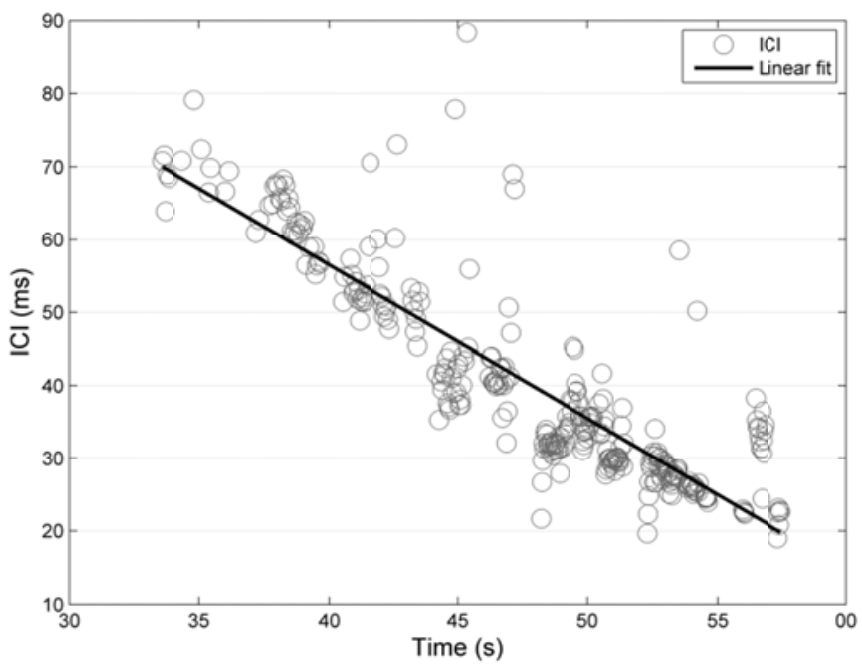

Figure 33 - Typical landmark sequence

A total of six highly likely landmark sequences were identified in the year of data from May 2010 - May 2011 from a single C-POD (unit \#718). As given by the equation above, the average initial distance from the instrumentation package at the start of a landmark sequence was approximately $60 \mathrm{~m}$. The sequences also indicate approaches to within $20 \mathrm{~m}$ of the instrumentation, on average. The farthest distance at which a landmark sequence begins is estimated to be approximately $90 \mathrm{~m}$. During postinstallation monitoring, it may be possible to evaluate landmark activity as a measure of porpoise awareness of the turbine, relative to landmark activity associated with a much smaller and quieter target like a Sea Spider.

\subsection{Effects of Existing Anthropogenic Noise on Harbor Porpoise}

As reviewed in Southall et al. (2007), harbor porpoise have been demonstrated to display avoidance to received levels of sound exceeding $140 \mathrm{~dB}$ re $1 \mu \mathrm{Pa}$ (broadband). The sensitivity of harbor porpoise to disturbances and their high presence in Admiralty Inlet combined to suggest that they would be an excellent marker species to evaluate the environmental effects of turbine noise, post-installation. In order to test this hypothesis, the responsiveness of harbor porpoise to anthropogenic sound was evaluated using a passenger ferry as a source of opportunity.

\subsubsection{Approach}

Data were analyzed from SS \#03 (C-POD unit \#1138), deployed for 93 days from Nov 2010 - Feb 2011 to the east of Admiralty Head. The passenger ferry passes over this location more than twenty times each day (inbound and outbound from Keystone Harbor).

As shown in Figure 34, median DPM/hour data shows the diel trend in harbor porpoise presence described in $\S 4.1 .1$. These trends are uncorrelated with average broadband sound pressure levels or current velocity. 

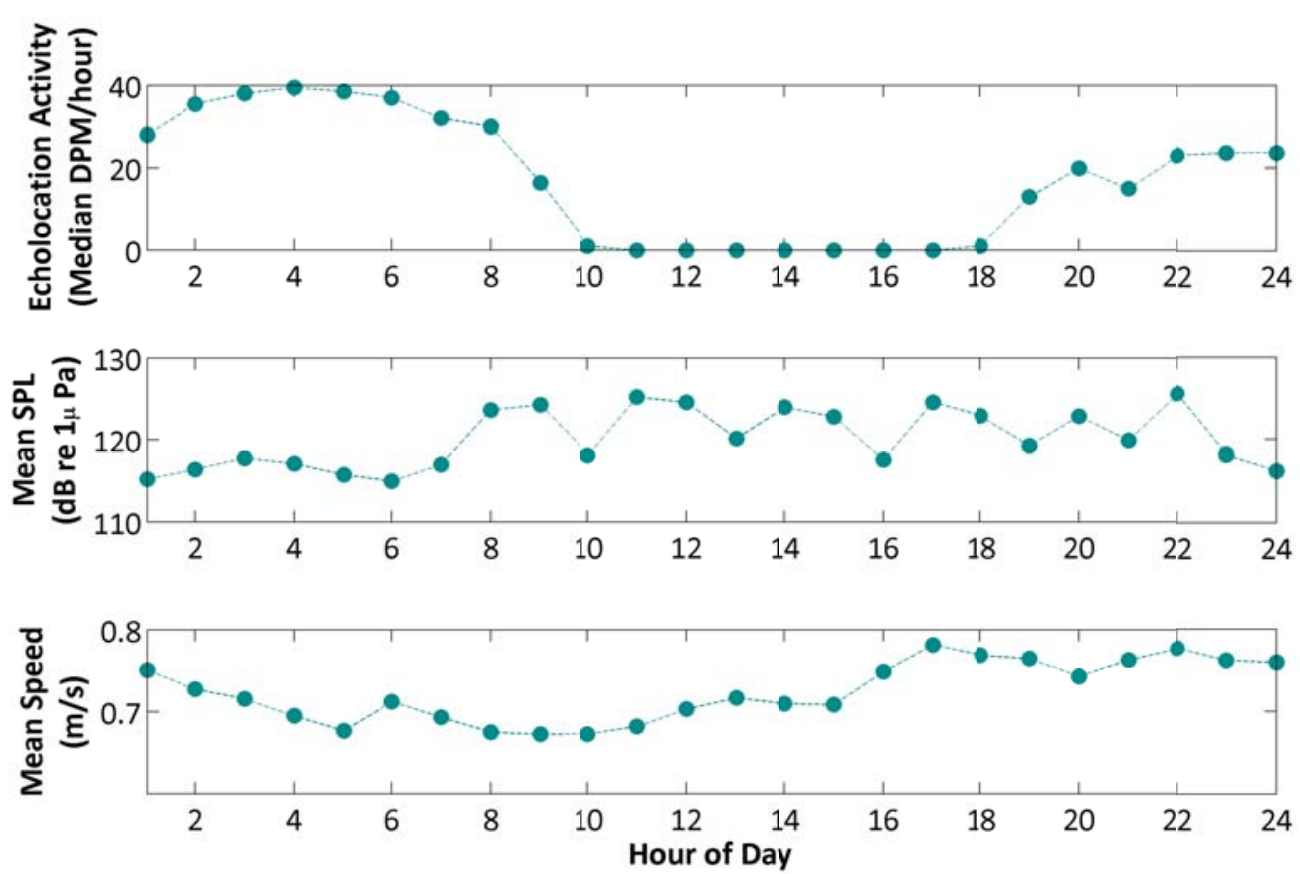

Figure 34 - Harbor porpoise echolocation activity at study site

In order to avoid bias associated with this diel variability, analysis focused on two sound exposures each day: the first inbound ferry during the morning and the last outbound ferry at night. Trends in echolocation activity were assessed over the 45 minutes prior to the inbound ferry case and 60 minutes following ferry passage for the outbound ferry case. Only periods without other vessels passing within $2.4 \mathrm{~km}$ of SS \#03 were analyzed (to avoid the confounding effect of a second vessel re-ensonifying the area). Out of the 93 possible inbound/outbound cases, 32 inbound cases and 20 outbound cases satisfied this criterion.

Based on analysis of ferry noise presented in Bassett et al., (submitted), during the ferry's closest point of approach to SS \#03, the average sound pressure level within the C-POD detection range (estimated as $250 \mathrm{~m}$ ) slightly exceeded $140 \mathrm{~dB}$. The best estimate for the ferry source level is $173 \mathrm{~dB}$ and, as shown in Figure 35, the sound profile of the ferry (and other shipping) is similar to the turbines in terms of spectral content (intensity for vessel traffic noise is generally much higher than estimated turbine noise). The duration of this ensonification was approximately one minute. 


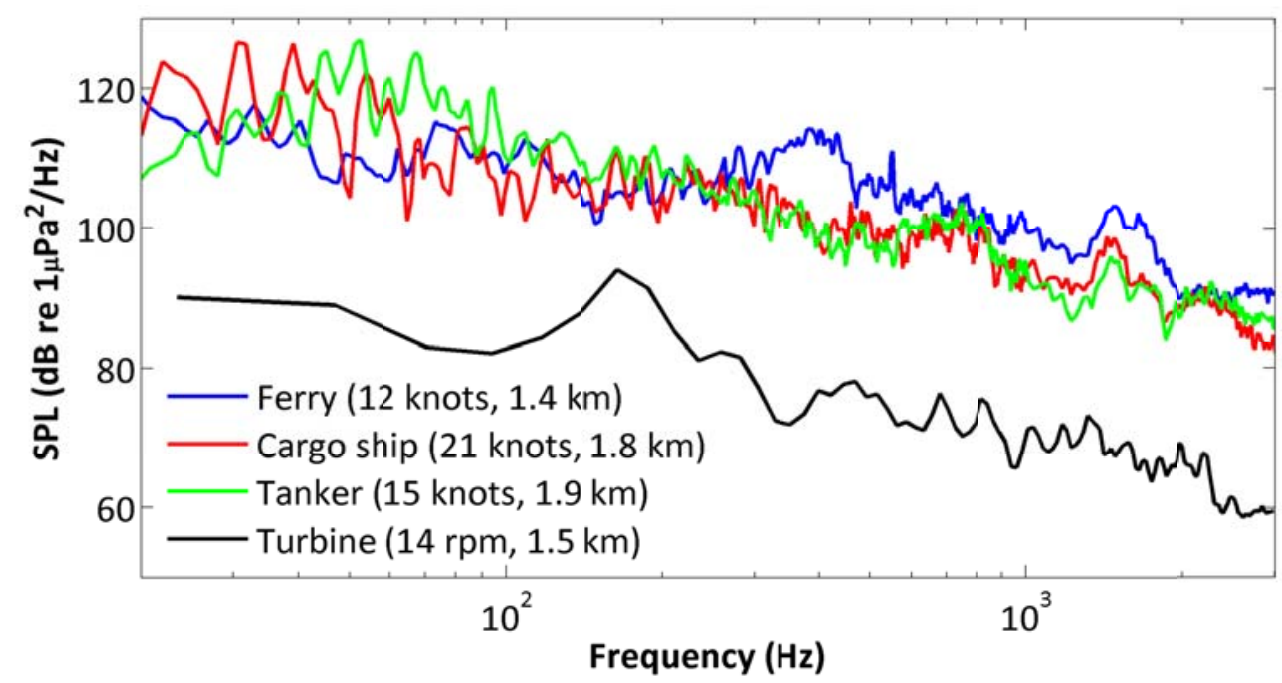

Figure 35 - Received levels associated with shipping and $6 \mathrm{~m}$ OpenHydro turbine at equivalent distances. Shipping noise from C. Bassett, unpublished data. Turbine noise from EMEC measurements ( $\$ 3.1$ ), adjusted to greater by distance assuming practical spreading.

\subsubsection{Results}

The first question we considered was whether the porpoise activity data suggested pronounced avoidance behavior after the final outbound ferry passage. This would be apparent as an extended period without echolocation activity. However, as shown in Figure 36, in more than $50 \%$ of the cases analyzed, echolocation activity did not cease or resumed shortly after ferry passage (within 10 minutes). Therefore, the data do not support a hypothesis of pronounced avoidance behavior due to noise from the ferry.

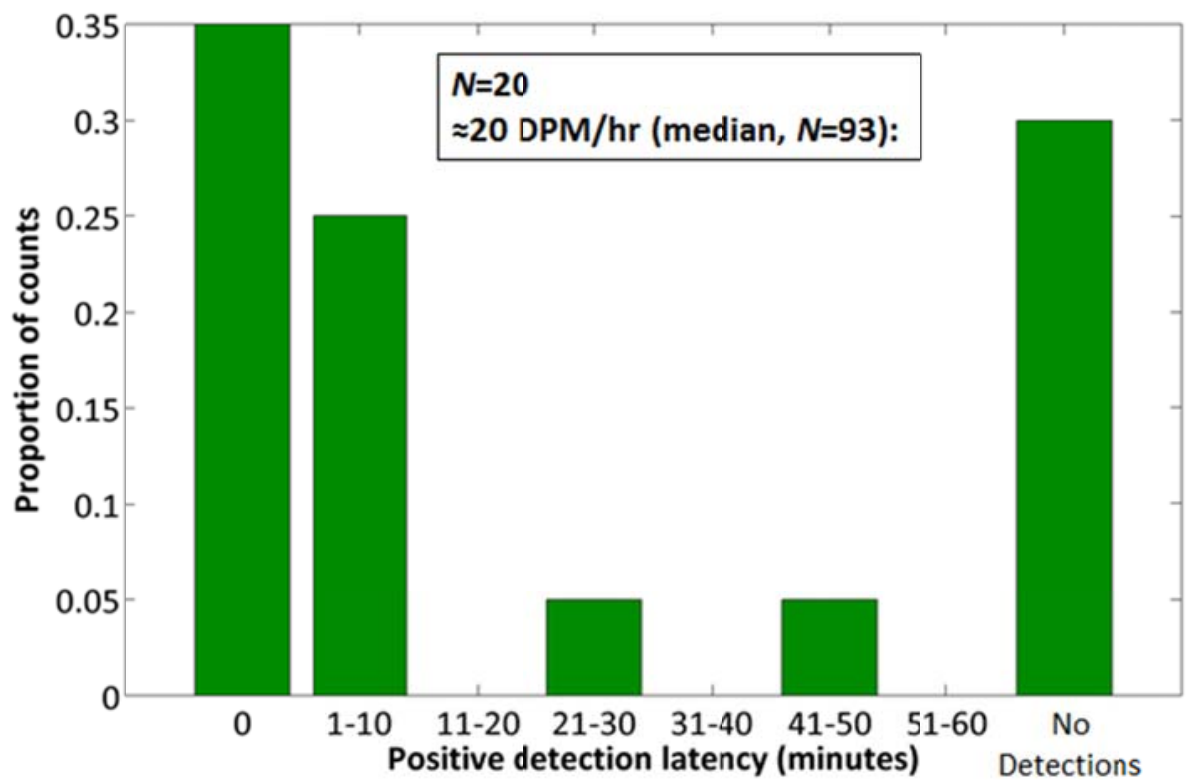

Figure 36 - Latency (in minutes) from time of ferry closest point of approach to first recorded porpoise echolocation click train.

The second question we considered was whether echolocation activity changed over time after the ferry's closest point of approach. As shown in Figure 37, there is no statistically significant correlation 
between the proportion of cases with detection positive minutes and ferry passage. The case shown is for the first inbound passage of the day. A similar lack of correlation is observed for the last outbound ferry of the evening.

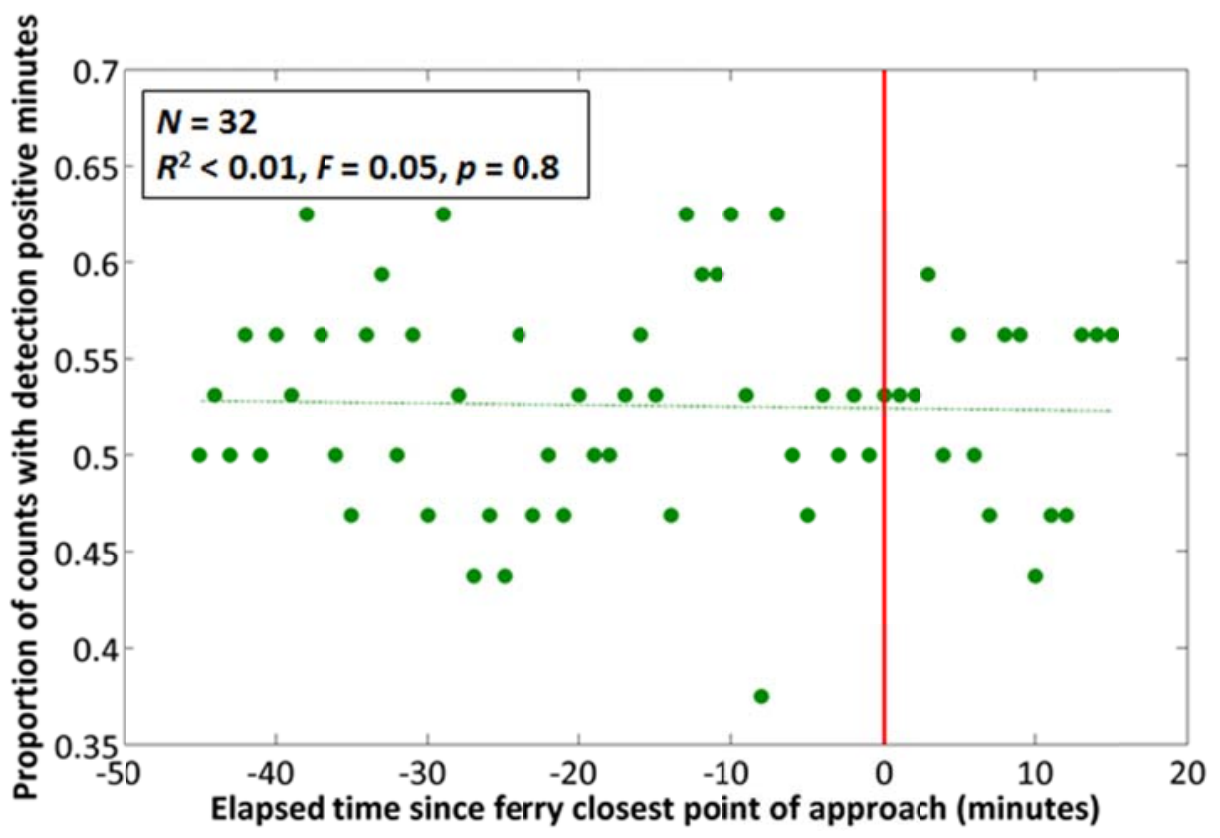

Figure 37 - Proportion of cases with detection positive minutes as a function of time before and after ferry closest point of approach on first inbound run of the day.

There are several plausible explanations for this result (or lack of result), most of which have implications for post-installation monitoring:

- Harbor porpoise in this area have become habituated to relatively intense broadband sound as a consequence of omnipresent vessel traffic (Bassett et al., submitted). If this is the case, then, we would not expect to observe an avoidance response using similar analysis techniques for C-PODs deployed in the proximity of the turbines.

- Harbor porpoise have specifically become habituated to the ferry noise, knowing that it will subside, reliably within a minute as the ferry passes through the area. If this is the case, then we might expect to still observe an avoidance response using similar techniques in post-installation monitoring since the duration of elevated sound from the turbine will be longer than for the ferry. However, the intensity will also be much lower most of the time, so these factors will compete.

- Harbor porpoise are demonstrating avoidance behavior, but this is not reflected in echolocation activity and, therefore, not detectable using C-PODs. This hypothesis can only be evaluated by combining C-POD data with shore observer or tag data.

Consequently, it is our opinion that C-POD monitoring of the turbines should still be undertaken, but with expectations of a detectable change tempered relative to expectations for avoidance reported previously in the literature. 


\subsection{Inference of Behavior through Click Properties}

\subsubsection{Approach}

Koschinski et al. (2008) found it possible to categorize wild harbor porpoise behavior based on ICI patterns in their T-POD data. They found that feeding behavior was associated with click trains that started with $\mathrm{ICls}$ in the range of $30-70 \mathrm{~ms}$ and decreased to a terminal $\mathrm{ICl}$ around $2 \mathrm{~ms}$ with a rapid decrease in $\mathrm{ICl}$ during the transition phase. They also identified approach behavior (equivalent to landmarks discussed above) which involved 20 to 74 s long click train sequences with ICl gradually decreasing from a median of $72 \mathrm{~ms}$ to $5 \mathrm{~ms}$. The final behavior category they ascribe with clicks is 'communication' which involved click trains of relatively constant but short $\mathrm{ICl}$ of $<8 \mathrm{~ms}$ and variable duration (100-1,270ms). Given the higher sensitivity of C-PODs, it is possible that ICI measures will be lower in C-PODs (due to a great number of clicks being detected), however this is difficult to predict as both the detection and classification routines in C-PODs have changed from T-PODs. Click train details were exported to text files from cpod.exe software and imported into Matlab and merged with the DPM data per hour so that only click trains from the hours involved in the porpoise presence analysis were retained. Linear models in $R$ were used to analyze the data, after log transformation to meet the assumptions of those tests. Further data were also extracted for specific time periods and events using the cpod.exe software to better understand and investigate the data.

\subsubsection{Results}

Of the 1,054,069 click trains detected in the data, 665,855 were retained for analysis, as they occurred during the hours of data that were used in the porpoise presence analysis above. For these preliminary analyses we focused on the maximum and minimum ICl in each click train. Largely due to the sample size, there was a significant difference in max and min ICI between night and day, as well as between seasons, even though the variance is large and the effect size small (Figure 38). Spring has the biggest difference, having the highest ICI (and standard deviation). Not only does this season have the lowest DPM per hour, it also has the most widely spread clicks (highest ICI). 


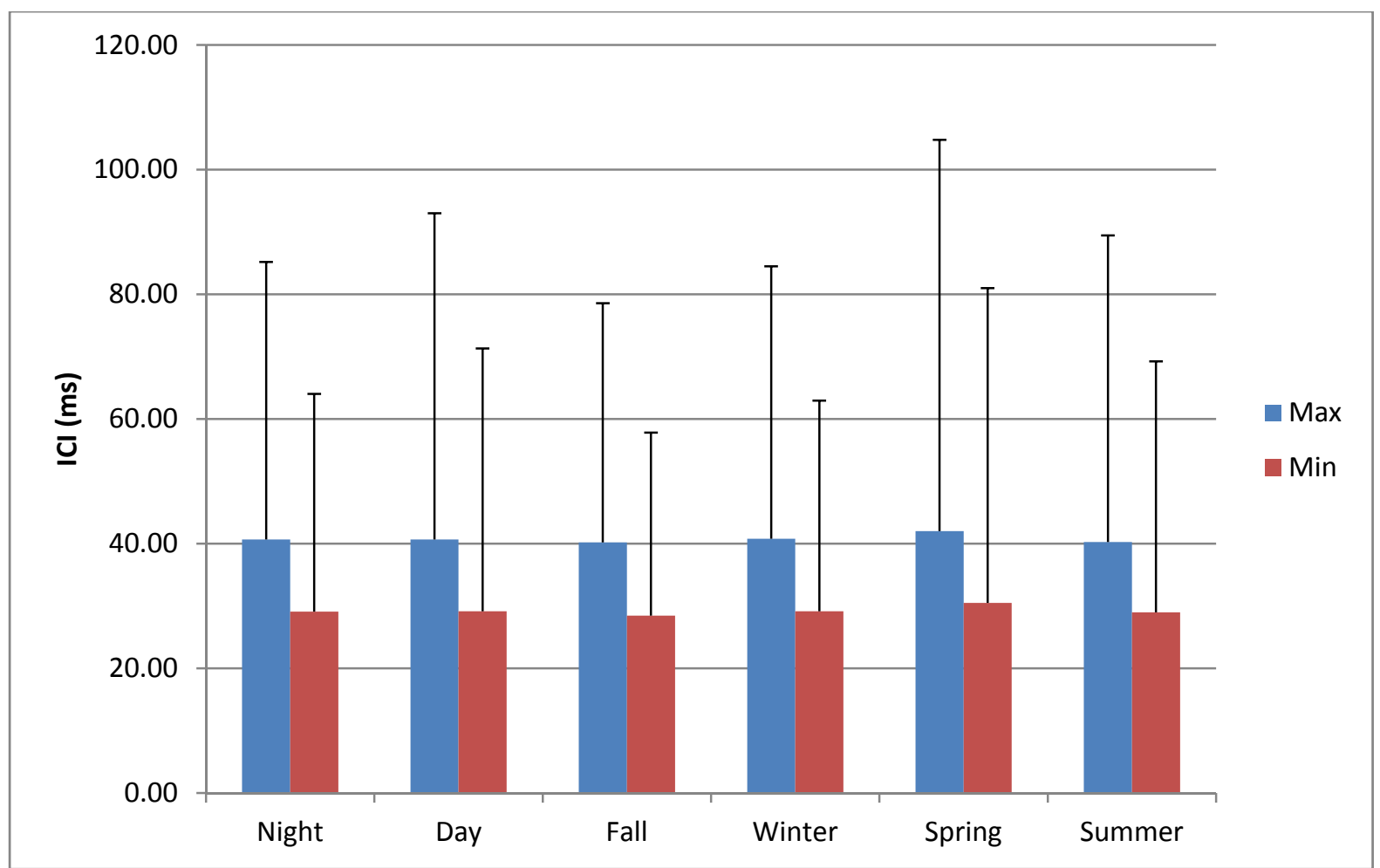

Figure 38 - Mean Inter Click Interval (ms) of the max and min ICl in each click train across day and season. Error bars are standard deviations.

The number of click trains in each month tended to mirror the DPM/hour for those months (Table 8). April had the fewest click trains and relatively low $\mathrm{ICl}$, while December had the highest number of click trains but fairly average $\mathrm{ICl}$. Most notable is the larger variance in $\mathrm{ICl}$ that occurs during the spring months.

Table $8-\mathrm{ICl}$ and standard deviation in $\mathrm{ICl}$ by month

\begin{tabular}{l|r|r|r|r|r}
\hline Month & $\begin{array}{l}\text { N click } \\
\text { trains }\end{array}$ & Mean ICI $_{\max }$ (ms) & ICI $_{\max }$ SD & Mean ICI $_{\min }$ (ms) & ICI $_{\min }$ SD \\
\hline \hline 1 & 72,255 & 39.24 & 40.28 & 28.01 & 30.33 \\
2 & 44,945 & 40.33 & 45.76 & 28.93 & 36.11 \\
3 & 62,858 & 42.63 & 45.79 & 30.45 & 35.40 \\
4 & 25,345 & 38.36 & 42.08 & 27.86 & 32.98 \\
5 & 26,797 & 51.80 & 89.37 & 38.10 & 71.89 \\
6 & 50,416 & 37.53 & 60.70 & 26.88 & 50.47 \\
7 & 71,346 & 41.26 & 56.80 & 29.45 & 46.92 \\
8 & 30,623 & 41.15 & 41.31 & 30.37 & 33.07 \\
9 & 60,171 & 39.37 & 36.35 & 28.42 & 28.27 \\
10 & 69,882 & 39.94 & 37.09 & 27.68 & 28.31 \\
11 & 71,314 & 43.06 & 40.47 & 30.75 & 30.98 \\
12 & 79,903 & 38.37 & 38.58 & 27.41 & 29.86
\end{tabular}


Time of day showed very little variation in ICl throughout the day (Table 9). The largest change was in the number of click trains in each hour with mid-day an order of magnitude lower than mid-night.

Table 9 - ICl and standard deviation by hour of day

\begin{tabular}{l|r|r|r|r|r}
\hline Hour & N click trains & Mean ICI $_{\max }(\mathbf{m s})$ & $\mathbf{I C I}_{\max }$ SD & Mean ICI $_{\min }(\mathbf{m s})$ & $\mathbf{I C I}_{\min } \mathbf{S D}$ \\
\hline \hline 0 & 59,298 & 40.17 & 47.36 & 28.97 & 37.57 \\
1 & 58,351 & 40.04 & 44.38 & 28.64 & 35.74 \\
2 & 46,817 & 40.78 & 47.90 & 29.11 & 38.41 \\
3 & 41,414 & 40.60 & 45.46 & 29.20 & 35.83 \\
4 & 44,295 & 41.90 & 46.96 & 29.73 & 36.13 \\
5 & 38,147 & 41.31 & 43.69 & 29.55 & 34.24 \\
6 & 24,462 & 39.68 & 45.28 & 28.36 & 35.07 \\
7 & 13,140 & 36.98 & 44.34 & 26.48 & 34.82 \\
8 & 5,740 & 33.57 & 55.63 & 24.16 & 46.59 \\
9 & 3,883 & 38.09 & 68.74 & 27.22 & 53.79 \\
10 & 2,880 & 38.99 & 54.28 & 28.56 & 48.60 \\
11 & 3,253 & 42.50 & 59.61 & 30.79 & 50.75 \\
12 & 4,262 & 39.75 & 50.12 & 28.85 & 42.32 \\
13 & 5,667 & 38.24 & 52.00 & 28.05 & 45.51 \\
14 & 4,908 & 38.84 & 64.25 & 28.37 & 53.10 \\
15 & 6,774 & 37.66 & 58.28 & 27.38 & 47.33 \\
16 & 8,078 & 39.18 & 55.43 & 28.16 & 46.55 \\
17 & 16,248 & 39.46 & 52.83 & 28.12 & 41.03 \\
18 & 30,280 & 41.30 & 46.12 & 29.31 & 36.97 \\
19 & 40,876 & 41.96 & 42.90 & 29.62 & 32.61 \\
20 & 48,065 & 40.84 & 47.03 & 29.00 & 36.06 \\
21 & 51,320 & 41.95 & 47.17 & 30.07 & 38.08 \\
22 & 49,779 & 42.03 & 47.68 & 30.26 & 38.24 \\
23 & 57,918 & 40.20 & 47.30 & 28.92 & 37.13
\end{tabular}

Given the lack of striking patterns in the averages of this large dataset, we chose to focus more closely on extremes to determine if these were more illustrative. We therefore selected click trains with maximum $\mathrm{ICl}>300 \mathrm{~ms}$ and minimum $\mathrm{ICl}<10 \mathrm{~ms}$. Max ICl does start to vary more widely with spring and day having the highest max ICl, however, there is little variation across season or time of day for min $\mathrm{ICI}$ (Table 10 and Table 11).

Table $\mathbf{1 0}$ - Max ICl for trains $>\mathbf{3 0 0}$ ms ICI

\begin{tabular}{l|r|r}
\hline $\begin{array}{l}\text { Season/Time of } \\
\text { Day }\end{array}$ & $\mathrm{N}$ & ${\text { Mean } \mathrm{ICI}_{\max }}$ \\
\hline \hline winter & 582 & 543.14 \\
spring & 915 & 594.83 \\
summer & 849 & 565.48 \\
fall & 455 & 523.78 \\
day & 1234 & 574.31 \\
night & 1567 & 555.26
\end{tabular}


Table $11-$ Min ICI for trains $<10 \mathrm{~ms}$ ICI

\begin{tabular}{l|l|l}
\hline $\begin{array}{l}\text { Season/Time of } \\
\text { Day }\end{array}$ & $\mathrm{N}$ & Mean ICI $_{\min }$ \\
\hline \hline winter & 43447 & 4.70 \\
spring & 26374 & 4.57 \\
summer & 33888 & 4.72 \\
fall & 40474 & 4.58 \\
day & 50312 & 4.65 \\
night & 93871 & 4.65
\end{tabular}

Although focusing on outliers (at least max $\mathrm{ICl}$ ) is more promising in terms of larger differences between seasonal or daytime averages, there is a clear need to focus more finely on individual or groups of click trains if behavioral clues are to be gained. CPOD.exe allows for an autocorrelation to be calculated on the DPM data to determine the duration of each 'encounter'. Running this on the annual data series described above with a time window of 1 minute indicates that encounters lasted from 168 to 388 minutes. These encounters are likely overestimates (and with larger window sizes the encounter durations do decrease). In addition, CPOD.exe only allows encounters to be defined with gaps ups to 120 minutes. We therefore used 120 minutes gaps to extract encounter details from our data using CPOD.exe. This resulted in 631 separate encounters. These data showed clear trends in median ICl levels (Figure 39). There are three distinct sections to the curve of sorted median ICl with break points around 15 and $40 \mathrm{~ms}$. Using these cutoffs, the encounters were split into three groups (low, mid, and hi ICI) and plotted across month (Figure 40). The hi ICl category is clustered in late spring and summer, while low $\mathrm{ICl}$ peaks in the spring and fall. It is possible that these hi ICl encounters are indicative of foraging, when initial echolocation clicks are used to search for more distant prey. If these and other click train parameters are indicative of harbor porpoise behavior in Admiralty Inlet then we will be able to use them to test for behavioral responses to the tidal turbines. 


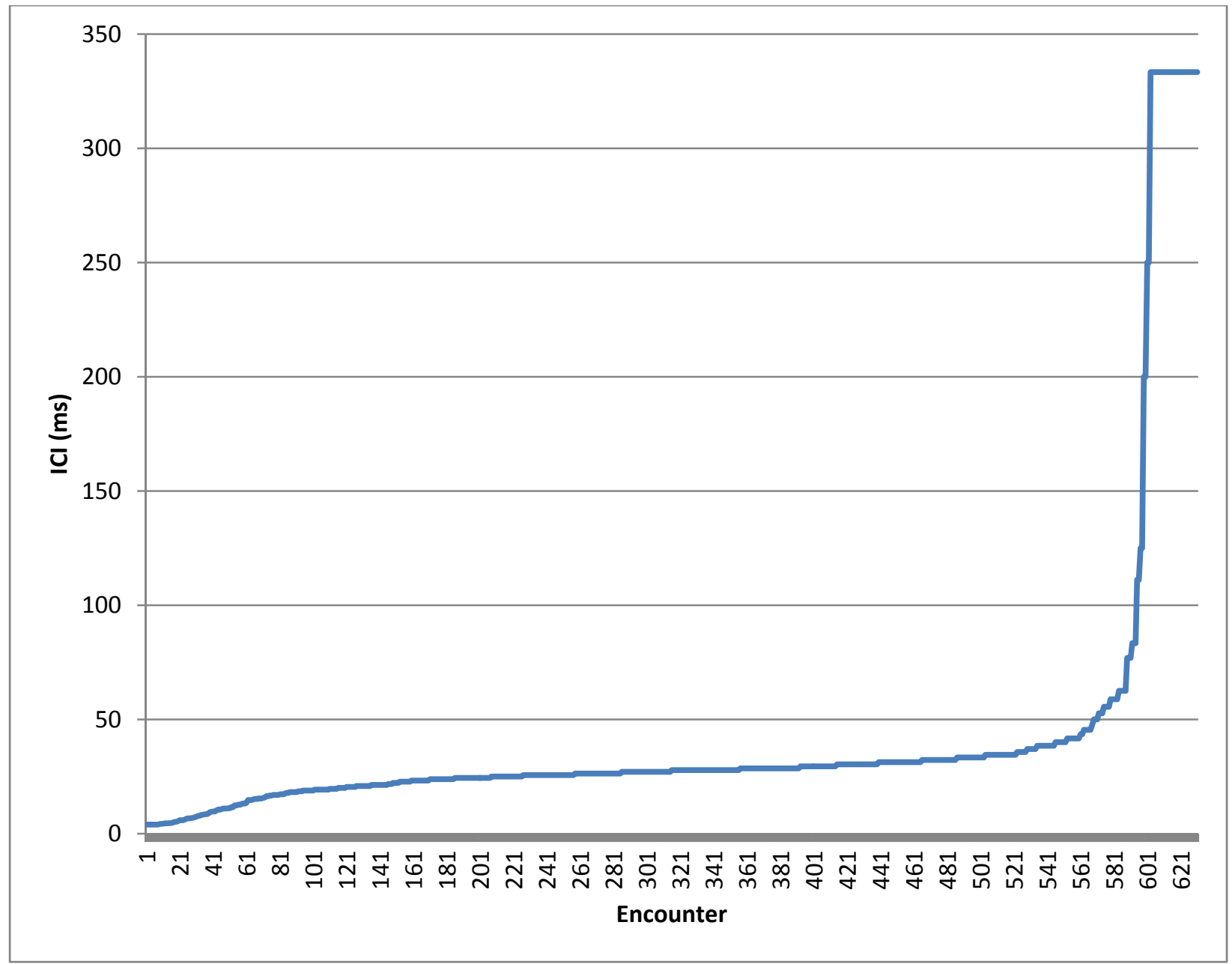

Figure 39 - Graph of encounters sorted by increasing median ICI. 


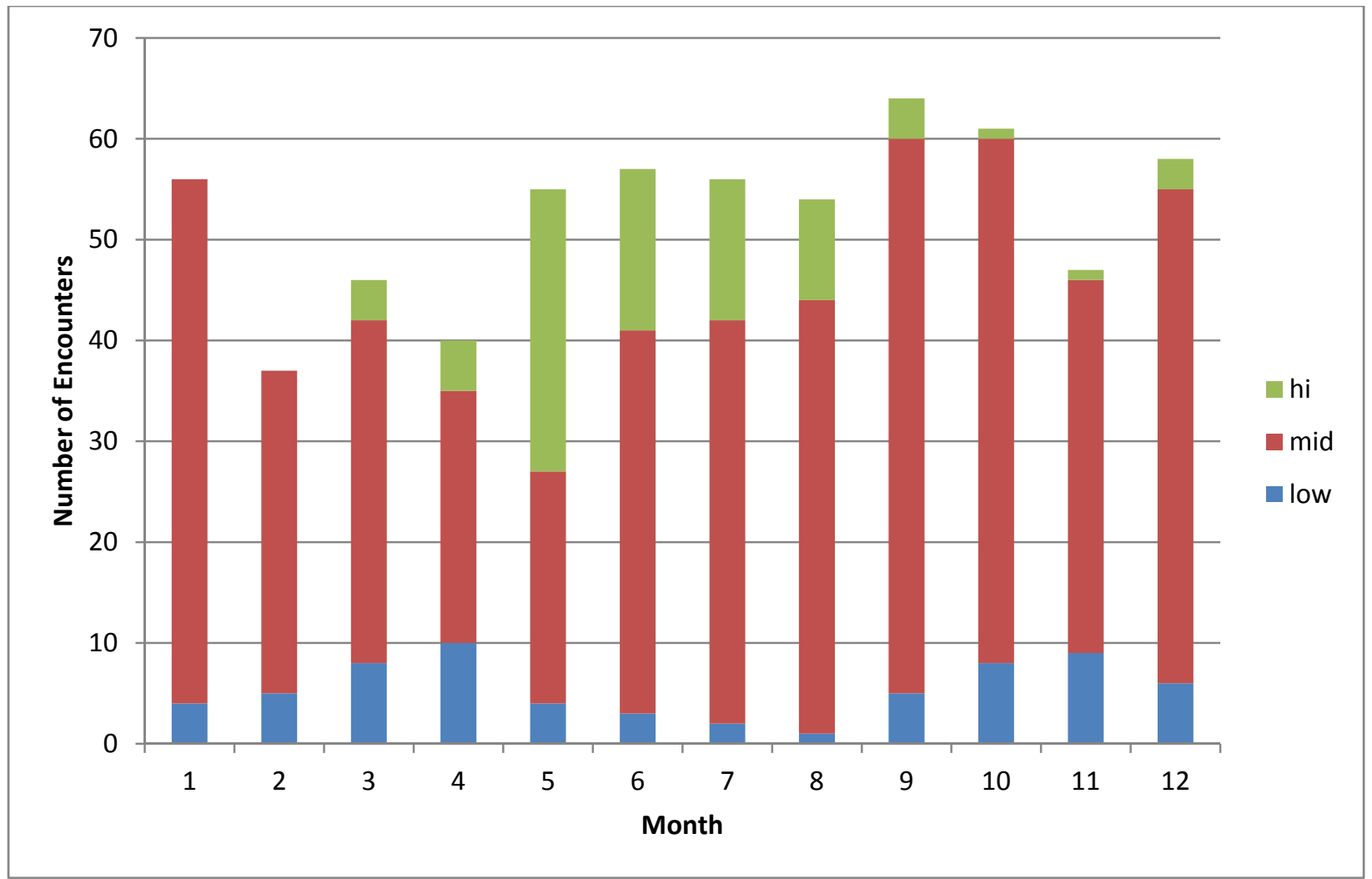

Figure 40 - Bar plot of the number of encounters by month with low, mid or hi ICl. 


\section{Task 4: Effects of Turbine Noise on Aquatic Species}

Noise in the aquatic environment is known to be a stressor to many types of aquatic life, including marine mammals, fish and birds. Marine mammals and birds are exceptionally difficult to work with for technical and regulatory reasons. Fish have been used as surrogates for other aquatic vertebrates as they have similar auditory structures. For this study, juvenile Chinook salmon (Oncorhynchus tshawytscha) were used as the experimental animal. Noise is known to affect fish in many ways, such as causing a threshold shift in auditory sensitivity or tissue damage. The characteristics of noise, its spectra and level, are important factors that influence the potential for the noise to injure fish. For example, the frequency range of sound from an OpenHydro (and, likely, most turbine variants) overlaps the audiogram (frequency range of hearing) of most fish. A summary of this study is presented here additional details may be found in Halvorsen et al. 2011.

\subsection{Approach}

Naturally spawning stocks of Chinook salmon that utilize Puget Sound are listed as threatened (http://www.nwr.noaa.gov/ESA-Salmon-Listings/Salmon-Populations/Chinook/CKPUG.cfm); the fish used in this experiment were hatchery raised and their populations are not in danger of depletion. Fish were exposed continuously for 24 hours to an rms sound pressure level (SPL) of $159 \mathrm{~dB}$ re $1 \mu \mathrm{Pa}$. This corresponds to the source level (nominal received level at $1 \mathrm{~m}$ from the sound source) for the $95^{\text {th }}$ percentile operating condition for the OpenHydro turbine (i.e., using the methodology described in Polagye et al. (in prep) sound from the turbine would only be expected to exceed this level $5 \%$ of the time. This represents a worse than worst-case exposure for juvenile salmon for three reasons:

1. The turbine is not a point source of sound. Rather, sound is likely to be produced along the blades and the shroud. As a result, a receiver $1 \mathrm{~m}$ from any portion of the turbine would be within the acoustic near-field and measure lower sound levels.

2. Since turbine sound is estimated to vary with power generation state and, at a minimum, is known to be negligible while tidal currents are below cut-in speed (0.5-1 m/s for most tidal energy technologies), sound cannot be produced continuously for 24 hours in operation and certainly not at the $95^{\text {th }}$ operating percentile.

3. In strong currents, it is unlikely that juvenile salmon could maintain position in close proximity to the turbine for extended periods of time.

This worse than worst-case scenario is useful to consider because if (as demonstrated here), the effects of such an exposure are minimal, then the effects of practical exposures would be even less severe. After they were exposed to simulated tidal turbine noise, the hearing of juvenile Chinook salmon was measured and necropsies performed to check for tissue damage. Experimental groups were 1) noise exposed, 2) control (the same handling as treatment fish but without exposure to tidal turbine noise), and 3) baseline (never handled).

\subsection{Results}

Based on results of evoked hearing potential tests, ANOVA comparisons of all treatments (i.e., exposure, control) did not show a significant difference $(p=0.326)$. AEP analysis to date indicates that the sound exposure did not have a definitive negative effect on test fish. 
As described in Halvorsen et al. (2011), salmon were examined externally and by necropsy for internal inspection to determine if physical injuries resulted from exposure to simulated tidal turbine sound at four different times following exposure: day 0 - exam immediately after exposure; day 1 - one day after exposure; day 3 - three days after exposure; day 6 - six days after exposure. Each fish was inspected for external injury and then inspected for internal tissue damage by necropsy. Injury assessment was guided by reference to a panel of 72 potential tissue injuries developed over several years of investigation of the response of fish to rapid decompression and exposure to sound. Injuries were weighted by physiological significance to produce a Response Severity Index (RSI) for each fish. Initial treatments had higher RSI levels than subsequent exposures, indicating that variables other than sound exposure affected the RSI. In all cases (including the initial cases), the Each fish was inspected for external injury and then inspected for internal tissue damage by necropsy. Injury assessment was guided by reference to a panel of 72 potential tissue injuries developed over several years of investigation of the response of fish to rapid decompression and exposure to sound.

Collectively, these results for a worse than worst-case exposure, indicate that Chinook salmon may be at a relatively low risk of acoustic injury from tidal turbines located in or near their migration path

\subsection{Challenges}

As for the turbine sound propagation experiments in Admiralty Inlet, uncertainty around the sound profile of an operating tidal turbine (frequency, intensity, and variations in both as a function of power generation state) complicated experimental planning. Consequently, the approach of exposing fish (with hearing thresholds encompassing the majority of turbine-generated frequencies) to a worse than-worst case acoustic dose was a practical solution to this ambiguity. 


\section{Products Developed}

\subsection{Publications}

Grey literature publications:

- Cruise reports from field work in Admiralty Inlet, including further details of instrument configuration and lessons learned (available through depts.washington.edu/nnmrec)

- Halvorsen, M., T. Carlson, and A. Copping (2011) Effects of tidal turbine noise on fish hearing and tissues, Pacific Northwest National Laboratory technical report, PNNL-20786.

Conference publications:

- Graber, J., Thomson, J., Polagye, B., and Jessup, A. Land-based infrared imagery for marine mammal detection, SPIE Photonics + Optics, San Diego, CA August 20-25, 2011.

- Bassett, C., Thomson, J., and Polagye, B. Characteristics of underwater ambient noise at a proposed tidal energy site in Puget Sound, MTS/IEEE Oceans 2010, Seattle, WA September 2023, 2010.

Peer reviewed journal papers submitted or in preparation:

- Basset, C., B. Polagye, M. Holt, and J. Thomson (submitted) A vessel noise budget for Admiralty Inlet, Puget Sound, WA (USA), Submitted to J. Acous. Soc. Am.

- Basset, C., J. Thomson, and B. Polagye (in preparation) Contribution of bedload transport to ambient noise in a high-energy environment.

- Cavagnaro, R., B. Polagye, J. Wood, and D. Tollit (in preparation) Harbor porpoise echolocation activity in Admiralty Inlet, Puget Sound, WA.

- Polagye, B., C. Bassett, J. Wood, and S. Barr (in preparation) Detection of tidal turbine noise: A pre-installation case study for Admiralty Inlet, Puget Sound, Washington (USA).

- Polagye, B., J. Wood, D. Tollit, and C. Bassett (in preparation) Indications of harbor porpoise habituation to sound from ferry traffic.

\subsection{Internet Dissemination}

Quality assured data collected through site monitoring is available for direct download or by request through the UW-NNMREC website: http://depts.washington.edu/nnmrec/project meas.html

Presentations of project results have been made through the DOE MHK Webinar Series and are available from download through TETHYS (http://mhk.pnnl.gov/wiki/index.php/Tethys Home), PNNL's knowledge management system.

\subsection{Networks and Collaborations Fostered}

This project has fostered collaborations with a wide range of scientific, industry, academic, and regulatory partners. Several examples are given here:

- NOPP BAA - Hydroacoustic Monitoring of Fish - This research project deployed three autonomous echosounders in Admiralty Inlet to evaluate the capabilities to detect, classify, and identify fish at marine and hydrokinetic project sites. Two of the echosounders were packaged on Mark II Sea Spider platforms patterned after those developed for this project. Operational experience from this project enabled rapid, accurate, and successful deployment and recovery of all instrumentation associated with that project. The NOPP project was motivated, in part, by 
the need to characterize fish species and abundance around hydrokinetic projects. In additional to helping to evaluate the exposure of fish to project stressors, this information could also help to interpret marine mammal behavior (e.g., potentially providing additional explanatory variables for harbor porpoise echolocation activity).

- NOAA - Vessel Noise - Over the course of this project, UW-NNMREC engaged with staff from the Northwest Fisheries Science Center to apply data collected from this project towards the development of a vessel noise budget for Admiralty Inlet. This has been submitted for publication (Bassett et al. 2011) and provides the first quantitative vessel noise budget for Puget Sound.

- Materials Suitability - The extended deployment of Sea Spiders in Admiralty Inlet provided opportunities to evaluate durability of composites in the marine environment and test the effectiveness of foul-release coatings. Specifically, UW-NNMREC undertook an in-situ study of composite "aging" (molecular diffusion of water into the composite matrix over time) and, in partnership with Hempel, S.A., undertook a static test of three foul-release coatings.

- Dissolved Oxygen Monitoring - The Washington Department of Ecology supports a dissolved oxygen monitoring program at sites throughout Puget Sound. Information from this program is essential to understanding environmental stressors on Puget Sound that lead to hypoxic or anoxic conditions in the terminal basins (Hood Canal and South Sound). As Admiralty Inlet is the primary entrance to Puget Sound, dissolved oxygen monitoring at this location has the capacity to detect intrusions of deep, low-oxygen water from the Pacific Ocean. However, while the Department of Ecology had the instrumentation available to monitor dissolved oxygen, they had no way to deploy it. In partnering with the project, the Department of Ecology provided a waterquality sensor (and technician support) for packaging with the Sea Spiders. This advanced Ecology's mission objectives and provided the project with more accurate temperature, salinity, and dissolved oxygen information than it would otherwise have been able to collect.

- Sandia National Laboratories - In analyzing the source of non-biological clicks leading to full buffers on the C-PODs (§ 2.3.3), one theory was that suspended sediment might be being advected through the project area and impacting on the C-POD hydrophone element or other instrumentation, producing clicks at frequencies above $20 \mathrm{kHz}$. Sandia National Laboratories was able to provide a LISST (Sequoia Instruments) to characterize particulate size distributions as a function of tidal state. Analysis indicated that particulate concentration is tied to the neapspring cycle (the basis for which has not yet been explained), but was unlikely to be the source of the non-biological clicks, as these occurred during any strong tidal currents (neap or spring).

- Chelonia, Ltd. - The C-PODs demonstrated their utility to collect and classify harbor porpoise echolocation clicks. However, they were not effective at classifying killer whale echolocation clicks - in part, because Chelonia, Ltd. has not previously had a reference data set to train the classifier algorithm. As part of this project, manually identified killer whale click sequences have been provided to Chelonia, Ltd. and will used to upgrade the classifier algorithm. If C-PODs are deployed for post-installation monitoring of the District's project (or other marine energy projects), this will improve the ability of these instruments to detect and classify clicks from a broader range of marine mammals. 
- Washington State Parks - Washington State Parks maintains Fort Casey and the Admiralty Head Lighthouse overlooking Admiralty Inlet. This is the best vantage point for site observations in close-proximity to the District's project site. State Parks generously allowed the project team access to the historic lighthouse to install the VHF antenna for the AIS monitoring system and staff support to periodically restart the data acquisition computer in the lighthouse basement.

\subsection{Technologies and Techniques}

This project furthered the development of instrumentation packages and techniques to characterize the biological and physical environments at tidal energy sites. The Mark II Sea Spiders developed for this project remain in service, collecting data in Admiralty Inlet using core-NNMREC funding provided by the US DOE. These are contributing to a 3+ year data record of velocity, noise, water quality, and marine mammal activity at this location, making it one of the best characterized tidal energy sites in the world.

\subsection{Inventions and Patent Applications}

No patent applications were filed as part of this project. 


\section{Conclusions}

This project has substantially contributed to the body of knowledge around the acoustic effects of tidal energy development in several ways:

- Through collection of data from Admiralty Inlet, established the sources of sound generated by strong currents and determined that low-frequency sound recorded during periods of strong currents is non-propagating pseudo-sound.

- Analyzed data collected from a tidal turbine operating at the European Marine Energy Center to develop a profile of turbine sound and developed a framework to evaluate the acoustic effects of deploying similar devices in other locations. This framework has been applied to the District's project in Admiralty Inlet to inform post-installation acoustic and marine mammal monitoring plans.

- Demonstrated passive acoustic techniques to characterize the ambient noise environment at tidal energy sites (fixed, long-term observations recommended) and characterize the sound from anthropogenic sources (drifting, short-term observations recommended).

- Demonstrated the utility and limitations of instrumentation, including bottom mounted instrumentation packages, infrared cameras, and vessel monitoring systems. In doing so, also demonstrated how this type of comprehensive information is needed to interpret observations from each instrument (e.g., hydrophone data can be combined with vessel tracking data to evaluate the contribution of vessel sound to ambient noise).

- Conducted a study that suggests harbor porpoise in Admiralty Inlet may be habituated to high levels of ambient noise due to omnipresent vessel traffic. The inability to detect behavioral changes associated with a high intensity source of opportunity (passenger ferry) has informed the approach for post-installation marine mammal monitoring.

- Conducted laboratory exposure experiments of juvenile Chinook salmon and showed that exposure to a worse than worst case acoustic dose of turbine sound does not result in changes to hearing thresholds or biologically significant tissue damage. Collectively, this means that Chinook salmon may be at a relatively low risk of injury from sound produced by tidal turbines located in or near their migration path.

In achieving these accomplishments, the project has significantly advanced the District's goals of developing a demonstration-scale tidal energy project in Admiralty Inlet. On March 1, 2012, the District filed its final license application, in which the information developed under this project figured prominently into the biological assessment. 


\section{References}

Au, W. W., Kastelein, R. a, Rippe, T., \& Schooneman, N. M. (1999). Transmission beam pattern and echolocation signals of a harbor porpoise (Phocoena phocoena). The Journal of the Acoustical Society of America, 106(6), 3699-705. Retrieved from http://www.ncbi.nlm.nih.gov/pubmed/10615708

Basset, C., B. Polagye, M. Holt, and J. Thomson (submitted) A vessel noise budget for Admiralty Inlet, Puget Sound, WA (USA), Submitted to J. Acous. Soc. Am.

Basset, C., J. Thomson, and B. Polagye (in preparation) Contribution of bedload transport to ambient noise in a high-energy environment.

Brandt, M., Diederichs, a, Betke, K., \& Nehls, G. (2011). Responses of harbour porpoises to pile driving at the Horns Rev II offshore wind farm in the Danish North Sea. Marine Ecology Progress Series, 421, 205-216. doi:10.3354/meps08888

Brunner, E., and Puri, M. L. (2001). Nonparametric methods in factorial designs. Statistical Papers, 42, 152.

Davison, A. and T. Mallows (2005) Strangford Lough Marine Current Turbine environmental statement, Royal Haskoning technical report 9P5161/R/TM/Edin, June 15, 2005.

Graber, J., J. Thomson, B. Polagye , and A. Jessup (2011) Land-based infrared imagery for marine mammal detection, SPIE Photonics + Optics, San Diego, CA August 20-25, 2011.

Halvorsen, M., T. Carlson, and A. Copping (2011) Effects of tidal turbine noise on fish hearing and tissues, Pacific Northwest National Laboratory technical report, PNNL-20786.

Hawkins, A. and A. Popper (2012) Effects of noise of fish, fisheries, and invertebrates in the U.S. Atlantic and Arctic from energy industry sound-generating activities, Draft literature synthesis, prepared for Bureau of Ocean Energy Management, http://www.boemsoundworkshop.com/documents/Literature Synthesis Effects of Noise on Fish Fisheries and Invertebrates.pdf

Hazelwood, R. and Connelly, J. (2005) Estimation of underwater noise - a simplified method. International J. Soc. Underwater Technology, 26:51-57.

Koschinski, S., Dierderchs, A., \& Amundin, M. (2008). Click train patterns of free-ranging harbour porpoises acquired using T-PODs may be useful as indicators of their behaviour. Journal of Cetacean Research and Management, 10(2), 147-155.

Kyhn, L. a., Tougaard, J., Teilmann, J., Wahlberg, M., Jørgensen, P. B., \& Bech, N. I. (2008). Harbour porpoise ( Phocoena phocoena) static acoustic monitoring: laboratory detection thresholds of TPODs are reflected in field sensitivity. Journal of the Marine Biological Association of the United Kingdom, 88(06), 1085 - 1091. doi:10.1017/S0025315408000416

Kyhn, L., J. Tougaard, L. Thomas, L.R. Duve, J. Stenback, M. Amundin, G. Desportes (2012) From echolocation clicks to animal density-Acoustic sampling of harbor porpoises with static dataloggers, J. Acoust. Soc. Am., 131(1), 550-560. 
Leeney, R. (2011). Using Static Acoustic Monitoring to Describe Echolocation Behaviour of Heaviside's Dolphins (Cephalorhynchus heavisidii) in Namibia. Aquatic Mammals, 37(2), 151-160. doi:10.1578/AM.37.2.2011.151

Mellinger, David K., Stafford, Kathleen M., Moore, Sue E., Dziak, Robert P., Matsumoto, H. (2007). Fixed Passive Acoustic Observation Methods for Cetaceans An Overview of. Oceanography, 20(4), 3645.

Myers, Raymond H., Montgomery, Douglas C., Vining, G. Geoffrey. (2002) Generalized Linear Models with Applications in Engineering and the Sciences. John Wiley \& Sons, Inc., New York

Ocean Renewable Power Company (2011) Application of ORPC Maine, LLC for a hydrokinetic pilot project license for the Cobscook Bay Tidal Energy Project, Federal Energy Regulatory Commission Docket P-12711, Sept. 1, 2011.

Polagye, B. and J. Thomson (submitted) Tidal energy resource characterization: methodology and field study in Admiralty Inlet, Puget Sound, US. Submitted to Proc. IMechE, Part A: J. Power and Energy.

Polagye, B., J. Epler, and J. Thomson (2010) Limits to the predictability of tidal current energy. MTS/IEEE Oceans 2010, Seattle, WA September 20-23, 2010.

Polagye, B., B. Van Cleve, A. Copping, and K. Kirkendall (eds.) (2011) Environmental effects of tidal energy development: Proceedings of a scientific workshop, March 22-25, 2010. NOAA Technical Memorandum NMFS F/SPO-116.

Polagye, B., C. Bassett, J. Wood, and S. Barr (in preparation) Detection of tidal turbine noise: A preinstallation case study for Admiralty Inlet, Puget Sound, Washington (USA).

Southall, B., Bowles, A., Ellison, W., Finneran, J., Gentry, R., Greene, C., Kastak, D., Ketten, D., Miller, J., Nachtigall, P., Richardson, W., Thomas, J., Tyack, P. (2007) Marine mammal noise exposure criteria: initial scientific recommendations. Aquatic Mammals, 33 (4).

Subacoustech, Ltd. (2008) Measurement and assessment of underwater noise from the Crest Energy /OpenHydro tidal turbine at the EMEC facility, Orkney. February 29, 2008.

Thompson, P. M., Lusseau, D., Barton, T., Simmons, D., Rusin, J., \& Bailey, H. (2010). Assessing the responses of coastal cetaceans to the construction of offshore wind turbines. Marine pollution bulletin, 60(8), 1200-8. Elsevier Ltd. doi:10.1016/j.marpolbul.2010.03.030

Thomson, J (2011) Observations of wave breaking dissipation from a swift drifter, J. Atmos. Ocean. Tech.

Tollit, D., Wood, J., Broome, J., \& Redden, A. (2011). Detection of Marine Mammals and Effects Monitoring at the NSPI (Open Hydro) Turbine Site in the Minas Passage during 2010. Report to Fundy Ocean Research Centre for Energy.

Wood, J. D., Tollit, D., Berta, S., \& Garrett, H. (2009). Snohomish PUD Admiralty Inlet Pilot Project: Marine mammal pre-installation study: Review of historical information and site-specific synthesis (p. 32). Everett.

Verdant Power (2010) Final license application for hydrokinetic pilot project license for Roosevelt Island tidal energy project, Federal Energy Regulatory Commission Docket P-12611, Dec. 29, 2010. 